\title{
Multi-objective optimization for eco-efficient food supply chains
}

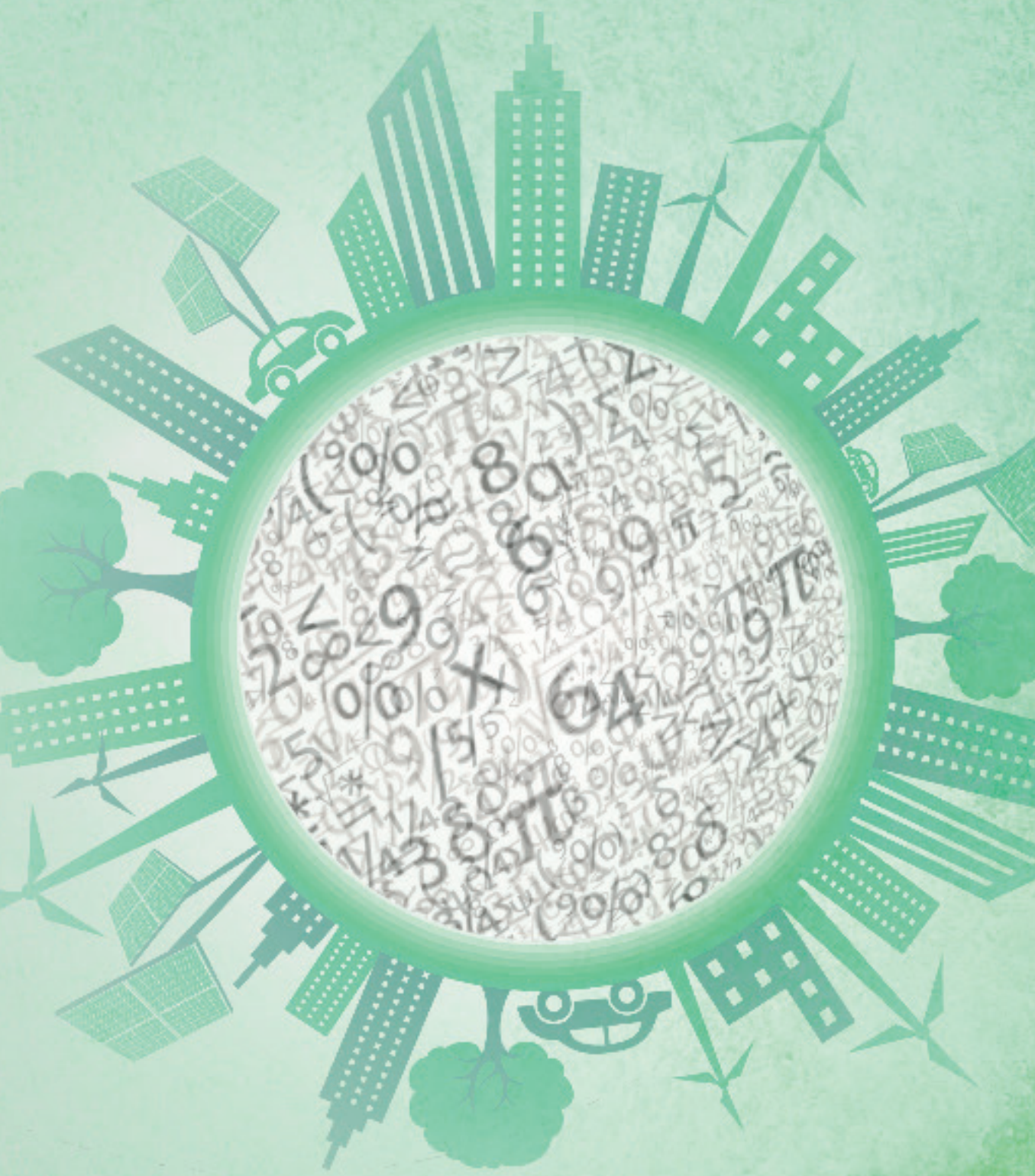

Aleksander Banasik 



\section{Multi-objective optimization for eco-efficient food supply chains}

Aleksander Banasik 


\section{Thesis committee}

\section{Promotors}

Prof. Dr J.M. Bloemhof-Ruwaard

Professor of Operations Research and Logistics

Wageningen University \& Research

Prof. Dr J.G.A.J. van der Vorst

Professor of Logistics and Operations Research

Wageningen University \& Research

\section{Co-promotor}

Dr G.D.H. Claassen

Associate professor, Operations Research and Logistics Group

Wageningen University \& Research

\section{Other members}

Prof. Dr R.M. Boom, Wageningen University \& Research

Prof. Dr D. Cattrysse, KU Leuven, Belgium

Prof. Dr W.E.H. Dullaert, VU University Amsterdam

Prof. Dr R. Dekker, Erasmus University Rotterdam

This research was conducted under the auspices of

Wageningen School of Social Sciences (WASS) 


\title{
Multi-objective optimization for eco-efficient food supply chains
}

\author{
Aleksander Banasik
}

\section{Thesis}

submitted in fulfilment of the requirements for the degree of doctor at Wageningen University

by the authority of the Rector Magnificus,

Prof. Dr A.P.J. Mol,

in the presence of the

Thesis Committee appointed by the Academic Board

to be defended in public

on Tuesday 14 March 2017

at 1.30 p.m. in the Aula. 


\section{Aleksander Banasik}

Multi-objective optimization for eco-efficient food supply chains, 147 pages.

PhD thesis, Wageningen University, Wageningen, the Netherlands (2017)

With references, with summary in English

ISBN 978-94-6343-094-4

DOI http://dx.doi.org/10.18174/405791 


\section{Table of contents}

$\begin{array}{ll}1 \text { Introduction } & 7\end{array}$

1.1 Introduction to the research project 9

$\begin{array}{ll}1.2 \text { Research problem description } & 10\end{array}$

1.3 Research objective and questions 12

1.4 Methodological design $\quad 14$

$\begin{array}{ll}1.5 \text { Thesis outline } & 16\end{array}$

2 Multi-criteria decision making approaches for green supply chains: a review $\quad 17$

$\begin{array}{ll}\text { Abstract } & 18\end{array}$

$\begin{array}{ll}2.1 \text { Introduction } & 19\end{array}$

$\begin{array}{ll}2.2 \text { Conceptual framework } & 20\end{array}$

2.3 Literature review method $\quad 24$

2.4 Results 25

2.5 Discussion and conclusions 36

3 Assessing alternative production options for eco-efficient food supply chains using multi-objective optimization $\quad 39$

$\begin{array}{ll}\text { Abstract } & 40\end{array}$

$\begin{array}{ll}3.1 \text { Introduction } & 41\end{array}$

3.2 Problem description $\quad 43$

$\begin{array}{ll}3.3 \text { Case study } & 47\end{array}$

3.4 Sensitivity analysis $\quad 57$

3.5 Discussion and managerial insights $\quad 59$

$\begin{array}{ll}3.6 \text { Conclusions and future research } & 60\end{array}$

$\begin{array}{ll}\text { Appendix } 1 & 62\end{array}$

$\begin{array}{ll}\text { Appendix } 2 & 63\end{array}$

4 Closing loops in agricultural supply chains using multi-objective optimization: $\begin{array}{ll}\text { a case study of an industrial mushroom supply chain } & 65\end{array}$

$\begin{array}{ll}\text { Abstract } & 66\end{array}$

$\begin{array}{ll}4.1 \text { Introduction } & 67\end{array}$

$\begin{array}{ll}\text { 4.2 Literature review } & 69\end{array}$ 
4.3 Industrial mushroom production

$\begin{array}{ll}4.4 \text { Results } & 80\end{array}$

$\begin{array}{ll}4.5 \text { Discussion } & 85\end{array}$

$\begin{array}{ll}\text { 4.6 Conclusions } & 87\end{array}$

5 Accounting for uncertainty in eco-efficient agri-food supply chain: a multi-objective two-stage stochastic optimization model for mushroom $\begin{array}{ll}\text { production planning } & 91\end{array}$

$\begin{array}{ll}\text { Abstract } & 92\end{array}$

$\begin{array}{ll}5.1 \text { Introduction } & 93\end{array}$

$\begin{array}{ll}5.2 \text { Literature review } & 94\end{array}$

5.3 Illustrative real-life case study 96

$\begin{array}{ll}5.4 \text { Results } & 103\end{array}$

$\begin{array}{ll}5.5 \text { Discussion and conclusions } & 105\end{array}$

$\begin{array}{ll}6 \text { Conclusions and general discussion } & 107\end{array}$

$\begin{array}{ll}\text { 6.1 Conclusions } & 109\end{array}$

6.2 Scientific contribution and integrated findings 112

$\begin{array}{ll}\text { 6.3 Managerial impact } & 115\end{array}$

$\begin{array}{ll}\text { 6.4 Future research directions } & 117\end{array}$

$\begin{array}{lr}\text { Summary } & 119\end{array}$

$\begin{array}{lr}\text { References } & 123\end{array}$

$\begin{array}{ll}\text { Acknowledgements } & 144\end{array}$

$\begin{array}{ll}\text { Completed Training and Supervision Plan } & 146\end{array}$ 
Chapter 1

\section{Introduction}





\subsection{Introduction to the research project}

Due to increased exposure in the media about global warming and depletion of resources, society is more aware of the environmental damage caused by human actions (Quariguasi Frota Neto et al., 2009). Resources are becoming scarce, and the consequences of climate change are having a large impact on the living environment. At the same time, it is estimated that about $50 \%$ of total food production is wasted in the supply chain and after reaching the customer, which accounts for over 1.3 billion tons of food wastage worldwide (Lin et al., 2013). Moreover, it is predicted that by 2050 , overall food production will need to be increased by some $70 \%$ to feed the increasing world population (Alexandratos and Bruinsma, 2012). To satisfy the future needs of the growing population, Food Supply Chains (FSCs), composed of organisations that produce, process and distribute crop- and animal-based products (van der Vorst et al., 2005), are challenged to increase productivity, eliminate current inefficiencies, and produce more sustainable and healthier products.

Concerns about sustainability around FSCs require action. The research in this thesis originates from the idea that food production could become more sustainable than it currently is if scarce resources (such as raw materials, energy sources, water, chemicals) are used efficiently (not producing more side streams than necessary) and effectively (by valorization of unavoidable side streams) without seriously harming the environment. This may imply a re-design of food production and distribution. Advanced decision support models can help re-design FSCs to eliminate current inefficiencies and to assess technical innovations at chain level (de Keizer, 2015; Rijpkema, 2014). This is challenging because these decision support models must deal with the complexity of FSCs and account for intrinsic characteristics of food products, such as alternative production options, perishability of products, as well as uncertainty in productivity, demand and prices (Soysal, 2015; Shukla and Jharkharia, 2013).

Most of the mathematical models for decision support in FSCs only consider economic aspects (Akkerman et al., 2010). However, sustainable supply chains require more than the economic validation of a single overriding objective (i.e. profit) for individual links within the chain. A sustainable supply chain involves multiple and (mostly) conflicting objectives and requires an integrated approach by the different stakeholders, including complex interrelated input-output relationships. Inevitably, choices have to be made and each alternative has a specific impact on the (conflicting) goals. Moreover, there is a need to develop and analyse sustainable supply chain models, instead of focusing on single-location models, which may result in a reduction of negative environmental impact at one location at the expense of an increase elsewhere in the chain (Chaabane et al., 2012; Tang and Zhou, 2012). The research in this thesis aims to provide the food sector with tools to take its social responsibility and to be prepared for the societal urge to improve on sustainability by developing decision support models for quantifying the impact of alternative production options and for optimizing flows of material in FSCs with respect to multiple criteria. 


\subsection{Research problem description}

Environmental concerns have become an important issue in supply chains, which are defined as "all activities associated with the flow and transformation of goods from raw materials stage, through to the end user, as well as the associated information flows" (Seuring and Muller, 2008). Until recently, supply chains focused mainly on delivering high-quality products at low cost and gave only secondary attention, if any, to environmental impact and depletion of natural resources. To avoid depletion of natural resources for future generations, nowadays decision makers in supply chains are focused on using natural resources to their full potential by using as little material as possible, not producing more side streams (or waste) than necessary, and valorizing unavoidable side streams (i.e. "to do more with less") to ensure environmental sustainability of supply chains.

\subsubsection{Improvement opportunities}

To improve the environmental performance of a supply chain, a so-called green supply chain should be considered, which extends the traditional supply chain to include activities that minimize the environmental impact of a product throughout its life cycle by giving attention to waste reduction, efficient use of energy resources, greenhouse gas emissions, and resource use efficiency (Paksoy et al., 2010; Beamon, 1999). The environmental impact of supply chains has been measured based on the amount of greenhouse gases (GHG) emitted (Aramyan et al., 2011; Bauer et al., 2010), energy consumed (Zanoni and Zavanella, 2012; van der Vorst et al., 2009), solid waste produced (Paksoy et al., 2010; Quariguasi Frota Neto et al., 2009), or water consumed (You et al., 2012; Oglethorpe, 2010). In the context of FSC, the sustainability discussion has mainly focused on reduction of waste and transportation emissions (Soysal et al., 2014; van der Vorst et al., 2009).

In addition, integration of forward and reverse logistics into so-called closed-loop supply chains has been explored (Chaabane et al., 2012; Paksoy et al., 2011; Jayaraman, 2006). Such considerations are extended to include recovery of (by)products, typically achieved through practices such as reuse, repair, recycle, remanufacture and reverse logistics (Chaabane et al., 2011; Paksoy et al., 2011; Chaabane et al., 2008). With respect to supply chains concerned with food products, quantitative models have been proposed for biofuel production (Ziolkowska, 2014; You et al., 2012), which can be seen as a reverse supply chain for food products, because it offers insights into potential ways to valorize food waste. However, as shown in Chapter 2, the literature lacks FSC decision support models that focus on closing loops by using waste as materials for production in the same chain. Furthermore, assessment of closing loop technologies needs to be performed with respect to both environmental and economic factors (Govindan et al., 2015d).

\subsubsection{Multi-criteria decision making}

It is clear that studying sustainability in supply chains requires the consideration of multiple goals. Any design of a supply chain usually involves trade-offs among different conflicting 
objectives (Wang et al., 2011), and only a limited number of initiatives for environmentfriendly production have proved to be profitable (Quariguasi Frota Neto et al., 2008), i.e. reduction of environmental impact often requires sacrifices in terms of economic performance of a supply chain. Moreover, evaluation of an FSC requires not only the assessment of environmental and economic aspects but also their interdependence. Multi-Criteria Decision Making (MCDM) is a research field within Operations Research that deals with any decision where multiple and conflicting criteria have an influence on the decision (Scott et al., 2012). Multi-criteria decision approaches are the basis for developing case-dependent models commonly used to address different decision problems in sustainable supply chains and to test the efficiency of various supply chain configurations and operating strategies (Aramyan et al., 2011; Chaabane et al., 2011; Ramudhin et al., 2010).

In this research, multi-objective optimization, one area of MCDM, is applied to balance the conflicting economic and environmental objectives. Multi-objective optimization is particularly suitable for finding the best compromise between economic and environmental dimensions of sustainability (Chaabane et al., 2011). The rationale is to develop decision support models that can be used to determine a set of eco-efficient solutions, i.e. a set of solutions for which it is impossible to improve the environmental objective without worsening the economic objective (and vice versa) (Quariguasi Frota Neto et al., 2009). Despite the vast body of literature on MCDM, determining eco-efficient solutions with multi-objective optimization is quite new and has been identified as a challenging task because of the computational difficulties (Dekker et al., 2012; Quariguasi Frota Neto et al., 2009). Moreover, when the environmental performance is expressed by multiple indicators, the set of eco-efficient solutions cannot be as clearly presented and interpreted because of the need for multiple dimensions.

\subsubsection{Embeddedness}

The issue of sustainability in food production is addressed in this work, which is part of a project called Valorisation of raw materials and process efficiency commissioned by the Top Institute Food and Nutrition (TIFN). The objective of the TIFN project is to investigate how current food production can be optimized with respect to resource use in terms of raw material valorization, which is interpreted as better use of raw materials, reduced use of energy and water, and the minimization of losses.

The TIFN project involves multiple food processing companies and research groups, two of which involve Wageningen University \& Research. The Food Process Engineering (FPE) group focuses on technological innovations to reduce inefficiencies and improve sustainability at the process level, and on using exergy analysis to quantify the environmental performance of FSCs. Exergy analysis is based on basic concepts in thermodynamics and can be used to objectively assess environmental impact (Zisopoulos et al., 2017). The advantage of exergy as an environmental indicator is that it allows the environmental impact of production and distribution activities to be quantified and expressed in a single unit (i.e. megajoules). In contrast to energy, exergy is exempt from the law of conservation, and in all real-life processes exergy input always exceeds exergy output (Apaiah et al., 2006), which means that some 
exergy is irreversibly lost in each processing step. The exergy balance applied to a process explains how much exergy supplied as input to the system has been irretrievably lost by the process (Kotas, 1995).

The data on technological innovations and exergy analysis delivered by the FPE group is used by the Operations Research and Logistics (ORL) group, which focuses on the identification and quantification of opportunities for valorization and waste stream management at the supply chain level using decision support models. This dissertation contributes to the work of ORL.

The TIFN project has embraced two case studies: the bread supply chain (partner: Sonneveld BV), and the mushroom supply chain (partner: C4C Holding BV). These cases were chosen based on their potential to recover waste materials; i.e. recycling of waste bread is central in the bread case, whereas reusing (parts of) the growing medium is central in the mushroom case. The setting of the TIFN project ensures strong involvement of the industry in the complete process, i.e. problem finding, data collection, and communication with the industrial partners. For each case study, a working group, including the industrial partners and senior researchers, was set up to provide focus, gather data, and discuss findings.

\subsection{Research objective and questions}

The overall objective of this research is to support decision making in FSCs by developing dedicated multi-objective models that are used to optimize and re-design FSCs by balancing economic and environmental criteria. The emphasis is directed towards the valorization of (by)product flows by means of closing loops and waste management at the chain level. In particular, we aim to: (i) develop blueprints for industry-specific FSC models by deriving ecoefficient solutions to assess alternative production options and to quantify the impact of closing loop technologies, (ii) assess the potential of exergy as a single indicator for the environmental dimension of sustainability, (iii) investigate the impact of uncertainty in model parameters on eco-efficient solutions in FSCs.

The challenge and scientific contribution of this work are to develop sophisticated optimization models that capture the underlying complexity of FSCs in order to support decision making in real life. The specific goals of the optimization models developed are to:

- Support managerial decisions for alternative production options that result in lower production costs and environmentally friendly food production;

- Perform ex ante, quantitative assessment of technological innovations on the economic and the environmental performance of the chain;

- Quantify the impacts of closing loops;

- Calculate and determine the trade-offs between important economic and environmental criteria to support decision making.

In line with the research objective, four research questions are defined, which are introduced in the following subsections. 


\subsubsection{Research challenges}

Incorporating environmental thinking into supply chains is not new, and a considerable amount of literature describing quantitative tools for eco-efficient supply chains is available. Literature review articles on quantitative approaches to support decision making in supply chains with environmental concerns include, for example, Brandenburg et al. (2014), Dekker et al. (2012), Soysal et al. (2012), and Seuring (2013). To the best of our knowledge, however, no reviews have focused specifically on MCDM approaches in eco-efficient supply chains. To investigate gaps and research challenges in the literature related to the use of multi-criteria approaches for decision making in supply chains, the following research question has been formulated:

RQ1: What is the state of the art and what are the research challenges in MCDM approaches applied to eco-efficient supply chains?

Some of the findings of the literature review, which is discussed in Chapter 2, include: (i) a lack of multi-objective optimization models to support decision making in real-life FSCs, (ii) a variety of indicators used in the literature to account for the environmental impact of food production, (iii) no attention given to closed-loop FSCs, (iv) most papers assume all data to be deterministic. These findings were the motivation to formulate research questions RQ2, RQ3, and RQ4 discussed in the following subsections.

\subsubsection{MCDM models to evaluate new technologies in FSCs}

The findings of the literature review suggest that only some isolated studies are built on empirical research, and in most cases, the developed models use illustrative (not real-life) examples. More attention should be given to industry-specific research on eco-efficient supply chains, and the multi-objective models developed should be linked to empirical data (Seuring, 2013; Hassini et al., 2012).

In food industries, technological innovations become available that allow for alternative ways to deal with waste materials, i.e. allow for reducing, reusing, or recycling waste materials from food production. However, there are few studies in the closed-loop supply chain literature that evaluate quantitatively the relationship between economic and environmental criteria simultaneously (Govindan et al., 2015d; Stindt and Sahamie, 2014). Best practices must be identified given the currently available technology and technological innovations, including e.g. pre-processing, new recipes and alternative activities. All these specificities need to be evaluated with the help of multi-objective optimization models that encompass features and specificities of the supply chains under consideration to assess the benefits of technological innovations and ultimately to determine eco-efficient configurations of an FSC. The following research question has been formulated:

RQ2: What type of MCDM models can be used to evaluate the effects of new technologies and logistical structures on eco-efficiency in food supply chains? 


\subsubsection{Indicator based on exergy analysis to account for environmental performance of an FSC}

For ease of interpretation and from a computational point of view, it is beneficial to use a single indicator for environmental performance. To account for the environmental impact of an FSC, this TIFN project proposes an indicator based on exergy analysis. Exergy analysis is a suitable scientific concept to study the impact on the environment because it measures all inputs and outputs in a single unit (MJ), making the results visible and the conclusions easy to draw (Zisopoulos et al., 2017; Wall, 2010; Apaiah et al., 2006; Apaiah et al., 2005). Exergy analysis is an accepted tool in engineering and has been successfully applied in many fields, including the energy and chemical sectors, environmental engineering, and construction industries, but has not been widely applied to FSCs (Zisopoulos et al., 2015). Despite the broad use of exergy analysis, its applicability in FSCs and its capacity to deal with the multi-dimensional nature of sustainability has not yet been evaluated. To address this problem, the following research question has been formulated:

RQ3: What is the added value of using a single metric indicator based on exergy analysis to account for the environmental performance of a food supply chain?

\subsubsection{Accounting for uncertainty in optimizing production planning decisions in FSCs}

Models developed for supply chain management with environmental considerations usually assume all data to be deterministic, i.e. the values of all parameters are assumed to be known and certain. In real-world optimization problems, however, the data are not known exactly at the time the problem is being solved because of measurement, estimation and implementation errors (Ben-Tal et al., 2009). In addition, in FSCs, not all the required data are available in advance because of various sources of uncertainty, e.g. risks related to the market, fluctuating demand, production yields, and prices. These uncertainties should be considered to give a better representation of reality in the mathematical models used to support decision making.

Notably, as presented in Chapter 2, most of the papers on eco-efficient supply chains assume all data to be deterministic, and uncertainty is hardly taken into account. Moreover, none of the sources of uncertainty related to food production (e.g. production yields or demand) are included in publications, which present decision support models for eco-efficient FSCs. To investigate the impact of uncertainty on the overall performance of an FSC, the following research question has been formulated:

RQ4: What is the impact of including uncertainty of data in optimization models on ecoefficient solutions in a food supply chain?

\subsection{Methodological design}

A considerable amount of literature describing quantitative approaches for eco-efficient supply chains is available and is the basis for answering RQ1. A comprehensive literature review is conducted to identify indicators to account for eco-efficiency and to investigate what MCDM 
approaches are used to tackle distribution, production, and inventory problems in supply chain models with environmental considerations. Answering this research question provides information on research opportunities in the use of MCDM approaches for eco-efficient (food) supply chains, and offers insights into potential models and their characteristics to answer the subsequent research questions.

To answer RQ2, we develop industry-specific models for two case studies, i.e. the bread supply chain and the mushroom supply chain. Before developing the mathematical decision support models, input-output relationships in the supply chains under consideration are investigated through extensive literature review, data analysis, and expert knowledge. Interrelations between links in the chain are identified to get a good understanding of the objectives involved, sourcing of raw materials, and production of intermediate products, final products, and by-products. In collaboration with the technological research partners and the industrial partners, we identify alternative processes, technological innovations, including opportunities for closing loops, and quantify the economic and environmental impact of all activities and processes in the case studies. The mathematical models are used for optimization of economic performance, improvement of current practices, and elimination of inefficiencies for specific FSCs. Identifying an appropriate MCDM model and applying it to the studies under consideration provides information on the optimal settings of the FSC structure.

The models developed to answer RQ2 are used to quantify trade-offs between economic and environmental indicators. Environmental indicators considered include $\mathrm{CO}_{2}$ emissions, energy consumption, waste generated, and exergy loss; the data were quantified by collaborating scientists. To address RQ3, a comparison is made between the single indicator of exergy loss against commonly used environmental indicators to assess FSCs. To evaluate the value of exergy as a single metric to account for environmental impact, we investigate if other indicators (compared with using an indicator based on exergy analysis) leads to different conclusions. Answering this research question provides information on the capacity of exergy to capture the environmental dimension of sustainability at the chain level.

Many production processes and distribution activities are characterized by uncertain data parameters. Uncertain data parameters are identified and evaluated by the industrial partners, which allows the probability distribution function of the uncertain parameters to be established. Stochastic programming is used to reformulate the problem with uncertain parameters into a tractable form, and the reformulated model is solved by standard optimization software to obtain the best expected values of the objectives. The approach developed is tested on a case study characterized by uncertainty in the input data parameters. Answering RQ4 delivers information on the added value of using stochastic programming in MCDM models in the FSC context. 


\subsection{Thesis outline}

This thesis includes a collection of four papers that discuss or apply the use of MCDM for ecoefficient FSCs. The papers are either published or under review for journal publication. The subsequent chapters comprise these papers, which address each research question. An overview of the thesis is shown in Figure 1.1. Chapter 2 reviews the literature on the use of MCDM approaches applied to eco-efficient supply chains. Chapter 3 discusses the assessment of alternative production options and compares the solutions when different environmental objectives are considered. Chapter 4 introduces a closed-loop industrial mushroom supply chain and proposes a model for an assessment of alternative production options and closing loop technologies. Chapter 5 proposes a two-stage stochastic production planning model to account for uncertainty in an eco-efficient FSC. Chapter 6 discusses the summarized findings and conclusions from the research. In addition, scientific contribution, managerial impact and recommendations for further research are provided.

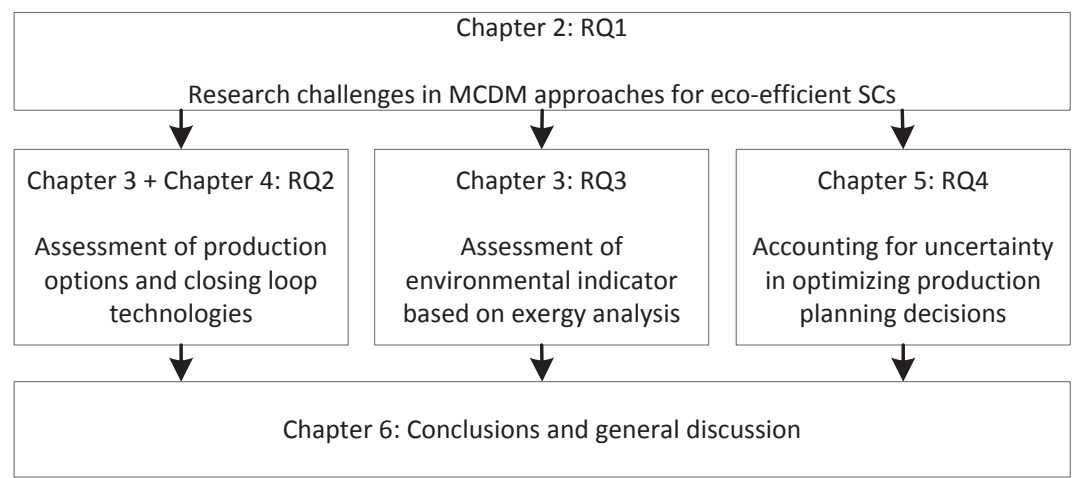

Figure 1.1 Thesis overview 
Chapter 2

\title{
Multi-criteria decision making approaches for green supply chains: a review
}

This chapter is based on the published journal article:

\begin{abstract}
A. Banasik, J. M. Bloemhof-Ruwaard, A. Kanellopoulos, G.D.H. Claassen, J.G.A.J. van der Vorst (2016) Multi-criteria decision making approaches for green supply chains: a review Flexible Services and Manufacturing Journal DOI: http://dx.doi.org/10.1007/s10696-016-9263-5
\end{abstract}




\begin{abstract}
Designing Green Supply Chains (GSCs) requires complex decision-support models that can deal with multiple dimensions of sustainability while taking into account specific characteristics of products and their supply chain. Multi-Criteria Decision Making (MCDM) approaches can be used to quantify trade-offs between economic, social, and environmental criteria i.e. to identify green production options. The aim of this chapter is to review the use of MCDM approaches for designing efficient and effective GSCs. We develop a conceptual framework to find relevant publications and to categorise papers with respect to decision problems, indicators, and MCDM approaches. The analysis shows that (1) the use of MCDM approaches for designing GSCs is a rather new but emerging research field, (2) most of the publications focus on production and distribution problems, and there are only a few inventory models with environmental considerations, (3) the majority of papers assume all data to be deterministic, (4) little attention has been given to minimization of waste, (5) numerous indicators are used to account for eco-efficiency, indicating the lack of standards. This study, therefore, identifies the need for more multi-criteria models for real-life GSCs, especially with inclusion of uncertainty in parameters that are associated with GSCs.
\end{abstract}




\subsection{Introduction}

Until recently, supply chains focused mainly on delivering high quality products at low costs and gave only secondary attention, if any, to environmental impact and depletion of natural resources. However, natural resources (like energy, water, minerals, metals and land) are becoming scarce, and their demand is expected to increase because of the growing world population (PWC, 2011). Additionally, society puts more pressure on companies to apply environmentally friendly practices due to the growing awareness of climate change caused by greenhouse gas emissions. Escalating deterioration of the environment leads to growing interest of researchers and practitioners in Green Supply Chains (GSCs), which extend the traditional supply chains to include activities that minimize environmental impact of a product throughout its entire life cycle (Beamon, 1999). To satisfy the future needs of growing population, supply chains are challenged to increase productivity and eliminate current inefficiencies. To achieve this, decision support models, which account for characteristics of products, such as e.g. increased risks related to uncertainty of the market and productivity, can be used to assess technical innovations at chain level and optimize the current logistic management (i.e. production, distribution and inventory management).

Eliminating inefficiencies and designing GSCs imply quantification of what is feasible from a technical point of view and calculation of trade-offs between economic and environmental indicators (Dekker et al., 2012). This leads to a concept of eco-efficiency, which we define as 'maintaining or increasing the value of economic output while simultaneously decreasing the impact of economic activity upon ecological systems' (Braungart et al., 2007). Eco-efficiency, therefore, combines environmental and economic demands (Govindan et al., 2014b), and an 'eco-efficient solution' is one where further environmental damage can only be prevented at higher costs (Dekker et al., 2012; Quariguasi Frota Neto et al., 2009).

Studying eco-efficiency in GSCs requires the consideration of multiple conflicting criteria, as any design of a Supply Chain (SC) usually involves trade-offs among different conflicting objectives (Wang et al., 2011). Inclusion of multiple criteria in supply chains is a natural way of dealing with different dimensions of sustainability (Eskandarpour et al., 2015; Kannegiesser et al., 2015). Multi-Criteria Decision Making (MCDM), refers to a general class of Operations Research models (Pohekar and Ramachandran, 2004), which aim to quantify feasible production alternatives and support decision makers in selecting (a subset of) alternative options based on two or more criteria (Wallenius et al., 2008). MCDM approaches have already been applied successfully in various research areas, such as energy fuels, management, or ecology (Zavadskas et al., 2014). Although literature reviews have been carried out on quantitative approaches for Supply Chain Management (SCM) with environmental concerns (Eskandarpour et al., 2015; Brandenburg et al., 2014; Seuring, 2013; Dekker et al., 2012), to the best of our knowledge, no reviews specifically focus on MCDM approaches in eco-efficient GSCs and related production, distribution and inventory problems.

The aim of this chapter is to review MCDM approaches that have been used for the design of Green Supply Chains. A conceptual framework is developed in Section 2 to categorise 
indicators and decision problems in GSCs based on existing literature reviews and to outline MCDM approaches and requirements for modelling GSCs. The approach we use to structure and design the literature review, including the search queries, is presented in Section 3. The results of the literature review are presented in Section 4, where publications are categorised according to the conceptual framework. Finally, Section 5 proposes research opportunities for MCDM approaches in eco-efficient GSCs and presents concluding remarks.

\subsection{Conceptual framework}

We started this research by identifying recent and relevant literature reviews on the topic of green supply chain management, which refers to integrating environmental thinking in SCM (Srivastava, 2007). This resulted in 10 review articles which were used as a basis for the development of the conceptual framework for this study. First of all, Dekker et al. (2012) discussed issues related to green logistics, and revealed Operations Research contributions to supply chains with environmental considerations. Seuring (2013) and Brandenburg et al. (2014) focused on forward supply chains and reviewed modelling approaches used for SCs with sustainability considerations. Seuring and Muller (2008) reviewed literature on forward sustainable supply chain management. Srivastava (2007) presented a state of the art literature review on green supply chain management with a focus on reverse logistics, whereas Carter and Rogers (2008) and Ashby et al. (2012) reviewed and discussed literature on supply chain management within the context of sustainability. Three review articles focused on perishable products. Perishability is an important source of inefficiency because it contributes to production of waste. Food production chains are characteristic example of supply chains where perishability and changing product quality is evident. Akkerman et al. (2010) reviewed quantitative approaches used for distribution management of food products and focus on quality, safety and sustainability; Shukla and Jharkharia (2013) reviewed literature in agri-fresh produce SCs and discussed operational issues causing post-harvest wastage; and Soysal et al. (2012) reviewed quantitative models used for sustainable food logistics management.

Analysing the key words and frameworks used in the 10 reviews and mapping these on the use of MCDM approaches in GSCs, we developed a conceptual framework for the literature analysis. This framework identifies which economic and environmental performance indicators are used to account for sustainability, categorise decision problems in SCs, and outline the impact of specific product characteristics on the decision problems and indicators (Figure 2.1). These characteristics are further explored as they should be included in MCDM models developed for GSCs. The proposed framework is used to identify relevant articles and conduct the literature review.

\subsubsection{Eco-efficiency indicators in Supply Chains}

During the production of final products from raw materials, and the delivery of products to final customers, supply chains inevitably harm the environment (Tang and Zhou, 2012). In Supply Chain Management with environmental concerns, the main business objectives are cost reduction, responsiveness improvement, and avoidance of permanent environmental damage 
(Soysal et al., 2012). In order to quantify the economic and environmental impact of supply chain activities and to improve environmental and economic performance, a set of indicators for eco-efficiency must be selected and considered to support decision making at SC level. Apart from commonly used indicators for economic performance of supply chains, such as total costs or profit, the analysis of the 10 review papers shows that important indicators to account for eco-efficiency are greenhouse gas (GHG) emissions, energy consumption and water consumption (Seuring, 2013; Dekker et al., 2012; Soysal et al., 2012).

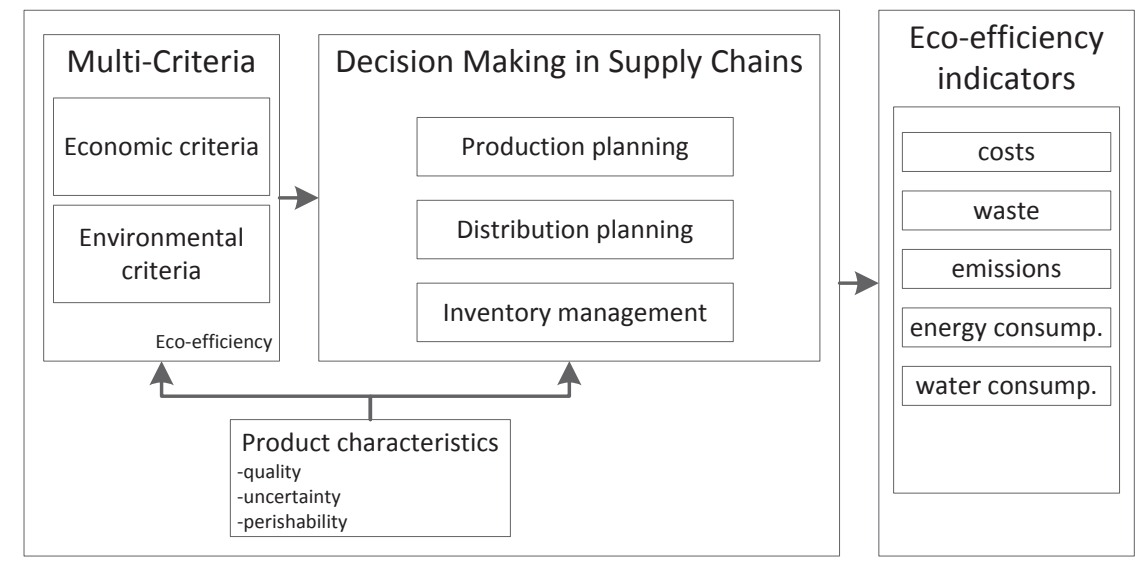

Figure 2.1 Conceptual framework for multi-criteria decision making in eco-efficient supply chains

Each supply chain is unique in its characteristics. Products are characterized by quality, fluctuations in demand and prices, seasonality, and perishability (Akkerman et al., 2010; Quariguasi Frota Neto et al., 2009; van der Vorst et al., 2009). These factors are associated with uncertainty. For instance, in Food Supply Chains (FSCs) these various sources of uncertainty lead to production of substantial amount of losses (Shukla and Jharkharia, 2013). Perishability and continuous quality change of products over time is not exclusively associated with food products, but holds for other products as well, e.g. other fast moving consumer goods. Quality change over time is also associated with uncertainty because the change in quality is usually not precisely known as it depends on environmental conditions. We conclude that product quality, uncertainty, and perishability should be taken into account when designing eco-efficient GSCs.

\subsubsection{Decision problems in supply chain management}

Research has been focusing on improving the environmental performance of SCs (Brandenburg et al., 2014). To categorise decision problems in the conceptual framework we adapt the classification proposed by Shukla and Jharkharia (2013), and distinguish between three decision problems that have an impact on eco-efficiency in GSCs: production planning, distribution planning, and inventory management.

Production planning commonly refers to decisions on how the production is organised, how, when, and how many products are produced, and when the products become available, to minimize operational costs of production and simultaneously use available resources and 
capacities efficiently. Within production planning two aspects play an important role (Dekker et al., 2012). The first aspect is the production process and the way the product is produced, i.e. what resources are used to make the product and what is the environmental impact related to production. Associated decisions include e.g. which raw materials and technology to use at which location to create the right number of finished products on time to satisfy the customer's demand. These decisions have an impact on eco-efficiency as they determine the amounts of (raw) material, energy, water, and fuel use, as well as the total amount of waste produced. The second relevant aspect with respect to production planning is whether a product's value can be (partly) recovered after its use. This issue is relevant also for FSCs, as products that cannot be sold (due to quality requirements) and are considered as post-harvest losses often still possess valuable nutrients. If products (or their components) can be processed and reused, it might improve eco-efficiency by reducing the total amount of waste and reducing the need for using other raw materials.

A second decision problem affecting the performance of a supply chain is distribution planning, which refers to two main topics: facility selection and transportation. Facilities are physical locations in a supply chain, comprising of production sites, distribution centres, airports, railway stations or ports. Related decisions on role, location, size and number of facilities have a substantial impact on the performance of a supply chain (Chopra and Meindl, 2013). Decisions concerning facilities affect not only total operating costs, but also the energy use of facilities. Additionally, the location and the number of facilities determine the total travelling distance of a product before reaching the final destination. Facility decisions therefore have an effect on the total time needed to reach the final customer, which is an important aspect in relation to products that degrade in quality over time. With respect to technological innovations, such as extending the shelf-life of products, a redesign of existing networks might bring economic and environmental benefits. A second aspect in distribution planning is transportation, which refers to the movement of products between facilities. Decisions in transportation include the selection of transportation mode, type and size of transportation unit, fuel choice, loading and routing of vehicles (Chopra and Meindl, 2013). Transportation activities account for $15 \%$ of total GHG emissions worldwide (TSP, 2010) and account at the same time for up to two thirds of the total logistic costs (Akkerman et al., 2010). Due to handling and deterioration of food products, transportation is also the biggest cause of food waste in FSCs (Shukla and Jharkharia, 2013). This shows that choices of transportation have a substantial impact on environmental and economic performance. New transportation equipment enables to reduce fuel consumption as observed in airplanes or ships (Dekker et al., 2012), and technological innovations allow the transportation of products in cooled or frozen conditions. This permits the control of the product's quality degradation over time but at the same time leads to additional energy consumption. These technological innovations make the transportation problems a highly dynamic environment requiring frequent reconsiderations of previously made choices (Akkerman et al., 2010).

The third decision problem closely related to performance of the supply chain is related to inventory management decisions and to the way the inventory is controlled, e.g. using a 
periodical or continuous reviewing system, determining safety stock levels, reorder points or reorder quantities. Decisions in inventory management determine how long the product is waiting before use. In relation to products with limited shelf-life, the most important factor in inventory models is to take into account the deterioration of produce over time (Shukla and Jharkharia, 2013). Inventory holding is associated with holding costs, and in the case of controlled holding conditions (such as frozen, cooled, or heated storage), which is often used for perishable products, inventory holding is also associated with environmental impact because of energy consumption (Dekker et al., 2012) and other issues such as buildings or equipment.

It should be mentioned that apart from the three aggregate categories of decision problems considered in this chapter (i.e. production planning, distribution planning, inventory management), other decision problems can be found in literature too, e.g. supplier selection, procurement planning, or combinations of decision problems, such as inventory routing, or production-distribution. These topics have also been investigated, but are categorised into one of the three main decision themes, i.e. distribution, production, and inventory. The topic of procurement planning can be characterized by making links between the buyer and the supplier, and supplier selection influences the physical location of links in a supply chain. Once physical locations of supply chain links are known, they can be translated into distances. Therefore, for simplification and to facilitate presentation, supplier selection and procurement planning are assigned to decision problems in the distribution planning category.

The environmental impact of a SC can be improved by practices such as reuse, repair, recycle, remanufacture and reverse logistics (Chaabane et al., 2012; Paksoy et al., 2011; Jayaraman, 2006). Thus, not only forward flows of products in a SC, but also reverse and closed-loop supply chains (integrated forward and reverse supply chains) are investigated to improve the environmental impact. The investigation can be divided into the three types of decision problems described above.

\subsubsection{MCDM model characteristics and requirements}

Decision makers in GSCs are confronted with multiple and mostly conflicting criteria of economic and environmental performance, which by definition implies that MCDM approaches are appropriate tools for decision support. Hence it is not surprising that MCDM approaches have already been used to address different decision problems in SCs and to test the efficiency of various SC configurations and operating strategies (Aramyan et al., 2011; Ramudhin et al., 2010). Within the MCDM field, existing approaches are divided in literature into two categories based on the number of feasible solutions (Wallenius et al., 2008; Mendoza and Martins, 2006; Hwang et al., 1980): 1) a small and finite set of solutions, called Multi-Attribute Decision Making (MADM), and 2) a large and infinite set of alternatives, referred to as Multi-Objective Decision Making (MODM) or Multi-Objective Programming (MOP). MADM approaches aim at identifying the best option based on the known attributes of a limited number of alternatives, whereas MODM approaches aim to find the best solution that satisfies the decision maker's desires (Scott et al., 2012). Some of the MADM approaches include analytic hierarchy process (AHP), analytic network process (ANP), decision-making trial and evaluation laboratory 
(DEMATEL), elimination and choice expressing reality (ELECTRE), preference ranking organization method for enrichment of evaluations (PROMETHEE), technique for order of preference by similarity to ideal solution (TOPSIS), and utility additive (UTA) method (Figure 2.2). For a description of MADM approaches see Tzeng and Huang (2011). Some basic MODM approaches are Weighting Method, $\varepsilon$-constraint, and Goal Programming. For a description of MODM methods see Miettinen (2008). The specific MCDM approach used to support decision making in GSCs depends on the case study and scope of the analysis. Additionally, MCDM approaches differ in complexity and model characteristics.

Within MCDM a distinction can be made depending on how data are taken into account. Deterministic data is often assumed for modelling simplicity and computational effort needed to arrive at a solution. In real-world optimization problems however, the data are not exactly known at the time the problem is being solved, due to measurement, estimation and implementation errors (Ben-Tal et al., 2009). Uncertainty in SCs is related to 'situations in which a decision maker lacks effective control actions or is unable to predict accurately the impact of possible control actions on system behaviour due to a lack of 1) information (or understanding) of the environment or current SC state, 2) a consistent model of the SC presenting the relationships between SC redesign variables and SC performance indicators' (van der Vorst, 2000). In SCs uncertainty can be related to supply of raw materials, demand for final products, processing parameters, prices, and in the light of reverse logistics quantity and quality of returned products (Soysal et al., 2012; Tang and Zhou, 2012; Ahumada and Villalobos, 2009). Due to the importance of uncertainty in SCs, in our literature review we differentiate between deterministic models and models taking uncertainty into account.

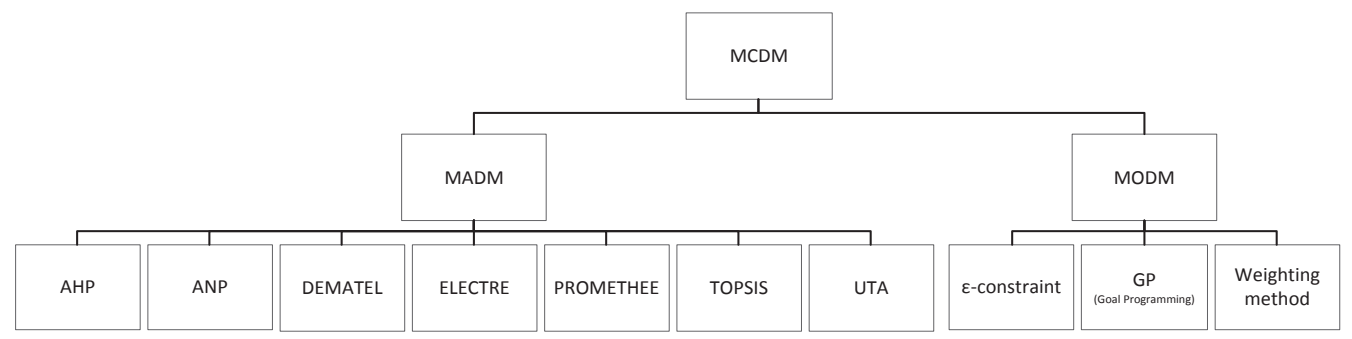

Figure 2.2 Some existing MCDM approaches, based on Tzeng and Huang (2011) and Miettinen (2008)

Specific characteristics of products, such as quality changes, demand and prices variability require model representations of the system dynamics and the interactions between time periods. For that reason, another characteristic of reviewed MCDM approaches is related to whether and how time is taken into account.

\subsection{Literature review method}

To review scientific literature concerned with applications of MCDM approaches to support decision making processes for establishing eco-efficient GSCs, we defined three categories of keywords: Multi-Criteria Decision Making, Supply Chain Management, and eco-efficiency. Based on the conceptual framework (Section 2), we created a set of keywords for each 
category. Within the eco-efficiency category, keywords are included that automatically entail simultaneous consideration of economic and environmental criteria, i.e. keywords such as "ecoefficient" or "sustainability", instead of using specific indicators or criteria as keywords. The intention is to find articles that position themselves under the umbrella of GSCs, instead of finding articles that focus on a specific aspect of environmental protection. A set of keywords for each category together form a search string that was used to explore existing literature in the ISI Web of Science database, one of the highest regarded science databases, which covers more than 11000 journals from multiple disciplines, allowing in-depth exploration of the literature.

A search for scientific publications fitting each of the three categories was conducted. The following search string was used:

(multicriteria OR multi-criteria OR multiobjective OR multi-objective OR multiattribute OR multi-attribute OR trade-off*)

AND ("supply chain" OR logistics or "network design" OR "production planning" OR "inventory management" OR "supplier selection" OR "distribution management" OR "distribution planning")

AND (green OR sustainable OR sustainability OR eco-efficien* OR "resource efficient")

Within the results found, we selected the articles that fit the scope of our analysis: i.e. those articles that concern quantitative models for supporting decision making in supply chains in a multi-criteria decision making context, while taking into account eco-efficiency considerations. We excluded publications concerned with non-quantitative analysis, publications describing non-MCDM approaches (e.g. simulation approaches, regression analysis, and single-objective inventory models), publications that do not describe supply chain analysis, and publications that do not include an indicator associated with eco-efficiency (e.g. models including carbon emission trading scheme in costs only).

\subsection{Results}

This section presents the results of the literature review. Publications that fit in each of the three categories (MCDM, Supply Chain Management, and eco-efficiency) are discussed in line with the developed conceptual framework. Additionally, these publications are analysed to determine the trends in literature with respect to indicators used to account for eco-efficiency, decision problems tackled, and approaches used.

Our literature review resulted in 418 publications out of which 188 publications (45\%) turned out to be relevant for our analysis and were included in the literature review. Figure 2.3 presents a distribution of publications considered by publication year, indicating that the considered research field is new and emerging. 


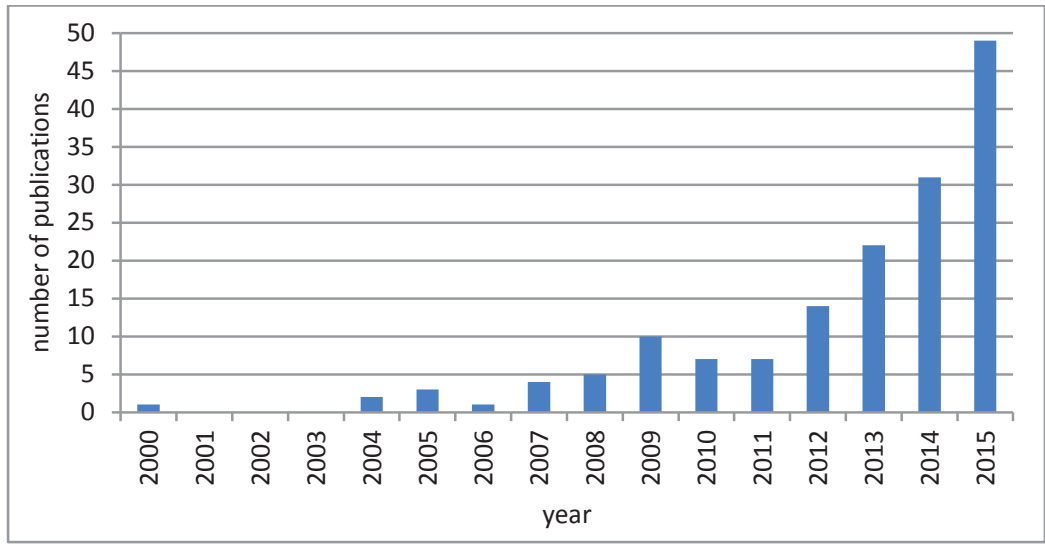

Figure 2.3 Distribution of publications between 2000 and 2015. Relevant publications include application of MCDM approaches to support decisions in inventory, production and distribution in green supply chains.

The articles were published in 68 different journals. In 43 of these journals only one article of interest was found (Table 2.1). Publications are most frequently found in journals associated with categories: operations research and management science; industrial, chemical, and environmental engineering; and environmental sciences. However, some publications are also found in journals associated with categories such as forestry, electrochemistry, thermodynamics or computer science. The distribution of publications among numerous journals, associated with such diverse categories, shows how multi-disciplinary the topic is. It is also observed that the number of conceptual studies from operations management and supply chain management journals is limited, providing a research opportunity to include green supply chain considerations within MCDM context.

\subsubsection{Decision problems}

Production and distribution planning models represent the majority of the publications. We found 69 articles concerned with distribution planning (Figure 2.4) and the associated decision problems related to supplier selection, reverse logistics project selection, third party contractor selection, facility location and transportation planning. Production planning problems were found in 39 papers. The related problems are e.g. capacity planning and technology selection, manufacturing, and scheduling. In 70 publications both production and distribution planning decisions are considered. These articles concern network design and associated production decisions, such as technology selection, or decisions on the quantity of products to be produced. 
Table 2.1 Distribution of papers across journals

\begin{tabular}{lcc}
\hline Journal & Articles & Year \\
\hline Journal of Cleaner Production & 18 & $2009-2016$ \\
\hline International Journal of Production Economics & 15 & $2008-2015$ \\
\hline International Journal of Production Research & 14 & $2007-2016$ \\
\hline European Journal of Operational Research & 9 & $2004-2016$ \\
\hline Expert Systems with Applications & 9 & $2011-2016$ \\
\hline Computers \& Chemical Engineering & 8 & $2000-2016$ \\
\hline Sustainability & 8 & $2014-2016$ \\
\hline Acs Sustainable Chemistry \& Engineering & 6 & $2013-2015$ \\
\hline Aiche Journal & 6 & $2009-2015$ \\
\hline Transportation Research Part E-Logistics and Transportation Review & 6 & $2014-2016$ \\
\hline Computers \& Industrial Engineering & 5 & $2005-2016$ \\
\hline Mathematical Problems in Engineering & 5 & $2013-2016$ \\
\hline International Journal of Environmental Science and Technology & 4 & $2009-2016$ \\
\hline Journal of Manufacturing Systems & 4 & $2015-2016$ \\
\hline Resources Conservation and Recycling & 4 & $2009-2016$ \\
\hline Computers \& Operations Research & 3 & 2015 \\
\hline Industrial \& Engineering Chemistry Research & 3 & $2008-2016$ \\
\hline International Journal of Hydrogen Energy & 3 & $2005-2014$ \\
\hline Production Planning \& Control & 3 & $2011-2016$ \\
\hline Applied Energy & 2 & $2013-2014$ \\
\hline Decision Support Systems & 2 & $2009-2011$ \\
\hline Energy & 2 & $2012-2016$ \\
\hline Flexible Services and Manufacturing Journal & 2 & $2014-2016$ \\
\hline Journal of Manufacturing Technology Management & 2 & 2015 \\
\hline Journal of the Operational Research Society & 2 & 2016 \\
\hline Journals with one article ${ }^{\text {a }}$ & 43 & $2004-2016$ \\
\hline
\end{tabular}

${ }^{a}$ Abstract and Applied Analysis, Annals of Operations Research, Applied Mathematical Modelling, Applied Soft Computing, Applied Thermal Engineering, Arabian Journal for Science and Engineering, Biofuels Bioproducts \& Biorefining-Biofpr, Biomass \& Bioenergy, Canadian Journal of Forest Research-Revue Canadienne De Recherche Forestiere, Computers in Industry, Croatian Journal of Forest Engineering, Ecological Indicators, Energy Conversion and Management, Energy Policy, Environment and Planning A, Environment and Planning B-Planning \& Design, Environmental Science \& Technology, Environmental Technology, Human and Ecological Risk Assessment, Ieee Transactions on Engineering Management, Information Sciences, Intelligent Decision Technologies-Netherlands, International Journal of Advanced Manufacturing Technology, International Journal of Sustainable Transportation, Journal of Advanced Mechanical Design Systems and Manufacturing, Journal of Food Engineering, Journal of Intelligent \& Fuzzy Systems, Journal of Natural Gas Science and Engineering, Journal of Scientific \& Industrial Research, Kybernetes, Mathematical and Computer Modelling, Omega-International Journal of Management Science, OR Spectrum, Proceedings of the Romanian Academy Series a-Mathematics Physics Technical Sciences Information Science, Processes, Renewable \& Sustainable Energy Reviews, Renewable Energy, Scientia Iranica, Scientific World Journal, Springerplus, Tehnicki Vjesnik-Technical Gazette, Transportation Research Part D-Transport and Environment, Waste Management

Inventory management with an environmental objective is hardly treated with MCDM models. Only ten publications include inventory management decisions while considering economic and environmental criteria. Bouchery et al. (2012) present the Sustainable Order Quantity, which is a multi-objective formulation of an Economic Order Quantity (EOQ) model, including economic, environmental and social objectives. An extension to multiple echelons is proposed, and the eco-efficient frontiers are characterized analytically. Andriolo et al. (2015) also propose a bi-objective EOQ optimization model, and develop a haulage-sharing lot sizing model to 
discuss the benefits of cooperation for cost and emission reduction. Konur and Schaefer (2016) model multi-item joint replenishment problem under indirect and direct grouping strategies. Chan et al. (2013) study vendor-buyers co-ordination and illustrate its benefits on economic and environmental performance.

Six publications are assigned to inventory and distribution problems. Jamshidi et al. (2012) present a bi-objective network design model with periodic review inventory replenishment policy (with back-ordering) in warehouses and distribution centres. Sazvar et al. (2014) develop a model to select the best transportation vehicles and to optimally replenish a deteriorating product in a two-echelon centralized supply chain under partial backorder assumption. Marti et al. (2015) use a continuous review inventory policy in the considered supply chain network design model with facility location, procurement and transportation decisions. The developed model is used to analyse the effects of different carbon policies, and allows distinguishing between functional or innovative products. Schaefer and Konur (2015) study continuous review inventory control systems with explicit transportation considerations, and consider models with less-than-truckload transportation and truckload transportation. Bouchery et al. (2016) formulate a model with simultaneous optimization of decisions on transportation mode and order quantity and propose analytical results to identify the efficient frontier when multiple transportation modes are available. Tang et al. (2016) propose a supply chain network design model to select number and location of warehouses and to select routes from manufacturers to warehouses and from warehouses to retailers, while using continuous review inventory policy. We observe that no publications are found that consider simultaneously production and inventory decisions in the context of eco-efficiency. These findings show that gaps in literature exist concerning the use of MCDM approaches to support inventory management decisions with respect to economic and environmental criteria.

Reverse logistics is considered in 27 publications, while only 11 papers combined forward and reverse logistics to support decision making in a closed-loop supply chain (Govindan et al., 2016a; Garg et al., 2015; Ghayebloo et al., 2015; Mota et al., 2015b; Devika et al., 2014; Kannegiesser and Gunther, 2014; Oh and Jeong, 2014; Pishvaee et al., 2014; Ozkir and Basligil, 2013; Paksoy et al., 2012; Quariguasi Frota Neto et al., 2010). Only few of the papers dealing with modelling material flows in a closed-loop supply chain presents a case study with realistic data. This shows that the actual economic and environmental implications of closing loops in real-life case studies still require investigation. Additionally, it is observed that none of the analysed papers concerning food products takes the principles of reverse logistics or closed loop into account. 


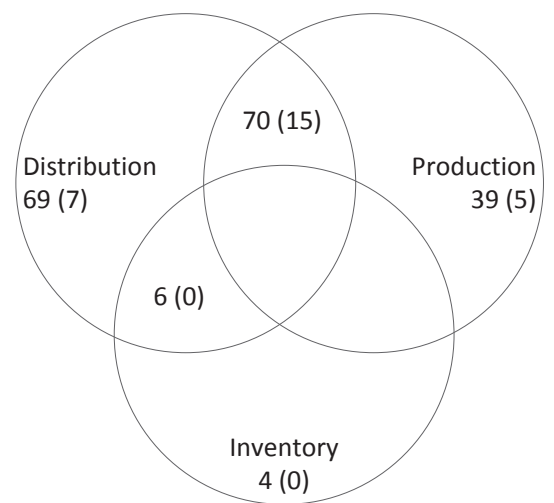

Figure 2.4 Number of publications for each decision problem; numbers in brackets indicate the number of publications considering reverse logistics or closed-loop supply chains

\subsubsection{Key performance indicators}

The analysis shows that the number and types of indicators considered are closely related to the applied MCDM approach. In MADM approaches (in which decision makers interactively assess alternatives with respect to multiple attributes or indicate their perceived importance of each criterion e.g. on a Likert scale), numerous economic, technological, environmental and social indicators are used. In each publication dealing with an MADM approach, a unique set of indicators is developed, which renders clustering and aggregating of these indicators problematic. For this reason we only outline the number of indicators used. The average number of indicators used in MADM approaches is 9.9; the largest number of indicators used is 31 in Govindan et al. (2015b); and the smallest number of indicators used is two in Validi et al. (2015). The largest number of objectives in papers concerned with MODM models is considered in Kostin et al. (2015) (15 objectives for two case studies presented), where an approach is proposed to reduce the number of objectives to a comprehensible number. In articles in which the ultimate goal is to derive a Pareto-efficient frontier, authors focus on two or three objectives. The most commonly used objectives in these studies are minimization of total costs and GHG emissions.

In MODM approaches the indicators (treated as objectives) most commonly used to account for economic performance are costs, profit, Net Present Value, expected return, economic output, financial risk, and total value of purchasing (Table 2.2). In seven publications assigned to production planning no economic indicators were used. Publications that did not use an economic indicator in production planning, focused on balancing between either energy consumption and total completion time (Mansouri et al., 2016; Yildirim and Mouzon, 2012; Mouzon et al., 2007), energy consumption and tardiness (Liu et al., 2014b), carbon emissions and total completion time (Liu et al., 2014a), or focused on environmental indicators objectives only in pinch analysis (Geldermann et al., 2007; Geldermann et al., 2006). In some publications two economic indicators are used simultaneously, e.g. profit and risk (Cruz, 2013; Cruz, 2009; Cruz and Matsypura, 2009). 
Table 2.2 Number of publications with a given indicator used in MODM approaches for different decision problems ( $\mathrm{P}$ - production planning, D - distribution planning, I - inventory management)

\begin{tabular}{|c|c|c|c|c|c|c|c|}
\hline & \multirow[b]{2}{*}{ Indicator } & \multicolumn{5}{|c|}{ Decision Problem } & \multirow{2}{*}{ total } \\
\hline & & $\mathrm{P}$ & $\mathrm{D}$ & I & $\mathrm{P}+\mathrm{D}$ & $\mathrm{D}+\mathrm{I}$ & \\
\hline \multirow{4}{*}{ 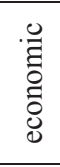 } & costs & 13 & 20 & 4 & 37 & 5 & 79 \\
\hline & profit & 2 & - & - & 21 & 1 & 24 \\
\hline & NPV & 4 & - & - & 11 & - & 15 \\
\hline & other economic ${ }^{a}$ & 6 & 3 & - & 6 & - & 15 \\
\hline \multirow{6}{*}{ 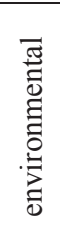 } & GHG & 12 & 14 & 4 & 42 & 6 & 78 \\
\hline & energy & 12 & 2 & 1 & 2 & - & 17 \\
\hline & LCA based & 2 & 1 & - & 13 & - & 16 \\
\hline & water & 10 & 1 & - & 1 & - & 12 \\
\hline & waste & - & 4 & 1 & 6 & - & 11 \\
\hline & other environmental $^{\mathrm{b}}$ & 7 & 5 & - & 6 & - & 18 \\
\hline \multirow{2}{*}{$\begin{array}{l}\dot{\bar{\Xi}} \\
\bar{\Xi}\end{array}$} & service level & 6 & 7 & - & 5 & - & 18 \\
\hline & social & 3 & 3 & 1 & 21 & - & 28 \\
\hline \multicolumn{2}{|c|}{ Number of MODM publications } & 31 & 21 & 4 & 67 & 6 & 129 \\
\hline
\end{tabular}

${ }^{\text {a }}$ Other economic indicators include: Economic score, Economic output, Economic value added, Expected return, Financial risk, Production, Revenue, Total credit, Total value of i) purchasing performance, ii) production performance, iii) delivery and logistics performance

${ }^{\mathrm{b}}$ Other environmental indicators include: Ecocosts, Environmental certification, Environmental efficiency, Environmental index, Environmental score, Exergy losses, Greenness, Green appraisal scores, Hazardous waste management, Non-renewable resources consumption, Recycling rate, Relative Direct Sustainability Index, Relative Total Sustainability Index, Remanufacturing activity, Reverse logistics program, Soil erosion, Volatile Organic Compounds

With respect to environmental indicators, some form of greenhouse gas (GHG) emissions, such as $\mathrm{CO}_{2}$-equivalent, $\mathrm{CO}_{2}$ emission per capita, embodied carbon footprint, air pollution, or impact on global warming is most commonly used. Greenhouse gasses were used as an indicator in $60 \%$ of publications, and were most frequently used in distribution planning models $(67 \%$ of publications), and in combination of distribution and production planning models (63\%). Energy consumption is used in $13 \%$ of publications, and was most frequently used in production planning models (39\%). LCA based indicators, such as ReCiPe 2008, Impact2002+ or EcoIndicator, are used in $12 \%$ of publications, water is used in $9 \%$ of publications, and waste is used as an indicator in $9 \%$ of publications. Other environmental indicators, e.g. green appraisal scores, environmental efficiency, environmental index, volatile organic compounds emissions, or exergy losses are used in $14 \%$ of the papers. Note that number of (environmental) indicators is larger than number of publications. This is because in some publications more than one indicator is used. Notably, none of the studied articles on FSCs use the amount of food waste as an objective.

Numerous indicators were identified to account for eco-efficiency throughout the considered literature. A variety of environmental indicators is observed, and it is concluded that the exact environmental indicator used depends on the specific problem environment and case study. Moreover, attempts are made to assess the environmental impact using standardised methods (e.g. Eco-indicator). However, such newly created measures continue to emerge (e.g. environmental impact score in Inghels et al. (2016), greenness level in Ghayebloo et al. (2015)), indicating the lack of standards. 
Service level indicators (e.g. total completion time, rejection rate, late delivered items, tardiness) are used in $14 \%$ of publications. Social indicators, such as number of accrued jobs, hours of employment, injury rate, satisfaction levels of stakeholders and customers, and social risks, were used in $22 \%$ of the publications.

\subsubsection{Solution approaches}

It is observed that the use of MADM approaches to balance conflicting criteria in eco-efficient SCs is well represented. Numerous approaches such as AHP, TOPSIS, ANP, PROMETHEE, DEMATEL, VIKOR and their combinations are used. In 78 out of 188 studied articles (41\%) one or more MADM approaches were applied. The most commonly used approach is AHP (32 publications), TOPSIS (23 publications), and ANP (16 publications). Most of the MADM approaches are applied to supplier selection or evaluation problems (44 publications, $56 \%$ of all MADM approaches), and technology or material selection ( 9 publications, 12\%). Within the relevant publications, 129 articles (69\%) use an MODM approach, mostly based on linear and non-linear programming problems. In some studies two or more approaches are presented. It is observed that MODM approaches most commonly focus on deriving a set of Pareto-efficient solutions (or Pareto-efficient frontier). Pareto-efficient solutions are derived to aid a decision maker in selecting most preferable solution that balances environmental and economic objectives. The methods most frequently used are the $\varepsilon$-constraint method (44 papers, 34\% of all MODM approaches) and weighting methods (35 papers, 27\%). Some problems are solved using heuristics (in case the problem is too difficult or takes too much computational effort to solve with standard optimization approaches), such as genetic algorithms (14 papers, 11\%), other evolutionary algorithms, multi-objective gravitational search algorithm, memetic algorithm, multi-objective heuristic based on variable neighbourhood search, or greedy heuristic. Additionally, in 19 publications (10\%) MADM and MODM approaches are combined to arrive at a final solution. In these articles AHP, ANP, and/or TOPSIS are used to obtain weights for multi-objective optimization problems, and a single solution out of the efficient set is selected, e.g. in Validi et al. (2014a) an AHP constraint is introduced to include decision makers' consensus opinions for vehicles used for distribution, and TOPSIS approach is used to evaluate results generated by (three genetic algorithm-based) optimizers to highlight the best candidate to a decision maker.

Among publications assigned to MODM approaches, we included Bouchery et al. (2012) which studies the SOQ model and analyses the efficient frontier analytically. The authors also develop an interactive procedure to find a balance between the considered objectives. Five publications concerned with supply chain network equilibrium problems (Cruz, 2013; Cruz and Matsypura, 2009; Nagurney et al., 2007) are also assigned to MODM approaches. The authors model the behaviours of multiple decision makers in the supply chain and derive the equilibrium conditions and optimality conditions for all actors, with the variables such as product flows, prices, or levels of social responsibility activities.

Publications in which the Data Envelopment Analysis (DEA) method is used are assigned to MODM or MADM approaches depending on its context. Publications of Dobos and 
Vorosmarty (2014), Zeydan et al (2011), and Kuo et al. (2010) are assigned to MADM approaches, and the authors use DEA to select the most appropriate suppliers, to rank them, and to choose a weight system. Two publications in which DEA is used are assigned to MODM approaches: Van Meensel et al. (2011) evaluate the ability of frontier approaches to support decision making and to analyse trade-offs between economic and environmental performance; Quariguasi Frota Neto et al. (2008) propose a methodology based on DEA and multi-objective programming to assess efficiency of logistic networks.

Current categorisation could be further extended by categorising the papers based on the involvement of the decision maker in selecting a solution from the efficient set. Within MCDM approaches a distinction can be made depending on when preferences of a decision maker are specified: 1) no articulation of preference, 2) 'a priori' articulation of preference information (before solution process), 3) 'progressive' articulation of preferences (during solution process), and 4) 'a posteriori' articulation of preferences (after solution) (Hwang et al., 1980).

\subsubsection{Model characteristics}

Within the 188 papers considered, 123 (65\%) assume all data to be deterministic (Table 2.3), and uncertainty is included more often in publications concerned with MADM approaches compared to MODM approaches. Non-deterministic data in MADM approaches are included in 46 articles (59\% of all MADM approaches), whereas in MODM approaches only 27 papers (21\% of all MODM approaches) use uncertainty in parameters. Among non-deterministic models fuzzy set theory is most frequently applied to take uncertainty into account. Fuzzy set theory is used to take uncertainty into account in weights of decision makers, demand, capacities, prices of products, and customer satisfaction levels. Fuzzy set theory was combined with AHP, ANP, TOPSIS and Multi-Objective Optimization models. In publications concerned with MADM approaches, fuzzy set theory is applied in majority of papers to treat uncertainty, and other approaches are used in five papers only. Liou et al. (2016), Chithambaranathan et al. (2015), Hashemi et al. (2015), and Wang et al. (2014) apply grey system theory based approach to integrate uncertainty in decision making process. In Cobuloglu and Buyuktahtakin (2015) stochastic AHP is proposed to treat uncertain information obtained from decision makers.

In 14 publications associated with MODM approaches uncertainty in parameters is treated with an approach different from fuzzy set theory. Eker and van Daalen (2015) consider multiple sources of uncertainty associated with biomethane production (e.g. resource availability, demand, capacity) and formulate a multi-objective robust optimization model. Brandenburg (2015) studies supply chain design problem under uncertain demands, and solves the proposed two-stage stochastic programming model with discrete number of scenarios to support production and transportation decisions. Gonela et al. (2015) consider uncertain parameters related to bioethanol price, demand, and biomass yield. A two-stage stochastic programming model is proposed to support design and production decisions in bioethanol supply chain. Govindan et al. (2015a) consider uncertain demand of retailers, and develop a scenario-based two-stage stochastic programming network design model including transportation and manufacturing decisions. Fahimnia and Jabbarzadeh (2016) apply a two-stage stochastic fuzzy 
goal programming approach to design a resiliently sustainable supply chain by considering a set of disaster scenarios. Kravanja (2010) includes uncertain parameters related to processing, and the non-linear problem including uncertainty is solved with the developed synthesizer to derive Pareto-efficient solutions. Radulescu et al. (2009) formulate a multi-objective stochastic programming model with random vectors (with multivariate normal distribution) in the objective function and solve the presented model with a genetic algorithm. Radulescu et al. (2008) solve a stochastic programming model (with random selling price coefficients) with optimization software maximizing one objective at a time. Wu and Chang (2004) use the grey system theory to account for uncertainty, and solve their problem with grey compromise programming approach. Guillen-Gosalbez and Grossmann (2009), and Guillen-Gosalbez and Grossmann (2010) include uncertainty related to environmental damage and use a chance constraint indicating that environmental impact must be within a given bound at a given probability. Three papers include uncertainty in demand in inventory models. Marti et al. (2015), and Schaefer and Konur (2015) consider uncertain demand while using a continuous review inventory policy. Sazvar et al. (2014) also consider uncertain demand and propose a two-stage stochastic programming model. Limited number of papers shows an opportunity for future research to consider uncertainty in parameters in MCDM approaches.

It can be observed that in eight out of ten papers concerned with food products, all data are assumed to be deterministic. Ziolkowska (2014) uses fuzzy set theory to evaluate linguistic variables assigned by decision makers to assess the relation between each production alternative and each attribute. Also in Azadnia et al. (2014) experts' (linguistic) evaluations are quantified based on fuzzy set theory. None of the sources of uncertainty listed in the conceptual framework related to food production (e.g. production yields or demand) are included in papers that model FSCs.

The time aspect is taken into account in 51 publications. Perishability and degrading product quality, however, is taken into account in only five publications associated with food products. Soysal et al. (2014) and Govindan et al. (2014a) take perishability into account by allowing a maximum number of consecutive time periods that a food product can be stored. You et al. (2012) take into account a given degradation rate during storage, i.e. it is assumed that during each time period a given fraction of stored products deteriorates and cannot be used. Miret et al. (2016) take into account biomass deterioration during the storage by considering a given (fixed) deterioration rate for each product. To consider perishability Bortolini et al. (2016) propose a quality function, which describes shelf life, to evaluate the quality decrease over the time and the related market purchase probability. 


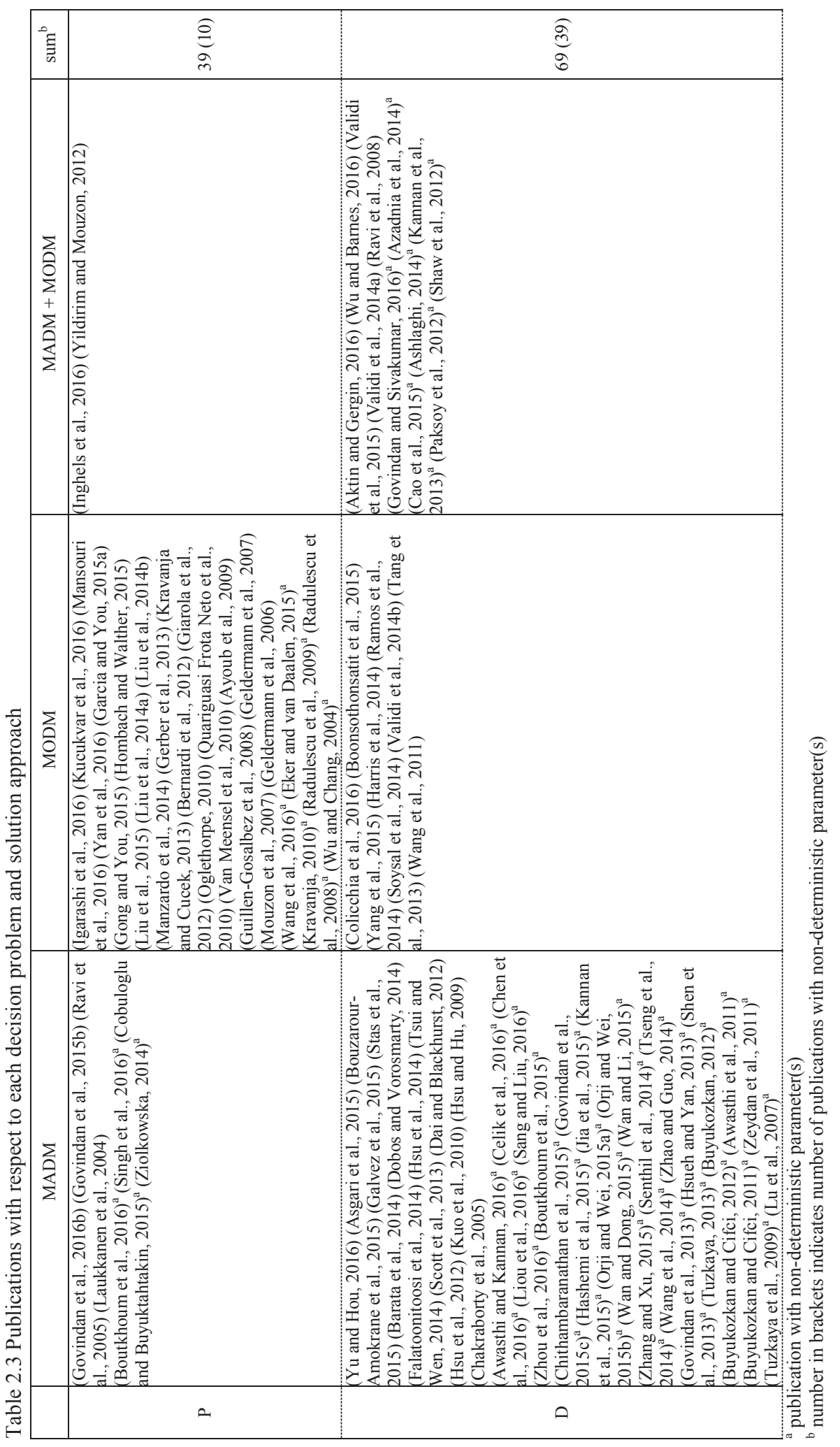




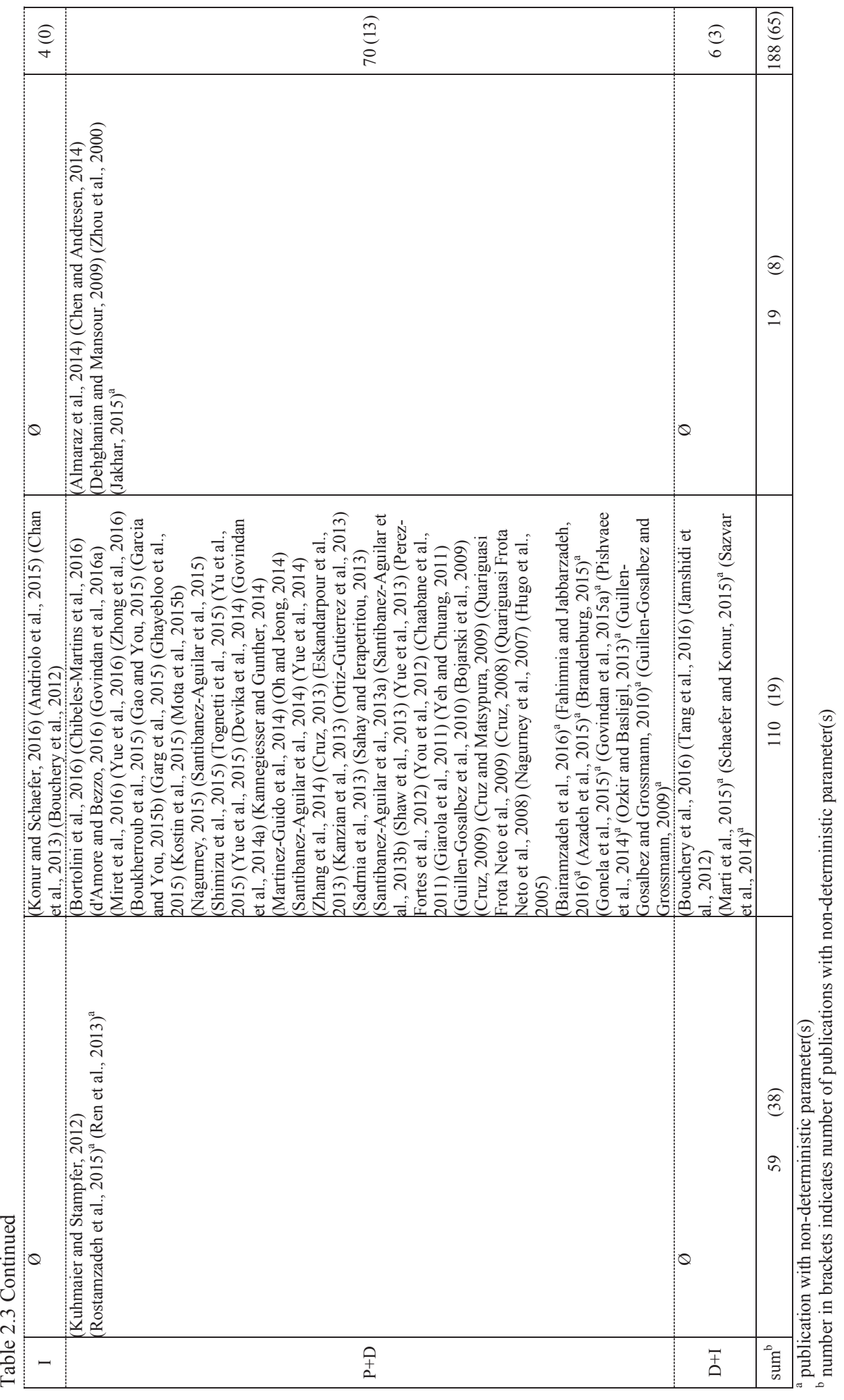




\subsection{Discussion and conclusions}

As observed by Dekker et al. (2012), environmental performance can often be improved substantially at a marginal expense of economic performance, and MCDM approaches can be very useful within this context. To the best of our knowledge, no reviews have specifically focused on MCDM approaches in GSCs and related production, distribution, and inventory problems. The aim of this chapter was to review studies and to identify research opportunities in this field. While MCDM approaches are important to identify solutions balancing environmental and economic concerns, there are other approaches that can be used to take environmental issues into account, e.g. financial evaluation of environmental criteria, for instance carbon tax as presented in Chaabane et al. (2008), or using economic objective and environmental constraints (or vice versa). In this manuscript, however, we focused on papers that as a starting point apply MCDM approaches to balance (conflicting) criteria of economic and environmental performance.

We found that MCDM approaches to support production, distribution and inventory decisions in GSCs gain an increasing interest in recent years. However, using MCDM approaches to design green supply chains is currently absent in many Operations Management and Supply Chain Management journals, which shows a gap in literature. Most of the studied publications focus on production and distribution problems. There are not many MCDM studies focusing on inventory management. The reason may be that inventory management decisions do not heavily influence the environmental impact. Storage of food products, however, often requires temperature controlled conditions that are associated with energy consumption. Nonetheless, we did not find any publications on inventory management for food products, which shows a gap in literature. In fact, multi-criteria approaches in green FSCs are especially scarce, despite the perishability of the products that often results in trade-offs between quality decay and costs. It is also surprising that no attention has been given to the closed loop principles in publications concerned with perishable products, as we are aware of technologies that can process agri-food waste into raw materials used in the same supply chain, as presented in e.g. Zisopoulos et al. (2015).

It is observed that numerous indicators are used to account for environmental performance in supply chains, indicating a lack of standards. We observe attempts to assess the environmental impact of a SC by using standardised methods such as Eco-Indicator, Impact2002, or environmental index. It appears, however, that there is no agreement on a unified indicator to be used to account for environmental damage, as newly created measures aggregating some indicators continue to emerge. Notably, none of the publications concerned with food products take food waste as an indicator. This is surprising knowing that food waste is a major concern in FSCs (Shukla and Jharkharia, 2013), and one-third of all food produced for human consumption is lost or wasted (FAO, 2013).

To assess the limited number of alternatives, multi-attribute decision making (MADM) approaches are used, mainly TOPSIS, AHP and ANP. These approaches are commonly applied 
to assess potential suppliers, to select most appropriate production technology, or to evaluate contractors for reverse logistics activities. Multi-objective decision making (MODM) approaches are used to find an optimal solution for a large or infinite set of alternatives. These approaches are used to support decision making in problems associated with network design, transportation planning, scheduling, and with allocation problems. Most publications concerned with MODM approaches focus on deriving Pareto-efficient solutions, which are especially informative, because they illustrate a quantified trade-off between conflicting economic and environmental performance. Pareto-efficient solutions are derived to aid a decision maker in selecting most preferable solution. Weighted sum method and $\varepsilon$-constraint method are most commonly used to derive these efficient solutions, while other methods often require involvement of the decision maker, who may not always be available or capable to participate in a weight elicitation process. In some publications Pareto-efficient solutions are derived, and an MADM approach is used to select a single solution out of the efficient set.

Notably, in the majority of papers on eco-efficient supply chains all data are assumed to be deterministic, and uncertainty is hardly taken into account. Fuzzy set theory is most commonly applied to take uncertainty into account, and the use of other approaches to treat uncertainty in a multi-criteria context is limited. We therefore conclude that there is a need for more emphasis to include uncertainty inherently associated with supply chains (in demand, prices, processing parameters, quality change in products, as pointed out in the developed framework). This can lead to the need for exploring other solution approaches that are capable of including uncertainty in various data parameters in all decision problems.

We conclude that more attempts to balance economic and environmental criteria in real-life SC decision problems are needed. In line with Brandenburg et al. (2014), we identify a need for more stochastic approaches in modelling to represent the uncertain decision environment of $\mathrm{SCs}$, to take intrinsic characteristics of products into account. It will be interesting to observe which impact stochasticity in parameters has on decision making and on eco-efficient frontiers in supply chains. 

Chapter 3

\title{
Assessing alternative production options for eco-efficient food supply chains using multi-objective optimization
}

This chapter is based on the published journal article:

\begin{abstract}
A. Banasik, A. Kanellopoulos, G.D.H. Claassen, J. M. Bloemhof-Ruwaard, J.G.A.J. van der Vorst (2016) Assessing alternative production options for eco-efficient food supply chains using multi-objective optimization Annals of Operations Research
\end{abstract} DOI: http://dx.doi.org/10.1007/s10479-016-2199-z 


\begin{abstract}
Due to tremendous losses of resources in modern food supply chains, higher priority should be given to reducing food waste and environmental impacts of food production. In practice, multiple production options are available, but must be quantitatively assessed with respect to economic and environmental performances before they are adopted in food supply chains. The objective of this chapter is to develop a mathematical model that can be used for such a quantitative assessment of alternative production options that are associated with different ways to deal with waste in food supply chains, i.e. prevention, recycling, and disposal of food waste. We develop a multi-objective Mixed Integer Linear Programming model to derive the set of eco-efficient solutions corresponding to production planning decisions. Environmental performance of the chain is expressed with an indicator based on exergy analysis, which has the potential to capture other commonly used indicators, such as energy consumption, fuel consumption, and waste generation, and express them in a single value. This simplifies the calculation of the eco-efficient frontier, and enables its intuitive graphical representation, which is much easier to communicate to the involved decision makers. The applicability of the developed model is demonstrated on a real-life industrial bread supply chain in the Netherlands. Results confirm the findings from literature that prevention is the best waste management strategy from environmental perspective. The advantages of using exergy as an indicator to capture the environmental performance is demonstrated by comparing the outcomes to other commonly used indicators of environmental performance. We illustrate the potential of studying food production planning decision problems in a multi-objective context, and demonstrate the applicability of the model in the assessment of alternative production options.
\end{abstract}




\subsection{Introduction}

Until recently, food production focused mainly on delivering high quality products at low costs with only secondary attention on environmental impacts, food losses, and depletion of natural resources. However, increasing awareness of environmental issues, increasing scarcity of resources, social pressure and new regulations force companies to reconsider their operations (Chaabane et al., 2012). A major concern in Food Supply Chains (FSCs) is related to food waste (Shukla and Jharkharia, 2013). According to FAO (2013) about 1.6 billion tons corresponding to one-third of all food produced for human consumption is lost or wasted. Processing and distribution of food are responsible for approximately 0.4 billion ton of food wastage. To remain competitive, FSCs are challenged to adopt new technologies that reduce or valorise food waste. These technologies can contribute to maintaining or increasing economic output and reducing environmental impact of current operations i.e. achieving what has been defined as eco-efficiency (Braungart et al., 2007). Quantitative assessment of both the economic and environmental benefits of these alternative technologies and production options increase the adoption rate and facilitates managerial decision making. Production planning models that optimize decisions on how, how much, what and when to produce to meet the demand can be used to combine available production options and assess quantitatively the economic and environmental consequences of new technologies.

Most of the production planning literature, i.e. lot sizing, is focussed on discrete (assembly) manufacturing and traditional models have been increasingly refined to incorporate more detail of specific production environments (Clark et al., 2011; Jans and Degraeve, 2008; Quadt and Kuhn, 2008). Nevertheless, almost all traditional models take the classical principle of optimality for lot-sizing as the ultimate objective, i.e. find the best compromise between total production costs on the one hand and total inventory-holding costs on the other hand (Claassen and Hendrix, 2014). In their special issue on lot-sizing, Clark et al. (2011) stated that changes in the philosophy of production planning and control triggered the debate about whether or not lotsizing as a trade-off between setups and stocks should be the ultimate objective in production planning. The authors noticed a lack of research on i) more realistic and practical variants of lot-sizing models and ii) the effect of using real life instances to carry out computational experiments. To explore eco-efficient logistical structures with production planning models it is important to be able to quantify the potential economic output for different levels of environmental impact (and vice versa). Consequently, multi-objective optimization is required.

Only a few studies apply multi-objective optimization in FSCs to account for economic and environmental indicators (Govindan et al., 2014a; Soysal et al., 2014; Validi et al., 2014a; Akkerman et al., 2009), but focus mainly on optimizing strategic distribution and location/allocation problems, and not production planning decisions. In these aforementioned studies $\mathrm{CO}_{2}$ emissions are used as an indicator for environmental performance. In multiobjective optimization models for supply chain management environmental performance of a $\mathrm{SC}$ is expressed by various indicators, such as greenhouse gases (GHG) emitted (Aramyan et al., 2011; Chaabane et al., 2011; Harris et al., 2011), energy consumed (Zanoni and Zavanella, 
2012; Quariguasi Frota Neto et al., 2009; van der Vorst et al., 2009), solid waste produced (Paksoy et al., 2010; Quariguasi Frota Neto et al., 2009), or water consumed (Oglethorpe, 2010; You et al., 2012). An important drawback of these indicators is the lack of a uniform metric for the comparison of different substances (e.g. different emissions, waste produced, energy and water consumed) including their impacts (Wall, 2010; Coatanéa et al., 2006). Moreover, often a single indicator is chosen in optimization models to express the environmental performance for computational purposes and for easiness of communicating results with the involved decision makers. To overcome these shortcomings aggregated environmental indicators have been proposed, such as Cumulative Energy Demand (CED) (Quariguasi Frota Neto et al., 2009) and total GHG emissions represented in tons of $\mathrm{CO}_{2}$ equivalent. However, these metrics have been criticized because they concentrate only on a single aspect of environmental performance (e.g. $\mathrm{CED}$ on energy use, $\mathrm{tCO}_{2} \mathrm{e}$ on greenhouse gas emissions). An alternative approach to quantify environmental impact in a single unit is based on the concept of exergy. Exergy analysis is an objective assessment method that has been applied in many fields, e.g. chemical sector, environmental engineering; and recently also in food industry (Zisopoulos et al., 2015). Despite its advantages, exergy analysis has not been used in combination with economic performance in optimization models to support decision making in FSCs.

This study adds to literature on supply chain management by 1) presenting a realistic variant of a lot sizing model used to assess alternative production options, and 2) providing a model to support production planning decisions in an FSC while taking into account economic and environmental criteria. The objective of this chapter is to develop a mathematical model that can be used to optimize production decisions in FSCs by quantifying trade-offs between (most of the time) conflicting economic and environmental indicators, and by exploring alternative production options (at food production chain level) with specific attention to food waste. This is achieved by developing a multi-objective multi-item capacitated lot-sizing optimization model. The applicability of the model to a real-life problem is shown on a bread supply chain in the Netherlands, where the total amount of food waste throughout the complete chain constitutes approximately 30\% of total bread production (Zisopoulos et al., 2015; Blonk, 2006) accounting for 330 thousand tons of bread waste annually. On the bread supply chain the differences in optimal solutions and trade-off curves are illustrated when environmental performance is expressed with different measures, which are: exergy loss, $\mathrm{CO}_{2}$ equivalent, and waste generated. Our analysis focuses on the eco-efficient solutions, i.e. solutions for which it is impossible to improve one objective, without worsening the other. Eco-efficient solutions provide insights in the costs for a unit improvement in environmental impact and vice versa.

This chapter is structured as follows. The next section discusses the conceptual model, in which we describe three options to produce a food product, introduce the concept of exergy analysis, which is used for quantification of environmental impact, and present the multi-objective mixed integer linear programming (MILP) model used to support production planning decisions in an FSC. Section 3 describes the bread supply chain in the Netherlands including three alternative bread production options, discusses the data, and gives the results of the mathematical model. 
Section 4 presents sensitivity analysis on important parameters of the mathematical model for industrial bread production. The last section presents conclusions.

\subsection{Problem description}

A typical FSC comprises the following links: suppliers of raw materials, processing facility, and retail outlet. Our analysis starts with procurement of raw materials (production of raw materials is not taken into account) and ends with meeting customer's demand. We look at a perishable food product that becomes waste if it is not sold on the day of production.

\subsubsection{Alternative production options}

Alternative production options are available in practice to produce a food product. Each production option, due to its unique production structure and processing steps, is inherently associated with (at least) one waste management option. According to Papargyropoulou et al. (2014) the most favourable option to deal with waste is prevention followed by re-use, recycle, recovery, and disposal. Three food waste management options are considered here: disposal, prevention, and recycling of food waste (Figure 3.1). Disposal of waste refers to a situation when the product is not sold before its due date, and is not recycled in the studied FSC. Prevention of waste, as considered in this chapter, is possible via potential storage of products in controlled conditions, therefore extending product's shelf life. Recycling of waste allows valorising not sold products by using processed waste as a raw material for production, therefore reducing the need for other raw materials.

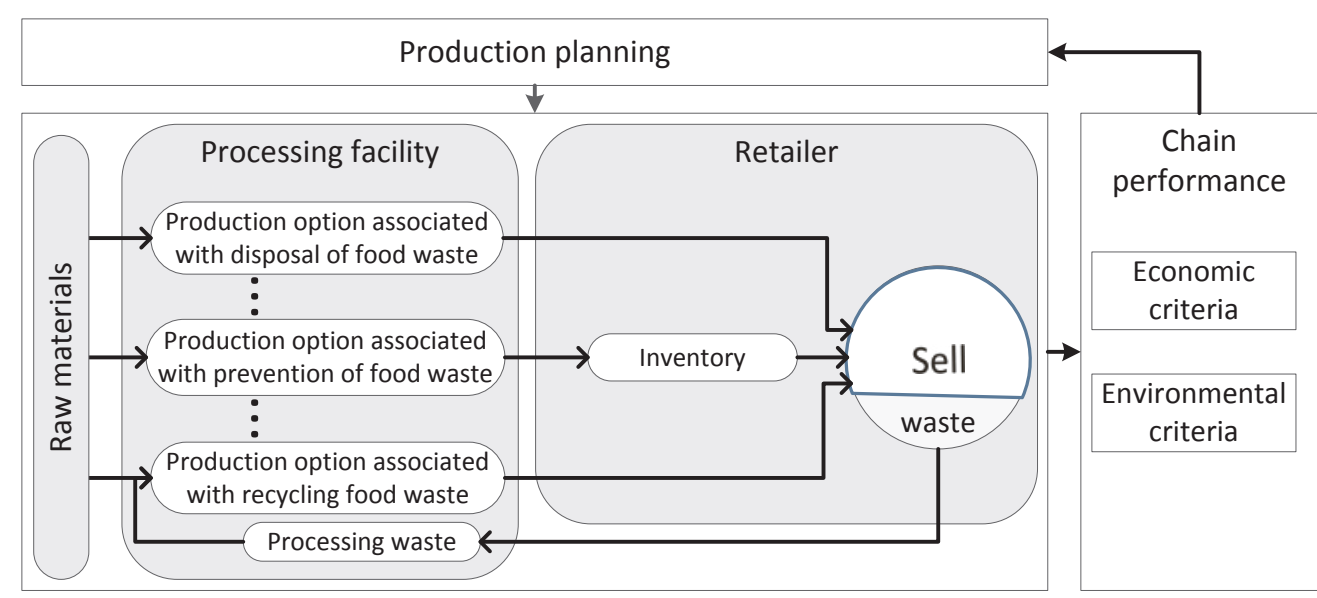

Figure 3.1 Conceptual model for assessing alternative production options with multi-objective production planning

Because the decision on production quantities must be made before the actual demand is exactly known, we assume that each production option is associated with a pre-defined amount of waste stream calculated as a fraction of total production with a given option. To compare the 
alternative production options, production planning models are needed that take both economic and environmental criteria into account.

Optimizing production planning decisions gives insights in the most preferable production option, which in turn will have an impact on the design of an FSC. Moreover, optimizing production planning decisions is important for improving eco-efficiency, because each production option has an effect on both the total amount of waste produced, and on other environmental indicators, such as water consumed, or emitted GHG. Producing a food product that has the potential to prevent waste may require additional processing steps or temperature controlled storage leading to additional energy consumption at different links of a chain. A food product that can be recycled may require an additional waste processing step and additional fuel consumption due to transportation. Therefore two aspects play an important role. First, the whole chain should be taken into account to avoid sub optimization, i.e. improving the performance of a single link of a supply chain, at the greater expense of the performance in other links. Secondly, multiple environmental indicators (next to an economic indicator) must be considered when assessing the impact of each production option. However, in cases of more than two objectives in multi-objective optimization models there is no guarantee of efficiency for the obtained solution and computation times may increase substantially with the number of conflicting objectives (Mavrotas, 2009). To simplify the problem we use an integrated indicator based on exergy analysis that has the potential to capture other commonly used environmental indicators and express them in a single value.

\subsubsection{Environmental assessment: Exergy analysis}

Exergy analysis is based on the basic concepts in thermodynamics and it is a suitable scientific concept to study the environmental impact because, unlike other single metric indicators, it measures all inputs and outputs in a single unit (MJ), making the results visible and conclusions easy to draw (Wall, 2010; Apaiah et al., 2006; Apaiah et al., 2005). Exergy analysis has been widely used as an assessment of environmental impact in various fields, including the chemical industry (Cortez et al., 1997; Morris, 1991) and, more recently, the food industry (Draganovic et al., 2013; Apaiah et al., 2006). Exergy measures the ability of a source to produce useful work (measured in MJ) that gives a numerical value not only to the quantity but also to the quality of the energy use (Apaiah et al., 2006; Apaiah et al., 2005). In contrast to energy, exergy is exempt from the law of conservation, and in all real life processes exergy input always exceeds exergy output (Apaiah et al., 2006), which means that some exergy is irreversibly lost in each processing step. An exergy balance applied to a process explains how much exergy supplied as an input to the considered system has been irretrievably lost by the process (Kotas, 1995). It enables the determination of the location, types and magnitudes of wastes (streams that still contain exergy) and losses (exergy irreversibly lost). Exergy analysis has also the potential to characterize each product by an exergetic value based on product's chemical composition. If a product is not (re)used and becomes waste, then the exergetic value of the product is considered as a loss. As a result the production process, transportation and waste can be quantified based on exergy losses, and exergy can be regarded as an umbrella indicator for the 
assessment of environmental impact. The concept of exergy is used in this chapter to assess environmental impact of alternative production options (defined by practitioners) that are associated with at least one waste management option considered i.e. disposal, prevention and recycling of food waste.

\subsubsection{Mathematical model}

The mathematical model for production planning in an FSC is formulated as a multi-objective mixed integer linear programming model with economic and environmental objectives. We formulated a multi-item capacitated lot-sizing model in line with Pochet and Wolsey (2006) and tuned it for comparing alternative production options that determine different ways of dealing with waste (dispose, prevent, or recycle waste). The economic objective is expressed in monetary units and represented by profit. The environmental impact is expressed in megajoules and represents exergy losses. The presented model supports decisions on start-ups of production and production amounts in each time period for each considered product type and production option.

Index sets

I Set of all product types

$B$ Set of all production options

$P \subset B \quad$ Set of production options (associated with prevention of food waste) allowing for storage of products

$R \subset B \quad$ Set of production options (associated with recycling food waste) that include (processed) waste as a raw material in production

$R^{\prime} \subset B$ Set of production options resulting in products, which waste can be recycled in production option(s) $r \in R$

$T$ Set of time periods

Decision variables

$X_{i, b, t} \quad$ amount of product $i \in I$ produced with production option $b \in B$ in time $t \in T$

$H_{i, b, t}$ inventory level of product $i \in I$ produced according to production option $b \in P$ at the end of time period $t \in T$

$Y_{i, b, t} \quad$ binary variable indicating if product $i \in I$ is made with production option $b \in B$ in time period $t \in T$

$S_{i, b, t}$ amount of product $i \in I$ produced with option $b \in B$ on shelf in retail outlet in period $t \in T[\mathrm{~kg}]$

$W_{i, b, t} \quad$ amount of waste from product $i \in I$ produced with option $b \in R^{\prime}$ recycled and used in period $t \in T[\mathrm{~kg}]$ 
Parameters

$d_{i, t} \quad$ demand for product $i \in I$ in period $t \in T[\mathrm{~kg}]$

$v_{i} \quad$ volume of product $i \in I\left[\mathrm{~m}^{3} / \mathrm{kg}\right]$

$b_{i} \quad$ processing time of product $i \in I[\mathrm{~h} / \mathrm{kg}]$

$c a p_{-} b \quad$ daily processing capacity in the processing facility [h]

$c a p \_h$ holding capacity in the retail outlet $\left[\mathrm{m}^{3}\right]$

$m_{i, b} \quad$ large constant

$z_{i, b} \quad$ fraction of product $i \in I$ produced with option $b \in B$ wasted at the retail outlet [\%]

$p b_{i, b} \quad$ selling price of product $i \in I$ produced with option $b \in B[€ / \mathrm{kg}]$

$c p_{i, b} \quad$ costs associated with producing one $\mathrm{kg}$ of product $i \in I$ produced with option $b \in B$ delivered to the retail outlet $[€ / \mathrm{kg}]$

ch holding costs per kilogram per day [€/kg]

$c y_{i, b} \quad$ production setup costs for product $i \in I$ produced with option $b \in B[€]$

$e p_{i, b} \quad$ total exergy losses for producing one $\mathrm{kg}$ of product $i \in I$ produced with option $b \in B$ delivered to the retail outlet $[\mathrm{MJ} / \mathrm{kg}]$

eh exergy losses associated with holding one $\mathrm{kg}$ of product in inventory per day $[\mathrm{MJ} / \mathrm{kg}]$

$e w_{i, b} \quad$ chemical exergy in one $\mathrm{kg}$ of product $i \in I$ produced with option $b \in B[\mathrm{MJ} / \mathrm{kg}]$

$r_{i, b}$ fraction of product waste $i \in I$ (based on recipe) needed as an ingredient to produce one $\mathrm{kg}$ of product with production option $b \in R[\%]$

$\max \left\{\sum_{i \in I, b \in B, t \in T} p b_{i, b}\left(1-z_{i, b}\right) S_{i, b, t}-\sum_{i \in I, b \in B, t \in T} c p_{i, b} X_{i, b, t}-\sum_{i \in I, b \in B, t \in T} c h H_{i, b, t}-\sum_{i \in I, b \in B, t \in T} c y_{i, b} Y_{i, b, t}\right\}$
$\min \left\{\sum_{i \in I, b \in B, t \in T} e p_{i, b} X_{i, b, t}+\sum_{i \in I, b \in B, t \in T} e h H_{i, b, t}+\sum_{i \in I, b \in B, t \in T} e w_{i, b}\left(z_{i, b} S_{i, b, t-1}-W_{i, b, t}\right)\right\}$

Subject to

$\sum_{b \in B}\left(1-z_{i, b}\right) S_{i, b, t}=d_{i, t}$

forall $i \in I, t \in T$

$X_{i, b, t}-S_{i, b, t}=H_{i, b, t}-H_{i, b, t-1}$

forall $i \in I, b \in B, t \in T$

$\sum_{i \in I, b \in B \backslash P, t \in T} H_{i, b, t}=0$

$X_{i, b, t} \leq m_{i, b} Y_{i, b, t}$

forall $i \in I, b \in B, t \in T$

$\sum_{i \in I, b \in B} b_{i} X_{i, b, t} \leq c a p \_b$

forall $t \in T$

$\sum_{i \in I, b \in B} v_{i} H_{i, b, t} \leq c a p_{-} h$

forall $t \in T$

$z_{i, b} S_{i, b, t-1} \geq W_{i, b, t}$

forall $i \in I, b \in R^{\prime}, t \in T$

$\sum_{b \in R} r_{i, b} X_{i, b, t}=\sum_{b \in R^{\prime}} W_{i, b, t}$

forall $i \in I, t \in T$

$\sum_{i \in I, b \in B}\left(H_{i, b, 0}+S_{i, b, 0}\right)=0$

$Y_{i, b, t} \in\{0,1\}$

forall $i \in I, b \in B, t \in T$ 
Objective function (1) specifies the economic objective function, and refers to maximization of profit over the planning horizon. Profit is defined as revenues minus production, inventory and setup costs. Total revenues are related to product sales at the retail outlet while total production costs are associated with costs related to sourcing of raw materials, energy, transportation, and labour. Inventory costs are related to energy consumption of inventory due to storage (in temperature controlled conditions), while setup costs (such as cleaning and warm-up of machines) are related to production. Objective function (2) refers to the environmental objective and aims to minimize total exergy losses related to production, holding and waste. Production losses include exergy losses related to fuel consumption in transportation of raw materials to the processing facility, transportation of products to the retail outlet, as well as exergy losses related to energy consumption in all processing steps in the processing facility. Holding losses relate to energy consumption due to temperature controlled conditions in the inventory in the retail outlet. Waste losses are calculated by multiplying total amount of wasted product with the exergetic value of one $\mathrm{kg}$ of product.

We assume that the demand is given per product type and independent of the production option. Constraints (3) ensure that demand for each product type is met while taking into account the amount of waste in the retail outlet. Constraints (4) ensure that any surplus of products is stored in an inventory. Constraint (5) implies that only products associated with preventing waste option can be held in inventory. Constraints (6) ensure that the set up binary variable gets value 1 if production of a particular product type takes place. Constraints (7) and (8) correspond to respectively production capacity in the processing facility and holding capacity. Constraints (9) ensure that the amount of recycled waste does not exceed available waste. Constraints (10) correspond to the amount of recycled waste needed to produce product made with recycled material. Constraint (11) sets the starting inventory and amount of product on the shelf at time period $\mathrm{t}=0$.

\subsection{Case study}

In this section we apply the general model to a specific case study of a bread supply chain in the Netherlands. We consider a bread supply chain with fixed raw material providers, a single industrial bakery, and supermarkets. We consider two bread types: white tin bread, and brown bun. These two bread types are considered to be the two extreme recipes, representative for the complete variety of bread products. Each bread type can be produced with one of the three available production options resulting in freshly baked bread (waste disposal), par-baked bread (waste prevention), or fermented breadcrumb bread (waste recycling). A time period of a week (Monday to Sunday) is considered to be representative, and we optimize a production plan for that time period taking into account fluctuations in demand throughout different weekdays.

The main raw materials needed for bread production are wheat flour, whole meal, water, yeast, salt, and bread improver. At the bakery the raw materials are combined in a mixing machine to produce dough. After the mixing phase, the dough is put on a conveyor for further processing steps. Dough is fermented for one hour, and subsequently divided and shaped in a desired form by a machine. Next, it is left for one more hour for another fermenting step, called proving. 
Finally the baking, cooling/freezing, and packing takes place, after which the products can be transported to the supermarkets.

Bread products are commonly transported from an industrial bakery to supermarkets every morning. A key characteristic of freshly baked bread in the Netherlands is its short shelf life. Most of the bread products must be sold on the production day due to quality characteristics and consumer acceptance. Freshly baked bread products not sold at production day become waste. Because the decision on production quantities is commonly made before the actual (exact) demand is known, supermarkets usually order more bread than the actual demand in order to avoid stock outs. This results in a large waste stream in supermarkets.

In the remainder of this section we describe three alternative bread production options evaluated in this study: i) freshly baked bread, ii) par-baked bread and iii) fermented breadcrumb bread.

Current practice for industrial bread production in the Netherlands is the so-called freshly baked bread (associated with disposal of food waste as presented in Figure 3.1, and corresponding to production option $\mathrm{b}=1$ ), referred to as fresh bread. Fresh bread production in this chapter refers to baking the products at the bakery and transporting the products daily to the supermarkets. In this traditional production option, after the dough preparation phase, breads are fully baked at the industrial bakery. Bread loaves are then automatically packed, loaded in returnable crates, and transported to supermarkets by (non-conditioned) trucks. In the supermarkets, fresh breads are directly put on shelves and must be sold on delivery day, otherwise it will become waste. It is estimated that $11 \%$ of fresh bread is wasted at supermarkets (Zisopoulos et al., 2015; Blonk, 2006). Currently, wasted bread products are typically given away for animal feed production.

Par-baked bread production (associated with prevention of food waste as presented in Figure 3.1 , and corresponding to production option $b=2$ ) is an alternative production option that has the potential to prevent bread waste. The main difference compared to the fresh bread production is that par-baked bread production involves two baking steps: a partial bake at the industrial bakery and a final bake at each supermarket (consequently losing economies of scale). Breads are first partially baked (for the same amount of time as fresh bread, but at lower temperature), and subsequently frozen. Frozen bread loafs are loaded in returnable crates and transported to supermarkets in trucks with a refrigeration unit under temperature controlled conditions. At the supermarket, par-baked bread can be stored up to 9 months in freezing conditions that entail electricity consumption. The final baking step is performed in response to the observed demand, which implies that quantities of wasted bread are substantially less compared to fresh bread production.

Fermented breadcrumb bread production (associated with recycling of food waste as presented in Figure 3.1, and corresponding to production option $b=3$ ) is an alternative that allows to recycle bread waste (Zisopoulos et al., 2015). Commonly, bread products not sold on the same day as being produced are considered as waste. However, the recipe for fermented breadcrumb bread production includes an ingredient that is based on bread leftovers. To produce fermented breadcrumb, the bread not sold at the supermarket should be collected and transported back to the bakery. At the bakery, the leftover bread is mixed with water and enzymes, and 
subsequently fermented and chilled. This so-called fermented breadcrumb is mixed with other raw materials defined by the recipe for fermented breadcrumb bread. Further processing is in line with processing steps for fresh bread production.

Decisions to be taken by management include the frequency of production, batch sizes, and (if par-baked bread is produced) the amount of inventory held. The alternative options can affect the production planning and logistical structure of the current bread supply chain with substantial consequences to economic and environmental performance of the chain as a whole.

All bread types can be produced according to the three described alternatives: produced at an industrial bakery (fresh bread, $b=1$ ), partially baked at the bakery and final baked in the supermarkets (par-baked bread, $b=2$ ), or prepared using processed bread waste, thus reducing the need of other ingredients (fermented breadcrumb bread, $b=3$ ). Fresh bread production is associated with the least processing and transportation per kilogram of bread produced, but entails high amounts of food waste (amount of fresh bread exceeds the demand to prevent stock outs). Production of par-baked bread allows reducing the amount of waste to a minimum (the final baking step is carried out to react to current demand), but requires more energy consumption due to an additional baking step, and electricity consumption in storage. Production of fermented breadcrumb bread is a way to valorise bread waste, but is associated with additional processing steps compared to fresh bread production.

\subsubsection{Data}

Data and assumptions are collected and assessed with industrial partners as well as collaborating scientists from food processing, who assess the environmental impact. Exergy analysis for this case study, the calculation of exergy losses per processing step, and all assumptions related to activities carried out to produce a food product (including fuel consumption for transportation, electricity and natural gas consumption for processing) are presented in Zisopoulos et al. (2015). Selling prices for bread products are the same for each production option, and the demand for breads (Figure 3.2) is aggregated and given per bread type, not per production option. In other words, the same product types produced with different production options are perfect substitutes. We aggregate all supermarkets in a region into one, and thus demand data of the single (aggregated) supermarket refers to demand of a complete region supplied by a single industrial bakery. 


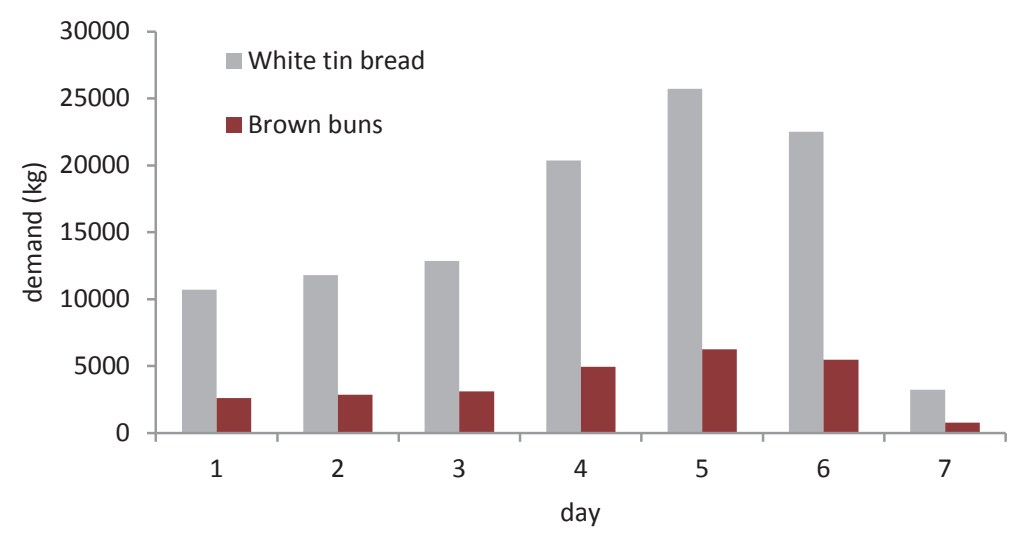

Figure 3.2 Demand for different bread types throughout a week (day 1 refers to Monday, day 2 to Tuesday etc.)

In the bakery, equipment used for processing raw materials (mixing machine and conveyor belt) is supplied by electricity, and a continuous oven is heated by natural gas. Energy usage differs for each production option, because each option determines the temperature needed for baking. An industrial oven can be used efficiently for $90 \%$ of a day ( 21.6 hours per day) and has the capacity to bake $1920 \mathrm{~kg}$ of white tin bread per hour, and $1080 \mathrm{~kg}$ of brown buns per hour.

At the supermarket, the environmental impact is associated with energy consumption related to (final) baking of par-baked breads, electricity consumption in storage room, and wasted bread products, i.e. bread is considered wasted if it cannot be sold the same day as being produced and if it is not recycled and used for (fermented breadcrumb bread) production.

Total exergy losses associated with production and transportation are expressed in a single value per kilogram of product produced for each bread type, and each production option (Table 3.1). This single value includes exergy losses associated with transport of raw materials, mixing, fermenting, dividing, proving, baking, transport of bread, and final baking per kilogram of product produced. Table 3.1 also provides data on other environmental indicators considered, i.e. bread waste, and total emission in production and transportation.

We used average data to fix the amount of bread waste at the supermarket. The amount of bread wasted is calculated as a fraction of total demand (assuming overproduction to avoid stock outs). Each production option entails a different amount of wasted bread, e.g. par-baked bread entails the lowest bread losses, as management of the bakery in the supermarket can react to low stock of bread products, and perform the final baking step. Based on industrial data and discussion with experts we assume that production of fresh bread, par-baked bread, and fermented breadcrumb bread entails $11 \%, 0 \%$, and $11 \%$ waste, respectively. Each type of bread produced with each option is associated with a different chemical exergy value (Table 3.1). This value is considered as exergy loss for each kilogram of bread product wasted. However, if the leftover bread at the supermarket is recycled and used for fermented breadcrumb bread production, then it is not associated with exergy losses. 
Table 3.1 Exergy losses in each production and transportation step $[\mathrm{MJ} / \mathrm{kg}]$, chemical exergy per 1 kilogram of bread $[\mathrm{MJ} / \mathrm{kg}]$, and production and transportation costs $[€ / \mathrm{kg}]$ for fresh, par-baked, and fermented breadcrumb

\begin{tabular}{|c|c|c|c|c|c|c|}
\hline \multirow[b]{2}{*}{$\begin{array}{l}\text { Values of parameters in the } \\
\text { objective functions }\end{array}$} & \multicolumn{3}{|c|}{ White tin } & \multicolumn{3}{|c|}{ Brown bun } \\
\hline & fresh & $\begin{array}{l}\text { par- } \\
\text { baked }\end{array}$ & $\begin{array}{l}\text { ferm. } \\
\text { bread. }\end{array}$ & fresh & $\begin{array}{l}\text { par- } \\
\text { baked }\end{array}$ & $\begin{array}{l}\text { ferm. } \\
\text { bread. }\end{array}$ \\
\hline $\begin{array}{l}\text { Total exergy losses in production } \\
\text { and transportation }[\mathrm{MJ} / \mathrm{kg}]^{*}\end{array}$ & 4.47 & 5.64 & 4.79 & 4.73 & 5.39 & 5.53 \\
\hline $\begin{array}{l}\text { Chemical exergy per } 1 \mathrm{~kg} \text { of } \\
\text { bread }[\mathrm{MJ} / \mathrm{kg}]\end{array}$ & 11.48 & 11.48 & 11.46 & 12.72 & 12.72 & 12.71 \\
\hline Setup costs [€/setup] & 1000 & 1000 & 1000 & 1000 & 1000 & 1000 \\
\hline Production costs $[€ / \mathrm{kg}]^{*}$ & 0.66 & 0.82 & 0.68 & 0.97 & 1.15 & 0.97 \\
\hline Selling price $[€ / \mathrm{kg}]$ & 1.61 & 1.61 & 1.61 & 2.75 & 2.75 & 2.75 \\
\hline $\begin{array}{l}\text { Bread waste at the supermarket } \\
\text { [\% of total production] }\end{array}$ & 11.2 & 0 & 11.2 & 11.2 & 0 & 11.2 \\
\hline $\begin{array}{l}\text { Total emissions in production } \\
\text { and transportation }\left[\mathrm{g} \mathrm{CO}_{2} \mathrm{e} / \mathrm{kg}\right]\end{array}$ & 303 & 414 & 343 & 298 & 404 & 356 \\
\hline
\end{tabular}

*detailed data on exergy losses and production costs per activity are given in Appendix 1 and Appendix 2, respectively.

Total costs associated with production and transportation (including fuel for transport of raw materials, energy costs at the bakery, labour costs in the bakery, fuel for transport of bread, energy costs for final baking at the supermarket, and labour costs in the supermarket associated with final baking step) are also expressed in a single value per kilogram of bread produced with each production option (Table 3.1).

Inventory holding costs, as well as exergy losses due to inventory holding, are associated with electricity consumption only, being $0.0005 €$ per kilogram of each product stored per day, and $0.0187 \mathrm{MJ}$ exergy losses per kilogram of each product stored per day. Setup costs associated with starting up the production (e.g. preparing the production line, heating up the ovens, cleaning the machines etc.) are set at $1000 €$ per bread type, per production option.

\subsubsection{Computational results: optimizing single objectives}

First results of the multi-objective MILP for bread production planning are given in this section. We present the optimal solutions while optimizing single environmental and economic objectives. Optimal solutions indicate the produced quantities of bread including production frequencies. The production planning model for a bread supply chain in the Netherlands was solved using Xpress-IVE version 7.2. The mathematical model comprises 42 binary variables, 192 continuous variables, and 171 constraints. Results are presented in Figure 3.3 that shows the daily amounts of bread produced with each production option for the optimal production plans with respect to economic and environmental performance.

The optimal economic production plan for white tin bread is to produce fresh bread daily (Figure 3.3a). Variable costs of fresh white tin bread are 26\% lower than for par-baked and 3\% lower than for fermented breadcrumb white tin bread. For production of brown buns, the parbaking option is selected and produced in two days in the considered planning horizon 
(Figure 3.3b). The variable costs of fresh brown buns are 19\% lower than for par-baked bread, which is not enough to compensate for the lower total setup costs of producing only twice parbaked brown buns. If the baking capacity constraint was removed from the model formulation, production of par-baked brown buns would have taken place on the first day to cover weekly demand.

When exergy losses are minimized, the optimal production plan includes daily production of par-baked bread for both bread types (Figure 3.3c and 3.3d). Despite higher exergy losses per unit of par-baked bread produced compared to other production options (Table 3.1), no bread losses at the supermarket make par-baking option favourable from an environmental point of view.

The optimal economic production plan has a profit of $126268 €$ and 835579 MJ exergy losses. The optimal environmental production plan has a profit of $112172 €$ and $745415 \mathrm{MJ}$ exergy losses. Therefore, the economic production plan has $12 \%$ more exergy losses than the environmental production plan, whereas the environmental production plan has $11 \%$ less profit than the economic production plan. This finding shows that the two objectives are conflicting for this case study.

Minimizing the total amount of waste would result in producing par-baked bread (no bread losses) for both bread types. Minimization of total emissions expressed in $\mathrm{CO}_{2}$ equivalents results in fresh bread only, which has the lowest amount emissions for both bread types. Therefore, under current assumptions, using exergy losses as an environmental objective yields the same optimal solution with respect to environment as if waste was used as an objective.

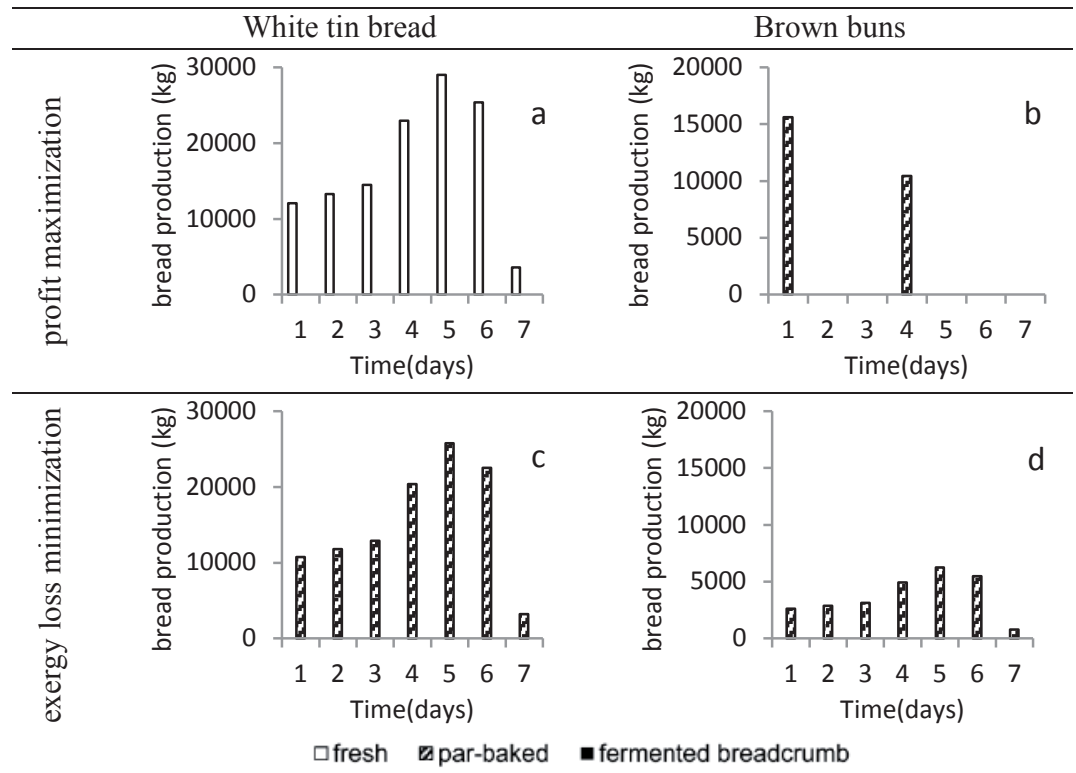

Figure 3.3 Optimal production plans with respect to economic (profit maximization) and environmental (exergy losses minimization) objectives 


\subsubsection{Computational results: multi-objective approach}

A number of approaches are available to solve multi-objective optimization problems, among them $\varepsilon$-constraint and weighted sum method are the most widely used (Miettinen, 2008). However, weighted sum method, in which the weighted sum of objectives is optimized, is not suitable for our problem because this approach does not find all Pareto-efficient points when the solution space is not convex (Chanta et al., 2014; Das and Dennis, 1997). Therefore, we selected the $\varepsilon$-constraint to solve the bi-objective optimization problem and to calculate the set of eco-efficient solutions. For a detailed description of the method we refer to Ehrgott (2005).

The eco-efficient solutions are generated by minimizing the environmental objective and varying parametrically (in 10000 iterations) a lower bound on the profit objective function value in the constraint set. This is performed for three scenarios depending on the environmental objective considered i.e. exergy losses, food waste, and $\mathrm{CO}_{2} \mathrm{e}$.

\subsubsection{Eco-efficient solutions for exergy loss as an environmental objective}

The set of eco-efficient solutions, while taking exergy loss as an environmental objective, is presented in Figure 3.4. The "jumps" in between some line segments on the efficient frontier are caused by discrete changes in selection of production options or changes in production days of bread types, and are often associated with the number of setups. The total number of setups, when minimizing total exergy losses, is 14 (i.e. producing par-baked bread every day for both bread types). By increasing the lower bound of profit the number of setups decreases, while still producing only par-baked bread. After the initial rapid increase in economic objective, the number of setups rises gradually and reaches 9 setups (due to a gradual change in production of par-baked white tin bread to daily production of fresh white tin bread) for the two production plans with the highest economic objective function value.

In all eco-efficient solutions, brown buns are produced only with the par-baking option (note that demand for brown buns corresponds to $19.5 \%$ of total bread demand). Moreover, the production of brown buns is carried out within two days to fulfil the weekly demand (i.e. there are only two setups) in each eco-efficient production plan for profit above $95 \%$ of the maximum profit. Par-baking is also the only production option for white tin bread when minimizing exergy losses. However, production of fresh white tin bread is observed for production plans on the eco-efficient frontier where exergy losses exceed 90\% of exergy losses obtained for best economic production plan (Figure 3.4). The number of days when fresh (white tin) bread is produced increases for eco-efficient production plans with increasing profit. At the same time, number of days when par-baked white tin bread is produced decreases from 7 to 0 . The total production of white-tin bread is complimented with fermented breadcrumb bread in some parts of the frontier. 


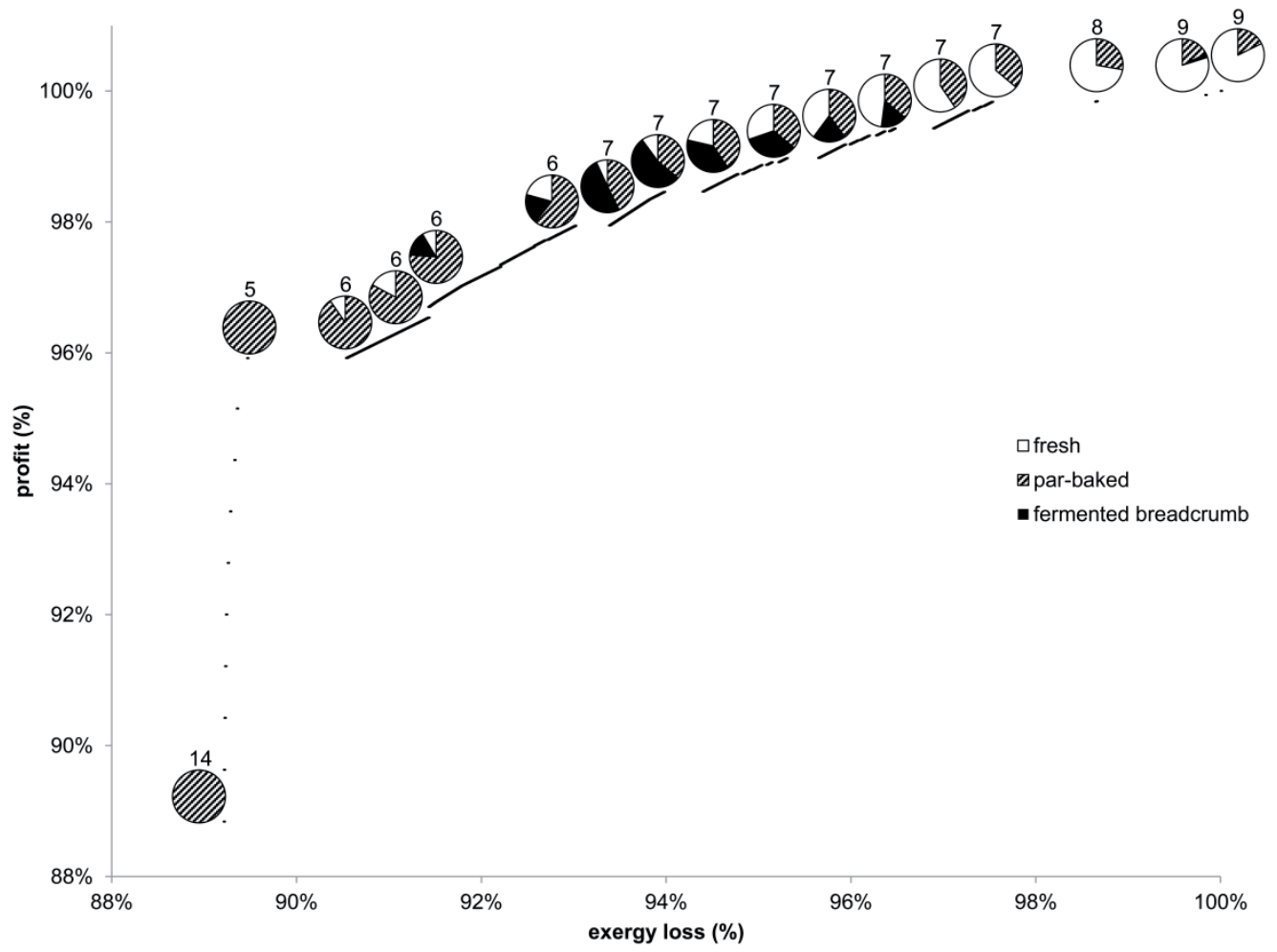

Figure 3.4 Trade-off between profit and exergy loss; pie charts above solutions indicate amount of bread produced with each option as a fraction of total (weekly) production; numbers above pie charts indicate total number of setups for both bread types in the considered production plan.

The curve presented in Figure 3.4 shows a clear trade-off between economic and environmental objectives. This shape of the curve (determined by the non-dominated solutions found) can be used to calculate the price of an improvement in environmental performance. For instance, for a production plan focusing only on profit maximization we can observe that for $0.17 \%$ (210€) of current profit we can improve the environmental performance by $2.45 \%$ (20690 MJ).

\subsubsection{Eco-efficient solutions for other environmental objectives}

The impact of the selected environmental indicator on the eco-efficient frontier is investigated by expressing the environmental performance by other commonly used indicators in SC literature. In Figure 3.5 and Figure 3.6 two sets of eco-efficient solutions are presented, corresponding to two scenarios: where the environmental objective is represented with total amount of total amount of $\mathrm{CO}_{2} \mathrm{e}$, and waste generated, respectively. 


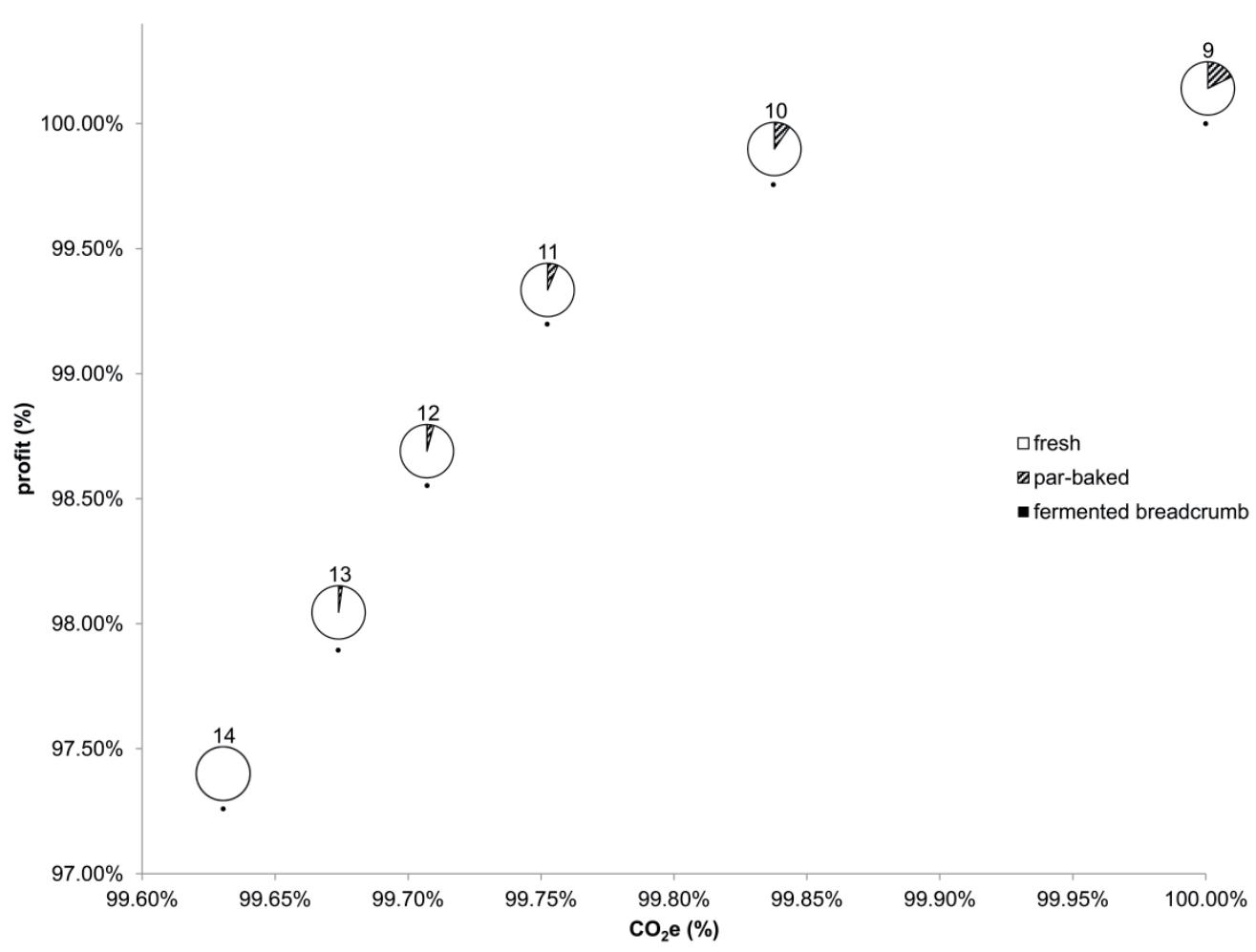

Figure 3.5 Trade-off between profit and $\mathrm{CO}_{2} \mathrm{e}$; pie charts above solutions indicate amount of bread produced with each option as a fraction of total (weekly) production; numbers above pie charts indicate total number of setups for both bread types in the considered production plan.

Using $\mathrm{CO}_{2} \mathrm{e}$ as an environmental objective yields a trade-off curve with only six solutions (Figure 3.5), and the best environmental solution when considering exergy losses (only parbaked bread) is different to the solution when using $\mathrm{CO}_{2} \mathrm{e}$ as an objective (only fresh bread). Analysis of this trade-off curve indicates that the production plan becomes more profitable by gradually changing the production for brown buns (white tin bread is freshly baked in each production option on the eco-efficient frontier) from fresh, to par-baked bread. This shows that apart from the best economic solution, all solutions on the eco-efficient frontier are different compared to considered scenarios where exergy loss is used as an environmental indicator. 


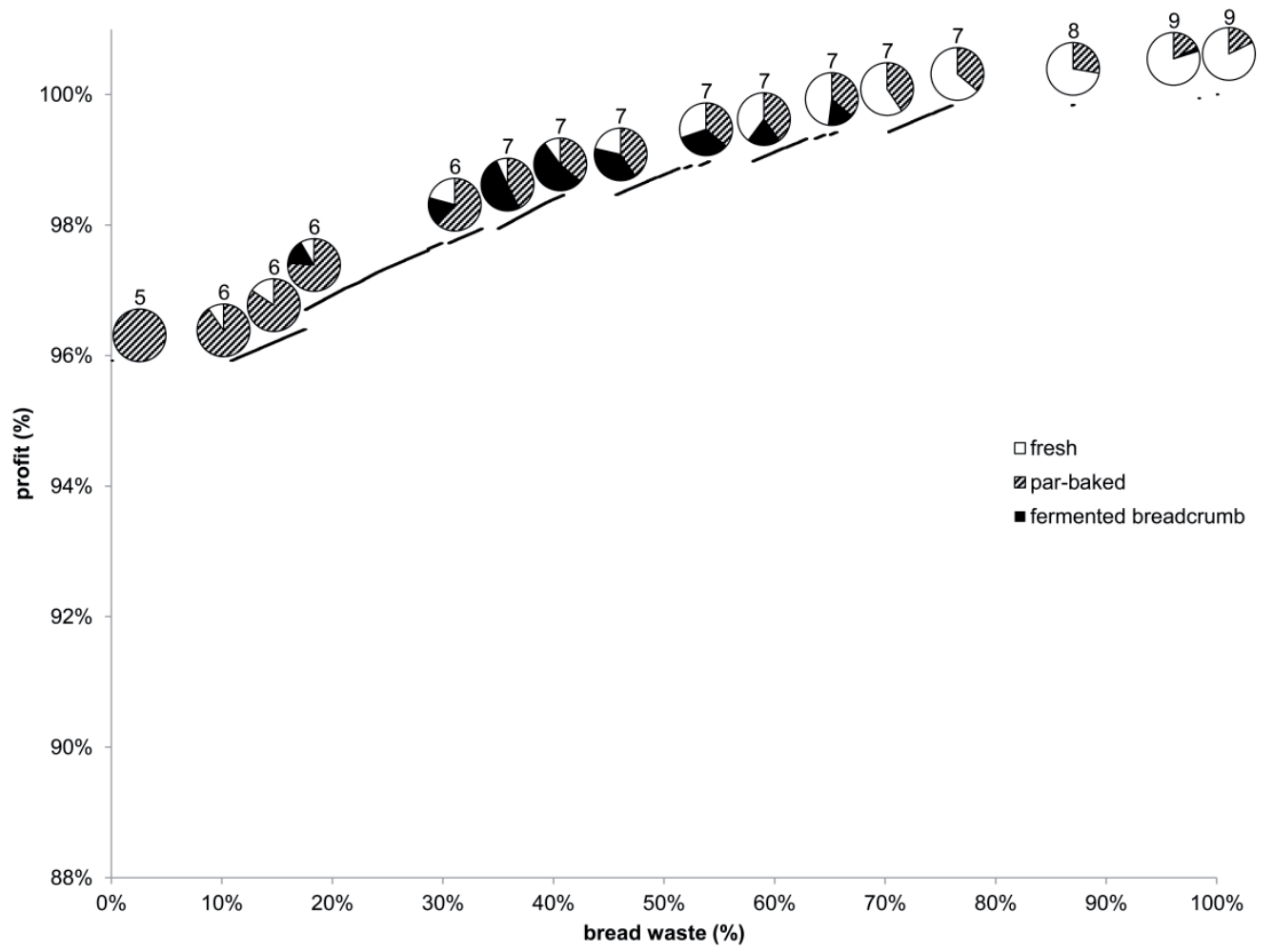

Figure 3.6 Trade-off between profit and bread waste; pie charts above solutions indicate amount of bread produced with each option as a fraction of total (weekly) production; numbers above pie charts indicate total number of setups for both bread types in the considered production plan.

We observe that using total amount of food waste generated as an objective for environmental performance (Figure 3.6) yields nearly the same trade-off curve compared to the scenario when total exergy losses are used. The main difference is the absence of most solutions in which only par-baked bread is produced, i.e. nine solutions observed in the bottom left corner of Figure 3.4. These solutions are not efficient when waste is the environmental objective, because they all correspond to solutions where no waste is produced (production with par-baked bread only). Overall, within the 10000 iterations performed, $88 \%$ of efficient solutions when waste is considered as an environmental objective (Figure 3.6), are also found on the eco-efficient frontier when exergy loss is considered as an environmental objective (Figure 3.4). In the remaining $12 \%$ of efficient solutions, the average difference in total exergy losses is $0.11 \%$ as compared to solutions when exergy loss is considered. This shows that the eco-efficient frontier is nearly the same when waste and exergy loss is used. The reason for having nearly the same eco-efficient frontier is that total exergy losses are most heavily influenced by chemical exergy associated with bread waste. 


\subsection{Sensitivity analysis}

Sensitivity analysis illustrates that the proposed model can be used to investigate the impact of parameter changes on the optimal solution. Results presented in previous section are based on the data obtained via collaboration with experts from industry. To make a reliable analysis, experts were involved before, during, and after the model development phase. While experts could estimate some model parameters relatively easy (e.g. bread prices, energy costs, labour costs, amount of bread waste for fresh bread production based on historical data), some other parameters are rather difficult to measure, e.g. par-baked bread losses at the supermarket and setup costs. For the current data structure, par-baked bread production seems beneficial as it is the only option used to produce brown buns in all production plans in the eco-efficient frontier. Moreover, par-baked bread production is selected in most production plans for white tin bread, given the assumption of no losses at the supermarket. Additionally, (high) setup costs make parbaking beneficial because in this production option inventory is allowed. Therefore, based on discussion with experts, the primary focus of sensitivity analysis was examining the impact of a change in the following parameters: assumed amount of par-baked bread losses, and setup costs.

Additionally, it was examined whether the solutions obtained by maximizing profit and minimizing exergy losses are sensitive to changes in other parameters in the objective functions. We varied each parameter separately by changing its value in an interval between $50 \%$ decrease, and $100 \%$ increase for all production options simultaneously. We found that the optimal economic solution is not sensitive to changes within the examined interval for selling price, and inventory holding costs. Production costs, however, are more sensitive to changes in parameters. Decrease by $10 \%$ in production costs entails more production of par-baked white tin constituting to $22 \%$ of total white tin bread production. Increase in production costs by $46 \%$ makes fresh bread somewhat beneficial for brown buns, and constitutes to $48 \%$ of total brown buns production. With respect to environmental objective expressed with exergy loss, we found that changes in chemical exergy, exergy losses related to production, and exergy losses associated with holding, do not affect the optimal production plan.

\subsubsection{Par-baked bread losses}

To evaluate the consequences of having some losses in the par-baking option, we calculated optimal production plans assuming losses of par-baked bread between $1 \%$ and $10 \%$. Sensitivity on this parameter with respect to economic objective does not affect the production plan for white tin bread (freshly baked only). For brown buns, production of fresh bread appears in the optimal production plan when losses of par-baked bread are 3\% (Figure 3.7) or higher. Parbaking, however, is still favourable and constitutes to more than $50 \%$ of the production for brown buns in each examined scenario (e.g. for 3\% losses, par-baking is $52.8 \%$ of brown bun production). 


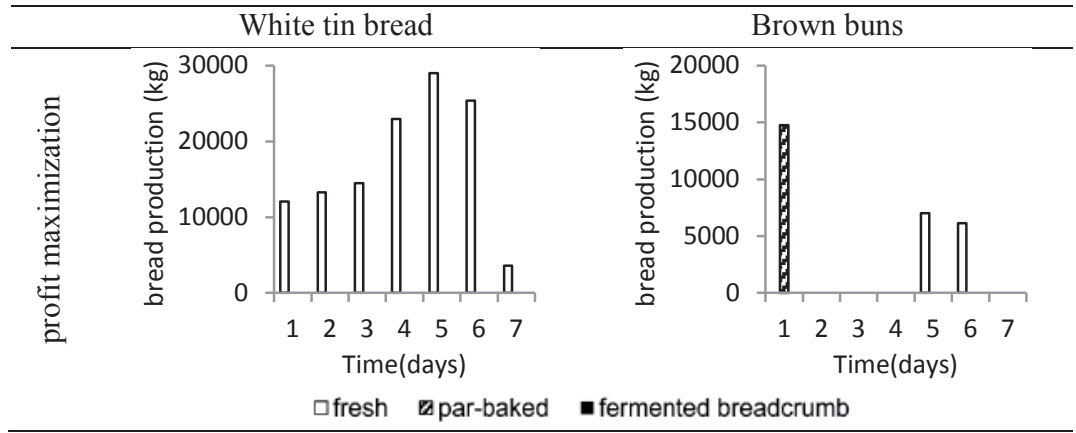

Figure 3.7 $\overline{\text { Optimal economic production plan with 3\% par-baked bread losses at the supermarket }}$

When minimizing exergy losses (Figure 3.8), fermented breadcrumb bread becomes the best option for white tin bread when losses of par-baked bread are $3 \%$ or more, because it offers the opportunity to valorise environmentally costly bread waste, which otherwise would result in exergy lost. Par-baking is preferred for brown buns until par-baked bread losses are lower than $8 \%$. Then, fermented breadcrumb bread becomes beneficial. In scenarios where fermented breadcrumb bread is produced it is observed that in the first time period(s) other production options are used, such that sufficient amount of waste is available, which is required as a raw material for fermented breadcrumb bread production.

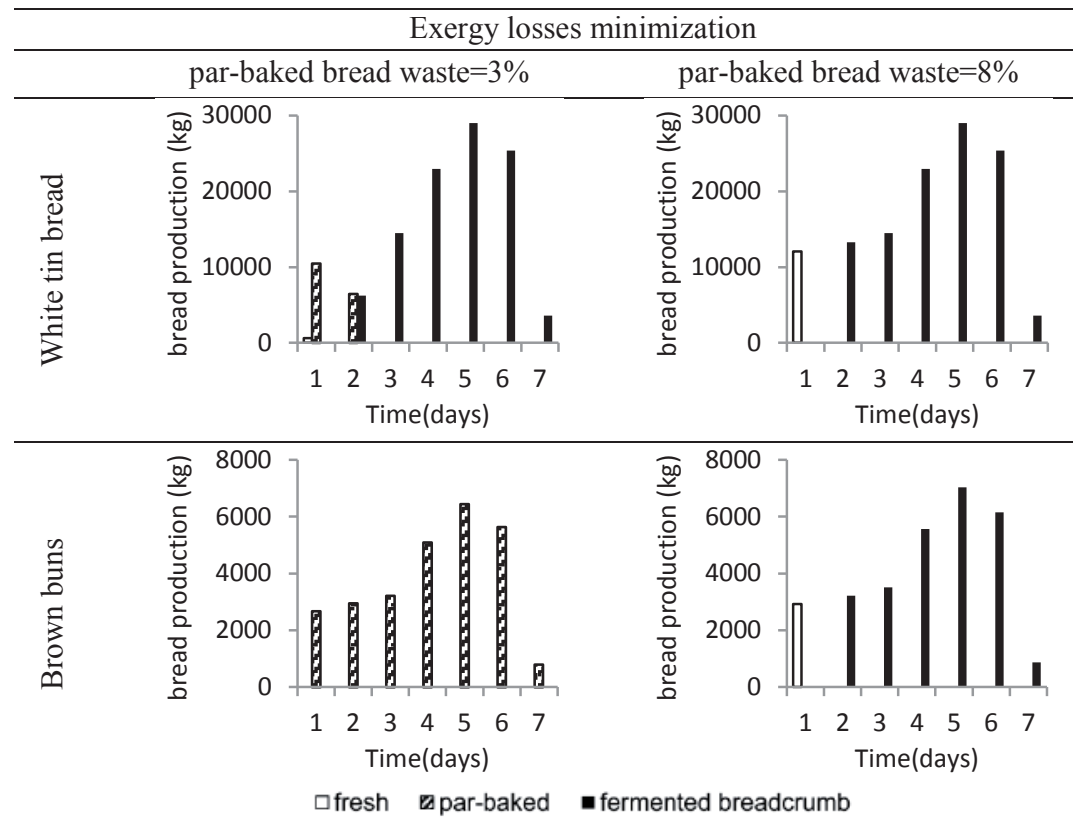

Figure 3.8 Optimal environmental production plans with $3 \%$ and $8 \%$ par-baked bread losses at the supermarket 


\subsubsection{Setup costs}

Sensitivity analysis of setup costs affects only the profit maximization model run. Results are presented in Figure 3.9. When setup costs are neglectable, production of fresh baked breads is most attractive (lowest variable costs, despite producing $11 \%$ waste). When setup costs are $2000 €$, par-baked production takes place for white tin bread to cover the lowest three demands thereby reducing the number of setups. On the second day full baking capacity is devoted to produce par-baked brown buns.

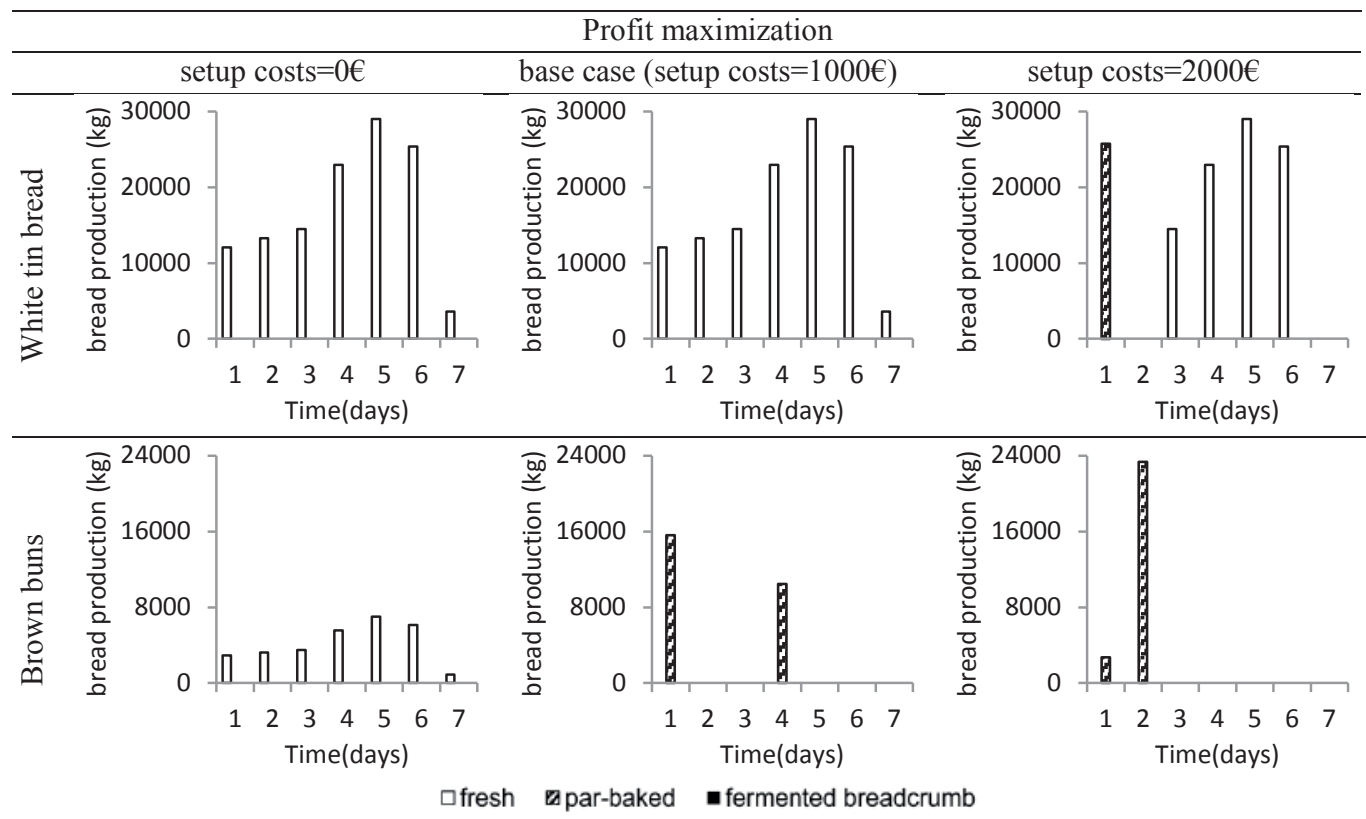

Figure 3.9 Optimal economic production plans with $0 €, 1000 €$, and $2000 €$ daily setup costs per bread type, per production option

\subsection{Discussion and managerial insights}

In spite of the impact of parameter settings, some general conclusions and managerial insights can be drawn. From an economic point of view fresh bread is beneficial for the majority of bread products (white tin bread in our study), especially under low setup costs. The par-baking production option is interesting when setup costs are high. An important managerial insight is that par-baking can bring economic benefits for some bread types (brown buns), if the management is able to react to the observed demand rapidly and minimize the losses. Therefore, par-baked bread production should be implemented as it can give economic and environmental benefits. The analysis also shows that the economic solution is hardly sensitive to changes in the selling prices and inventory holding costs. However, changes in production costs have a clear impact on the quantities of par-baked and fresh bread, i.e. a decrease in production costs entails more production of par-baked bread, and an increase in these costs entails more production of freshly baked bread. 
From the environmental perspective par-baking is beneficial for all bread types in the base case scenario. It turns out that exergy losses (chemical exergy, exergy losses related to production, and exergy losses associated with holding) hardly affect the optimal production plan. Fermented breadcrumb bread production can give better results if losses of par-baked bread are higher than a threshold value of $3 \%$. From a technological point of view, it is interesting to investigate if wasted bread, or processed wasted bread can be stored (and if so, for how long) and used as a raw material for fermented breadcrumb bread production after more than one day (as assumed here).

Sensitivity analysis shows that the preferred production option depends on parameter settings. Each production option is dominant in some scenario, depending on the overriding objective, and depending on used parameter values. Future research can help to determine more accurately the demand patterns, amount of waste at the supermarkets and setup costs.

We assumed that the selling price of bread is independent of the production option. In practice, the price of bread produced might be different between production options, which will have a direct effect on the results of our analysis.

\subsection{Conclusions and future research}

The main contribution of this study is the development of a model to assess alternative production options for waste management, by optimizing production planning decisions in FSCs with respect to economic and environmental criteria. We fill the gap in literature by assessing the eco-efficiency of production options using a lot sizing model for a real-life case study, namely industrial bread supply chain in the Netherlands. Three options to produce a bread product are available, and each production alternative is associated with a different option to deal with waste, i.e. par-baked bread (prevention), fermented breadcrumb bread (recycling), and freshly baked bread (disposal). We found that prevention of waste appears to be the most beneficial solution for all bread types from an environmental point of view, what is in line with the guideline provided in the food waste hierarchy (Papargyropoulou et al., 2014). Prevention of waste is also beneficial for a fraction of all bread types from an economic point of view. The possibility to store par-baked bread and sell when is needed gives additional flexibility and reduces substantially the setup costs. Shift to a par-baked bread production implies that shelf life of a product can be substantially extended, and this offers change in the design of a bread supply chain. These findings encouraged our industrial partners to carry out a follow up research to investigate the potential alternative logistical structures, including location and sizes of distribution centres, which are enabled due to par-baked bread production. Future research on this industrial bread supply chain should also investigate inventory management related issues, such as alternative reviewing policies, and safety stock levels of frozen breads. It is also important in future research to quantify production setup costs, to determine the accuracy of the demand patterns, and to investigate if (processed) bread waste can be stored before being used for production of fermented breadcrumb bread. The applicability of the model has been demonstrated by performing sensitivity analysis on input parameters. Sensitivity analysis 
revealed that optimal solutions depend on parameters not precisely known in advance, and we conclude that future research is needed to take into account uncertainty in parameters.

The environmental impact of the bread supply chain is expressed by the concept of exergy. We show in the case study that the optimal solutions obtained are different when exergy losses are used as an environmental indicator compared to a scenario in which the most commonly applied indicator, i.e. $\mathrm{CO}_{2}$ equivalents, is used. $\mathrm{CO}_{2}$ equivalents focuses only on specific issues, and does not always provide an integrated assessment of environmental impact. Using $\mathrm{CO}_{2}$ equivalents, therefore, may point to solutions that are not overall environmentally friendly. When environmental impact is expressed with the total amount of bread waste generated, solutions obtained are nearly the same as when exergy losses are used. This confirms that exergy is able to capture both energy and waste impact, and provides some evidence that exergy analysis offers an objective assessment of environmental impact. Future case studies are needed to confirm this.

In the study we illustrated the potential of studying food production planning problems in a multi-objective context, and demonstrated that the developed model can provide insights in assessment of alternative production options. 


\section{Appendix 1}

\begin{tabular}{|c|c|c|c|c|c|c|}
\hline \multirow[b]{2}{*}{$\begin{array}{l}\text { Activity associated with exergy } \\
\text { losses }\end{array}$} & \multicolumn{3}{|c|}{ White tin } & \multicolumn{3}{|c|}{ Brown bun } \\
\hline & fresh & $\begin{array}{l}\text { par- } \\
\text { baked }\end{array}$ & $\begin{array}{l}\text { ferm. } \\
\text { bread. }\end{array}$ & fresh & $\begin{array}{l}\text { par- } \\
\text { baked }\end{array}$ & $\begin{array}{l}\text { ferm. } \\
\text { bread. }\end{array}$ \\
\hline Transport raw materials [MJ/kg] & 0.09 & 0.09 & 0.09 & 0.09 & 0.09 & 0.10 \\
\hline $\begin{array}{l}\text { Mixing, fermenting, dividing, } \\
\text { proving }[\mathrm{MJ} / \mathrm{kg}]\end{array}$ & 1.22 & 1.21 & 1.28 & 1.22 & 1.19 & 1.36 \\
\hline Baking $[\mathrm{MJ} / \mathrm{kg}]$ & 2.28 & 1.99 & 2.57 & 2.25 & 1.66 & 2.67 \\
\hline Cooling $[\mathrm{MJ} / \mathrm{kg}]$ & 0.31 & - & 0.24 & 0.60 & - & 0.60 \\
\hline Freezing $[\mathrm{MJ} / \mathrm{kg}]$ & - & 0.90 & - & - & 1.00 & - \\
\hline Packing $[\mathrm{MJ} / \mathrm{kg}]$ & 0.01 & 0.00 & 0.01 & 0.02 & 0.00 & 0.02 \\
\hline Transport bread $[\mathrm{MJ} / \mathrm{kg}]$ & 0.56 & 0.55 & 0.56 & 0.56 & 0.55 & 0.56 \\
\hline Final baking $[\mathrm{MJ} / \mathrm{kg}]$ & - & 0.91 & - & - & 0.91 & - \\
\hline Processing waste $[\mathrm{MJ} / \mathrm{kg}]$ & - & - & 0.05 & - & - & 0.22 \\
\hline
\end{tabular}




\section{Appendix 2}

\begin{tabular}{|c|c|c|c|c|c|c|c|}
\hline \multirow{2}{*}{\multicolumn{2}{|c|}{ Component of production costs }} & \multicolumn{3}{|c|}{ White tin } & \multicolumn{3}{|c|}{ Brown bun } \\
\hline & & fresh & $\begin{array}{l}\text { par- } \\
\text { baked }\end{array}$ & $\begin{array}{l}\text { ferm. } \\
\text { bread. }\end{array}$ & fresh & $\begin{array}{l}\text { par- } \\
\text { baked }\end{array}$ & $\begin{array}{l}\text { ferm. } \\
\text { bread. }\end{array}$ \\
\hline \multicolumn{8}{|c|}{$\begin{array}{r}\text { Electricity consumption }(\mathrm{MJ} / \mathrm{kg}) \\
\text { price }=0.03 € / \mathrm{MJ}\end{array}$} \\
\hline \multirow{4}{*}{\multicolumn{2}{|c|}{$\begin{array}{l}\text { Mixing, dividing, proving } \\
\text { Cooling/Freezing } \\
\text { Packing } \\
\text { Processing waste into sourdough }\end{array}$}} & 1.06 & 1.05 & 1.22 & 1.03 & 1.00 & 1.28 \\
\hline & & 0.22 & 0.89 & 0.21 & 0.21 & 0.98 & 0.21 \\
\hline & & 0.01 & 0.00 & 0.01 & 0.02 & 0.00 & 0.02 \\
\hline & & - & - & 0.04 & - & - & 0.04 \\
\hline \multicolumn{8}{|c|}{$\begin{array}{r}\text { Natural gas consumption }(\mathrm{MJ} / \mathrm{kg}) \\
\text { price }=0.01 € / \mathrm{MJ}\end{array}$} \\
\hline \multirow{2}{*}{\multicolumn{2}{|c|}{$\begin{array}{l}\text { Baking } \\
\text { Final baking }\end{array}$}} & 2.15 & 1.86 & 2.48 & 2.11 & 1.51 & 2.59 \\
\hline & & - & 0.89 & - & - & 0.89 & - \\
\hline \multicolumn{8}{|c|}{$\begin{array}{l}\text { Fuel consumption }(\mathrm{L} / \mathrm{kg}) \\
\qquad \text { price }=1.47 € / \mathrm{L}\end{array}$} \\
\hline \multicolumn{2}{|c|}{ Raw materials transport } & 0.0023 & 0.0023 & 0.0025 & 0.0024 & 0.0023 & 0.0026 \\
\hline Bread transport & & 0.0147 & 0.0144 & 0.0147 & 0.0147 & 0.0144 & 0.0147 \\
\hline \multicolumn{8}{|c|}{ Recipe for $1 \mathrm{~kg}$ of bread $(\mathrm{kg})$} \\
\hline Flour & {$[0.34 € / \mathrm{kg}]$} & 0.72 & 0.72 & 0.67 & 0.32 & 0.31 & 0.31 \\
\hline Whole meal & {$[0.34 € / \mathrm{kg}]$} & - & - & - & 0.32 & 0.31 & 0.31 \\
\hline Water & {$[0.00 € / \mathrm{kg}]$} & 0.42 & 0.42 & 0.44 & 0.38 & 0.37 & 0.40 \\
\hline Yeast & {$[3.50 € / \mathrm{kg}]$} & 0.01 & 0.01 & 0.01 & 0.04 & 0.04 & 0.03 \\
\hline Salt & {$[0.14 € / \mathrm{kg}]$} & 0.01 & 0.01 & 0.01 & 0.04 & 0.04 & 0.03 \\
\hline Bread Improver & {$[2.32 € / \mathrm{kg}]$} & 0.01 & 0.01 & 0.01 & 0.01 & 0.01 & 0.01 \\
\hline Waste & {$[0.00 € / \mathrm{kg}]$} & - & - & 0.06 & - & - & 0.07 \\
\hline Enzymes & {$[4.00 € / \mathrm{kg}]$} & - & - & 0.002 & - & - & 0.002 \\
\hline \multicolumn{2}{|c|}{ Labour costs $(€ / \mathrm{kg})$} & 0.25 & 0.28 & 0.28 & 0.25 & 0.28 & 0.28 \\
\hline \multicolumn{2}{|c|}{ Packaging costs $(€ / \mathrm{kg})$} & 0.02 & 0.14 & 0.02 & 0.05 & 0.20 & 0.05 \\
\hline
\end{tabular}



Chapter 4

\section{Closing loops in agricultural supply chains using multi-objective optimization: a case study of an industrial mushroom supply chain}

This chapter is based on the published journal article:

A. Banasik, A. Kanellopoulos, G.D.H. Claassen, J. M. Bloemhof-Ruwaard, J.G.A.J. van der Vorst (2017).

Closing loops in agricultural supply chains using multi-objective optimization: A case study of an industrial mushroom supply chain International Journal of Production Economics Volume 183, Part B, Pages 409-420 DOI: http://dx.doi.org/10.1016/j.ijpe.2016.08.012 


\begin{abstract}
Environmental concerns and scarcity of resources encourage decision makers in supply chains to consider alternative production options that include preventing the production of waste streams, and simultaneously reusing and recycling waste materials. Until now, hardly any quantitative modelling approaches exist in literature on closing loops in agri-food supply chains. In contrast to closed-loop studies in discrete parts industry, in agri-food supply chains the value of the final product itself cannot be regained. However, the components used for production such as organic matter or a growing medium, can be recycled. In this chapter, the consequences of closing loops in a mushroom supply chain are revealed. We propose a multi-objective mixed integer linear programming model to quantify trade-offs between economic and environmental indicators and explore quantitatively alternative recycling technologies. The model was developed to redesign the logistical structure and close loops in the mushroom supply chain. We found that adopting closing loop technologies in industrial mushroom production has the potential to increase total profitability of the chain by almost $11 \%$ while the environmental performance improves by almost $28 \%$. We conclude that a comprehensive evaluation of recycling technologies and re-designing logistical structures requires quantitative tools that optimize simultaneously managerial decisions at strategic and tactical level.
\end{abstract}




\subsection{Introduction}

Resources become scarce, ecosystems are threatened, and the consequences of climate change have a large impact on the living environment. People become aware of environmental pressure, which in turn causes an increasing demand for sustainable food production. To become more environmentally friendly, food supply chains need to adopt innovative technologies that focus on using natural resources and materials to their full potential.

The concept of "closing loops", which refers to the integration of forward and reverse supply chain activities (Guide et al., 2003), is one of the options considered to ensure the sustainability of supply chains (Chaabane et al., 2012). This topic has been widely studied and has given rise to the field of Closed Loop Supply Chains (CLSCs) (Paksoy et al., 2011). In CLSCs, items no longer desired or used are taken care of and their value is (partly) recovered (Flapper et al., 2005). Examples of new logistical structures exist in which the concept of closing loops has been used and showed that resource use efficiency can be substantially improved. However, these examples mostly refer to returning products to original equipment manufacturers (OEM) in discrete parts industry e.g. car industry (van der Laan, 1997), refrigerators (Krikke et al., 2003), copiers (Krikke et al., 1999), and electronic equipment (Quariguasi Frota Neto et al., 2010). Value of OEM products can be regained after their use because these products consist of materials and components that are suitable for reuse. In agri-food chains, defined as supply chains that produce and distribute agricultural or horticultural products (Ahumada and Villalobos, 2009; Aramyan et al., 2006), raw materials used for production usually either disappear due to consumption or lose their value (e.g. due to product decay), and wasted food products can be valorised in other supply chains, e.g. for biofuel production or feed production. Thus in contrast to discrete parts industry, in a closed-loop agri-food supply chain it is not the value of what is in the products that can be regained (in the same chain), but rather the components used for production, such as organic matter or a growing medium. Therefore, closing loops in agri-food chains may require a fundamental reconsideration of business processes and redesign of distinct logistical structures.

To redesign an agri-food supply chain, decision support models are needed that can optimize decision making at chain level. Additionally, these decision support models should enable the assessment of multiple indicators. This can result in the calculation of trade-offs between conflicting objectives, which make decision makers aware of (individual) trade-offs and can facilitate the discussion and exploration of alternative logistical structures. Govindan et al. (2015d) confirm that there are hardly studies in the CLSC literature that evaluate quantitatively the relationship between economic and environmental criteria simultaneously. Bell et al. (2013) emphasize the need for studies to demonstrate how closed loop technologies can lead to improved environmental performance. Moreover, in order to investigate the relation between economic and environmental criteria, Soysal et al. (2012) and Brandenburg et al. (2014) confirm the need for quantitative models on real-life case studies.

The research presented in this chapter attempts to fill in these gaps. More specifically, we evaluate quantitatively a mushroom supply chain, in which farm waste materials are used for 
mushroom production. Horse and chicken manure are some of the ingredients that can be used for the production of substrate for growing mushrooms. Spent mushroom substrate, a material remaining after cultivating mushrooms can cause environmental burden, i.e. for instance in the Netherlands over 800000 tons of spent mushroom substrate is produced annually (Phan and Sabaratnam, 2012), and need to be transported hundreds of kilometres just to be used as fertilizer. The activities related to disposal are neither economically nor environmentally attractive. The amount of mushrooms produced in the Netherlands constitutes to less than $9 \%$ of global mushroom production (Koopman et al., 2010). These figures demonstrate the magnitude of this waste stream worldwide. Simultaneously, the figures show the potential for improvement, as the economic and environmental performance could be improved substantially if only a minor part of the nutritious waste materials could be reused or recovered in the same chain for production. Amount of spent mushroom substrate can be reduced by extending production cycles, i.e. using the same substrate for more subsequent production rounds at mushroom production level. Such an option will reduce the amount of disposed substrate, however, always at the expense of the yearly production yield. Technological innovations provide potential for reusing and recycling parts of the spent mushroom substrate to close the loop in mushroom supply chains. The feasibility of these technological innovations including their impact on sustainability must be further investigated. It is therefore important to quantify the implications of valorisation of materials on the performance of a mushroom supply chain.

The objective of this chapter is to evaluate the economic and environmental performance of closing loop technologies at chain level in a mushroom supply chain. A multi-objective (mixed integer) linear programming model is developed to support production and distribution planning decisions by optimizing material flows in a closed-loop mushroom supply chain. The mushroom supply chain provides an example of an agri-food supply chain in which not the product itself, but the medium for growing the product can be reduced, reused, or recycled. We demonstrate how environmental and economic performance of alternative closed-loop logistical structures can be evaluated in a multi-objective context. To the best of our knowledge, this chapter presents the first decision support model to optimize flows of materials with respect to economic and environmental objectives in a closed-loop agri-food supply chain. Deriving a set of Pareto-optimal solutions allows to obtain insights in the environmental costs of activities in a mushroom supply chain.

This chapter is structured as follows. Section 2 presents an overview from literature in the related areas, i.e. closed-loop supply chains, and the use of multi-criteria decision making models in agri-food supply chains. Section 3 introduces a mushroom supply chain in which possibilities exist to close material loops. We propose a multi-objective decision support model that can be used to quantify the benefits of closing loops. Section 4 presents the results of the model applied to the real-life mushroom supply chain. Section 5 focuses on the generalizability of the case study to create a framework for closed-loop agri-food supply chains. The main conclusions are summarized in Section 6. 


\subsection{Literature review}

A vast body of literature exists that focuses on improving the environmental performance of supply chains (SCs) (Brandenburg et al., 2014). Reduction of environmental impact, however, often requires sacrifices in terms of economic performance in a SC, and only a limited number of initiatives for environmental friendly production have proven to be profitable (Quariguasi Frota Neto et al., 2008). Assessment of alternative options requires the consideration of multiple criteria, because any (re)design of a SC usually involves trade-offs between different conflicting objectives (Wang et al., 2011). Multi-objective optimization has already been used to address different decision problems in SCs and to test the efficiency of various SC configurations and operating strategies (Aramyan et al., 2011; Ramudhin et al., 2010).

One of the environmental issues in SCs is associated with the amount of waste produced and in response, the recovery of products is drawing attention of researchers and practitioners (Paksoy et al., 2010). Commonly, the aim is to regain the incorporated value of some products once their use has ended, instead of land filling or incinerating the remains (Dekker et al., 2012). Regaining value of a product typically involves reverse logistic activities, such as reuse, repair, recycle and remanufacture (Chaabane et al., 2012; Paksoy et al., 2011; Jayaraman, 2006). Reverse logistics, therefore, includes the activities all the way from used products (i.e. no longer required by the user), to products that are reusable in a market (Fleischmann et al., 1997). Applications of reverse logistics in literature include e.g. hi-tech products (Eskandarpour et al., 2013), computer hardware (Ravi et al., 2008), electronic equipment (Quariguasi Frota Neto et al., 2009), plastic recycling (Senthil et al., 2014), or tire recovery (Dehghanian and Mansour, 2009). Reverse supply chain activities improve supply chain management by giving the advantage of closing the material loop of products from resource extraction, through production, use, and end-of-life (Paksoy et al., 2010).

A Closed Loop Supply Chain (CLSC) is defined as a chain in which both forward and reverse logistics are combined. In a CLSC flows of materials are circular and finished products do not become waste after their use, but instead are disassembled, reused, remanufactured, or recycled into a source of raw materials (Hassini et al., 2012). Examples of CLSC optimization models including economic and environmental criteria can be found for instance in automotive industry (Kannegiesser et al., 2014) or electronic equipment (Quariguasi Frota Neto et al., 2010).

Within the context of agri-food supply chains the sustainability discussion focuses on emissions related to all activities in the supply chain, including the reduction of waste (Bloemhof and van der Vorst, 2014). Amorim et al. (2012) present a multi-objective model to minimize the costs, and maximize the remaining shelf life of a perishable product. Akkerman et al. (2009) study sustainable production and distribution of industrially prepared meal elements, while taking into account products' quality degradation. To ensure the product's quality, its enthalpy levels in the developed mathematical model must be below a given threshold when delivered to customers. Soysal et al. (2014) study a beef logistics network problem. The authors develop a generic biobjective linear programming model to support decisions on the amount of livestock slaughtered per period, the amount of livestock kept in inventory, flows between different 
actors in a supply chain, and the number of trucks used, while taking into account the possibility of using less than full loaded trucks and its impact on fuel consumption.

Food waste mostly arises at the beginning and at the final stage in a supply chain i.e. agricultural production, postharvest handling and storage, and consumption phase (FAO, 2013). Valorisation of waste materials arising from food production gains growing attention in recent years (Chen et al., 2017). Food waste can be used in a wide range of industrial applications, including energy production, animal feed production, chemical or pharmaceutical applications (Girotto et al., 2015). A number of publications present mathematical models to optimize biofuel production in a multi-criteria context. Biofuel production can be seen as a reverse supply chain for food products, as it offers insights in potential ways to valorise food waste. For instance, Ziolkowska (2014) investigates optimal biofuel production, and presents a fuzzy PROMETHEE approach to derive coefficients for an LP model, which includes fuzzy constraints related to uncertain resource availability, such as water and land use. You et al. (2012) study sustainable cellulosic biofuel supply chains, and develop a Multi-Objective Mixed Integer Programming model at the strategic design level and at operational planning level. The developed model predicts optimal network design, technology selection, capital investment, production operations, inventory control, and logistics management decisions while taking the products degradation rate into account.

While the above mentioned publications provide mathematical models for what can be seen as reverse supply chains for food products, these publications do not concern CLSCs because the waste products are not used in the same chain. It is observed by Stindt and Sahamie (2014) that research on CLSC in process industry is limited, and the challenges regarding non-discrete products are not sufficiently covered. In discrete manufacturing products can often be disassembled to valuable flows of materials with the same original properties, and kept at an inventory until being used. In closed-loop agri-food chains, on the other hand, deterioration of products plays a role, and products to be recovered often need to be enhanced by adding value in processing. Because of perishability, the need for enhancing product's value during recovery, and specific reverse flows of waste materials, which come from manufacturing stages and not the customers, the models developed in closed-loop agri-food supply chains are different from the models developed for discrete part industries. To the best of our knowledge, there are no agri-food supply chain decision support models in literature that optimize the flows of materials in closed loop form by using waste as materials for production in the same supply chain. Additionally, according to Mirabella et al. (2014), environmental and economic implications of closing loops in an agri-food supply chain context need to be investigated, particularly in reallife case studies. Moreover, the prevalent recovery options (i.e. reuse, repair, remanufacturing, refurbishing, retrieval and recycling) are not applicable to non-discrete products, and there is a challenge to redefine the recovery options for process industry (Stindt and Sahamie, 2014). Based on the case study considered in this chapter, we make a first attempt to create a framework for a closed-loop agri-food supply chain. 


\subsection{Industrial mushroom production}

Mushrooms are grown on industrially prepared substrate that consists of two layers: compost as a bottom layer, and casing soil as a top layer. All raw materials needed for substrate production are transported to a substrate production factory. Raw materials used for compost production usually include horse manure (main source of carbon and nitrogen), chicken manure (source of nitrogen), straw (source of carbon), and gypsum (source of calcium, helps to control the $\mathrm{pH}$ value of the compost). Other raw materials used for production include water and ammonium sulphate (source of nitrogen). Casing soil is usually produced from peat and limestone.

Production of compost is divided in three subsequent phases: (1) mixing (duration of around 5 days), (2) main micro-biological process (duration of around 6 days), (3) combining mycelium with compost (duration of around 16 days). The final product of phase (3) is called full-grown inoculated compost, which is delivered to the growers. It is crucial that full-grown inoculated compost is produced just-in-time, because it can be stored for at most 24 hours (and becomes waste afterwards).

Substrate is transported to mushroom growers who provide appropriate growing conditions for mushrooms. The same substrate can be used to obtain multiple flushes of mushrooms. Substrate cannot be used for more than three flushes because of increasing risks for pests and diseases. In general, productivity of substrate decreases with each flush. The quality and consequently the selling price of fresh mushrooms mainly depends on the size of the produced mushrooms. After the last harvest, spent mushroom substrate has to be steamed to become pathogen-free and is discarded on agricultural land. Discarding the substrate involves substantial disposal costs associated mainly with transportation. Additionally, spent mushroom substrate is rich in nutrients that are wasted if the material is not reused or recycled.

Technological innovations at processing level that allow for recovery of spent substrate to produce compost and casing soil have recently become available. These innovations provide alternatives that can result in more sustainable mushroom production and can definitely affect managerial decision making at chain level. Currently, feasibility is investigated of reusing the bottom layer of spent mushroom substrate (spent mushroom compost) directly as an ingredient for compost production. Reusing spent mushroom compost is possible after separating the two layers of substrate by scrubbing and removing the top layer. Alternatively, the spent mushroom compost can be recycled and used for casing soil production. Such recycling stage requires the spent mushroom compost to be fermented before it can be used to replace other raw materials in casing soil. To recover the waste product (i.e. spent mushroom compost), it needs to be treated/processed directly after usage for quality reasons. The implications of these closing loop technologies on strategic (e.g. network designing) and tactical (e.g. production planning) managerial decision making have not been evaluated quantitatively. 


\subsubsection{A closed-loop supply chain model for a mushroom supply chain}

In agri-food supply chains, tactical production planning decisions can directly affect strategic network design decisions and vice versa. Chain level assessment requires simultaneous optimization of these decisions. For that reason, the proposed multi-objective mixed integer linear programming model comprises two coupled components. The first component describes location allocation decisions in factories, which produce compost and casing soil. This location allocation model supports decisions on how much of each raw material to source each time period, and how much components to produce in each factory such that demand of growers for substrate is fulfilled. The model includes binary decisions on operationalising production options that can be associated with valorisation of wasted materials, thus allowing closing the loop in the considered supply chain. This has the potential to improve the economic and environmental performance by 1 ) replacing other raw materials and producing less waste, and 2) reducing the total transportation distance. The second component of the model supports decisions at (tactical) harvest and production planning level, i.e. when to start and finish the harvest (i.e. how many flushes to cultivate), such that mushroom production will result in the greatest benefits regarding the defined objectives. Additionally, the option to include a closing loop in the considered supply chain has been modelled in order to valorise the waste stream (spent mushroom substrate) and use it as a raw material for production. Both components of the model account for economic and environmental objectives to investigate a potential trade-off between both dimensions, and to inform decision makers about the costs associated with improving the environmental performance.

We consider a number of (real-life) production factories. The potential locations of substrate production factories $I$, as well as mushroom growers' $J$ are fixed. The general structure of the case study supply chain is presented in Figure 4.1. Demand for mushrooms does not depend on mushroom size and is assumed to be known in advance. Moreover, for each mushroom size three different selling prices are defined: mushrooms within the specified demand are sold at the highest price, mushrooms produced exceeding the demand are sold at a lower price, and low quality mushrooms are sold to a processing company also at a lower price. In the next section we present an outline of the applied model in practice. 


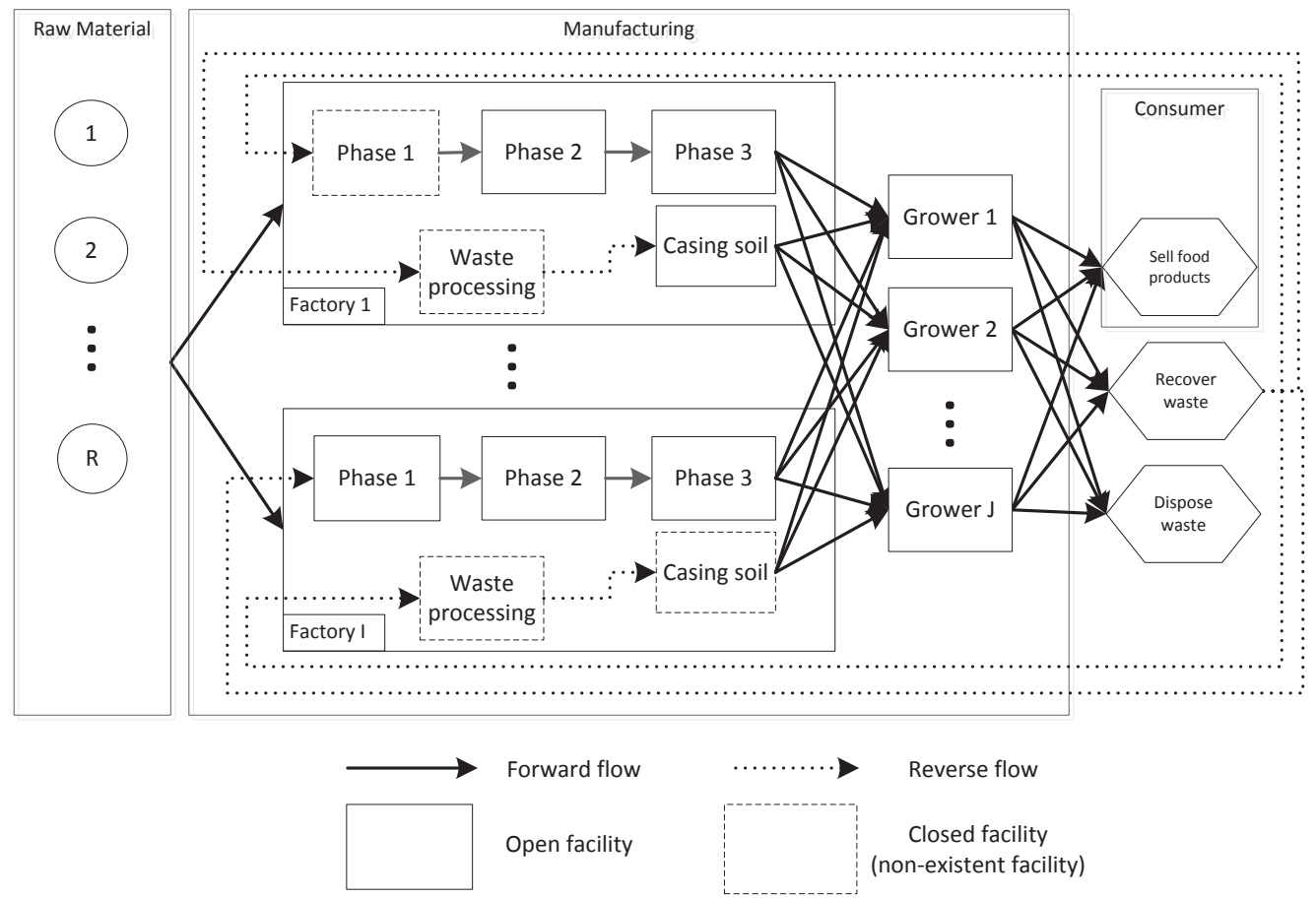

Figure 4.1 General structure of the mushroom supply chain considered in the case study

\subsubsection{Bi-objective mixed-integer linear programming model}

The model for production planning in a mushroom supply chain is formulated as a multiobjective mixed integer programming model. The objectives of the model include an economic objective and an environmental objective. For the readability we split the model into two components, i.e. the location/allocation model in Section 4.3.2.1 and production planning model in Section 4.3.2.2.

For the mathematical description of the model the following notation is introduced:

Indices

index for compost production option, $m=1, \ldots, M$

index for casing soil production option, $n=1, \ldots, N$

index for a substrate production factory, $i=1, \ldots, I$

index for a mushroom grower, $j=1, \ldots, J$

index for a time period, $t=1, \ldots, T$

index for age of cultivated substrate, $a=1, \ldots, A$

$c \quad$ index for size of mushroom, $c=1, \ldots, C$ 


\section{Monetary parameters}

$\begin{array}{ll}c o_{r, i} & \text { price per ton of raw material } r \text { sourced to factory } \mathrm{i} \\ t c_{i, j} & \text { costs per ton of product transported from factory i to grower } \mathrm{j} \\ o p_{m, n} & \text { operating costs per ton of substrate produced with compost } m \text { and casing } n \\ c n_{m, n, r_{2}} & \begin{array}{l}\text { recovering costs per ton of a bottom layer of spent substrate produced with compost } m \text { and } \\ \text { casing } n \text { to be used as raw material } r_{2}\end{array} \\ f a c_{i, m, n} & \begin{array}{l}\text { fixed cost of operationalizing in factory } i \text { production of substrate with compost } m \text { and } \\ \text { casing } n\end{array} \\ p p_{c, t} & \text { selling price of one kilogram of mushrooms size } c \text { fulfilling the demand in period } t \\ p s_{c, t} & \text { selling price of one kilogram of mushrooms size } c \text { exceeding the demand in period } t \\ p l_{c, t} & \text { selling price for one kilogram of low quality mushrooms size } c \text { in period } t \\ t c h_{j} & \text { disposal and transportation costs per ton of disposed material from grower } j \\ c s_{a} & \text { variable and labour costs per ton of substrate at age } a \\ c d & \text { handling costs per kilogram of mushrooms due to diseases }\end{array}$

Environmental parameters

\begin{tabular}{|c|c|}
\hline$o_{r, i}$ & $\begin{array}{l}\text { vironmental impact associated with transporting } 1 \text { ton of raw material } r \text { sourced } \\
\text { ctory } i\end{array}$ \\
\hline$w_{i, j}$ & $\begin{array}{l}\text { vironmental impact associated with transporting } 1 \text { ton of product between factory } i \text { and } \\
\text { ower } j\end{array}$ \\
\hline$w_{m, n}$ & $\begin{array}{l}\text { vironmental impact associated with producing } 1 \text { ton of substrate with compost } m \text { and } \\
\operatorname{sing} n\end{array}$ \\
\hline$r a_{m, n, r_{2}}$ & $\begin{array}{l}\text { vironmental impact associated with recovering } 1 \text { ton of bottom layer of spent substrate } \\
\text { oduced with compost } m \text { and casing } n \text { to be used as raw material } r_{2}\end{array}$ \\
\hline & 1 impet of dicnocin 11 of \\
\hline ewh & $\begin{array}{l}\text { ironmental impact associated with producing } 1 \mathrm{~kg} \text { of mushrooms cultivated on substrate } \\
\text { ed on compost } m \text { and casing } n\end{array}$ \\
\hline$C$ & $\begin{array}{l}\text { ironmental impact of associated with transporting } 1 \text { ton of waste for disposal from } \\
\text { wer } j\end{array}$ \\
\hline & $\begin{array}{l}\text { vironmental impact associated with disposing } 1 \text { ton of substrate produced with com } \\
\text { and casing } n\end{array}$ \\
\hline
\end{tabular}

Technical parameters

\begin{tabular}{|c|c|}
\hline $\operatorname{clp}_{r, m, n}$ & cunnlycongrity of rous mariol $r$ providor \\
\hline $\operatorname{cap}_{-} r m_{r}$ & $\begin{array}{l}\text { supply capacity of raw material } r \text { provider } \\
\text { capacity in factory } i \text { for substrate produced with compost } m \text { and casing } n\end{array}$ \\
\hline${ } p_{-} f a c_{i, m, n}$ & capacity in factory $i$ for substrate produced with compost $m$ and casing $n$ \\
\hline & fraction of compost in substrate produced with compost $m$ and casing $n$ \\
\hline$r_{2}$ & $\begin{array}{l}\text { fraction of material recovered from bottom layer of substrate, produced with compost } m \\
\text { and casing } n \text { to be used as material } r_{2}\end{array}$ \\
\hline & yield $(\mathrm{kg})$ of mushrooms size $c$ per ton of substrate at age $a$ \\
\hline & capacity of grower $j$ \\
\hline & ratio of mushroom loss due to diseases at age $a$ \\
\hline & fraction of low quality mushrooms at age $a$ \\
\hline & demand for mushrooms at location $j$ in time period $t$ \\
\hline & processing time of a part produced with compost $m$ and casing $n$ \\
\hline & ocessing time of a wasted product to be used as a raw material $r$ \\
\hline
\end{tabular}


Decision variables:

$X_{r, i, t} \quad$ amount of raw material $r$ sourced to factory $i$ in period $t$

$Y_{i, j, m, n, t} \quad$ amount of substrate produced with compost $m$ and casing $n$ in factory $i$ transported to grower $j$ in period $t$

$U_{i, j, m, n, r_{2}, t} \quad$ amount of bottom layer of spent substrate produced with compost $m$ and casing $n$, sourced

$y_{i, m, n}^{f a c}$ by factory $i$ from grower $j$ to be recovered and used as a raw material $r_{2}$ in period $t$ binary variable indicating if substrate produced with compost $m$ and casing $n$ is operational in factory $i$

$Z_{j, m, n, t, a} \quad$ amount of substrate produced with compost $m$ and casing $n$ cultivated by grower $j$ in time period $t$ at age $a$

$S T P_{j, m, n, t, a} \quad$ amount of substrate produced with compost $m$ and casing $n$ thrown away by grower $j$ in time period $t$ at age $a$

$M_{j, c, t} \quad$ The amount of premium quality mushrooms size $c$ sold in period $t$ by grower $j$

$O D_{j, c, t} \quad$ The amount of surplus mushrooms size $c$ sold in period $t$ by grower $j$

$L_{j, c, t} \quad$ The amount of low quality mushrooms size $c$ sold in period $t$ by grower $j$

4.3.2.1 Location allocation model for substrate production planning

$$
\begin{gathered}
\min \left\{O F_{e c o}^{1}=\sum_{r, i, t} c o_{r, i} * X_{r, i, t}+\sum_{i, j, m, n, t}\left(o p_{m, n}+t c_{i, j}\right) * Y_{i, j, m, n, t}\right. \\
\left.+\sum_{i, j, m, n, r_{2}, t}\left(t c_{i, j}+c n_{m, n, r_{2}}\right) * U_{i, j, m, n, r_{2}, t}+\sum_{i, m, n} f a c_{i, m, n} * y_{i, m, n}^{f a c}\right\} \\
\min \left\{O F_{e n v}^{1}=\sum_{r, i, t} e t o_{r, i} * X_{r, i, t}+\sum_{i, j, m, n, t}\left(e t w_{i, j}+e w_{m, n}\right) * Y_{i, j, m, n, t}\right. \\
\left.+\sum_{i, j, m, n, r_{2}, t}\left(e t w_{i, j}+e r a_{m, n, r_{2}}\right) * U_{i, j, m, n, r_{2}, t}\right\}
\end{gathered}
$$

Subject to:

$$
\begin{array}{ll}
\sum_{i} X_{r, i, t} \leq \text { cap_rm }_{r} & \forall r, \forall t \\
X_{r, i, t}=\sum_{m, n, j} \text { recipe }_{r, m, n} * Y_{i, j, m, n, t+t_{1}^{m, n}} & \forall r, \forall i, \forall t \\
\sum_{k=0}^{t_{1}^{m, n}-1} Y_{i, j, m, n, t+k} \leq \operatorname{cap}_{-} f a c_{i, m, n} * y_{i, m, n}^{f a c} & \forall i, \forall t, \forall m, \forall n \\
\sum_{i} Y_{i, j, m, n, t}=Z_{j, m, n, t, a} & \\
\sum_{i, r_{2}} U_{i, j, m, n, r_{2}, t} \leq \sum_{a} a_{m, n} * S T P_{j, m, n, t, a} & \forall j, \forall m, \forall n, \forall t, a=1 \\
\sum_{i, j, m, n} d r_{m, n, r_{2}} * U_{i, j, m, n, r_{2}, t}=\sum_{i} X_{r_{2}, i, t+t_{2}^{r_{2}}} & \forall j, \forall m, \forall n, \forall t
\end{array}
$$


The first component of the economic objective $\left(O F_{\text {eco }}^{1}\right)$ minimizes total costs associated with production and transportation of substrate, which is delivered to growers. It comprises four terms: (a) acquisition costs of raw materials, (b) substrate production costs, and transportation costs of substrate to growers, (c) transportation costs of spent compost to be recovered, and recovery costs of spent compost, (d) fixed cost associated with operationalizing production options (by setting fixed costs to 0 the model becomes a typical allocation model).

The first component of the environmental objective $\left(O F_{\text {env }}^{1}\right)$ minimizes total environmental impact associated with production and transportation of substrate. It comprises three terms: (a) environmental impact associated with transportation of raw materials, (b) environmental impact associated with production and transportation of substrate, (c) environmental impact associated with transportation of spent compost to be recovered, and environmental impact associated with recovery of spent compost.

Constraints (1) ensure capacity restrictions on raw material providers for substrate production. Constraints (2) are recipe constraints that ensure the amount of raw materials sourced correspond to the requirements for substrate production, while taking into account processing time of production option $n$. Constraints (3) ensure capacity restrictions on each production option. Constraints (4) ensure balanced flows of materials between facilities, i.e. the amount of substrate supplied by factories must be equal to the grower's demand for substrate. The constraints in (5) ensure that the recovered amount of compost is not larger than the amount of spent compost (disposed by growers). Constraints (6) ensure that the amount of recovered materials correspond to the amount used in production while taking into account mass change during recovery. 
4.3.2.2 Production planning model

$$
\begin{gathered}
\max \left\{O F_{e c o}^{2}=\sum_{j, c, t}\left(p p_{c, t} M_{j, c, t}+p s_{c, t} O D_{j, c, t}+p l_{c, t} L_{j, c, t}\right)-\sum_{j, m, n, t, a} c s_{a} Z_{j, m, n, t, a}\right. \\
-\sum_{j, m, n, c, t, a} c d * r l_{a} * p d_{c, a} * Z_{j, m, n, t, a} \\
\left.\quad-\sum_{j, m, n, t} t c h_{j}\left(\sum_{a} S T P_{j, m, n, t, a}-\sum_{i, r_{2}} U_{i, j, m, n, r_{2}, t}\right)\right\} \\
\min \left\{O F_{e n v}^{2}=\sum_{j, m, n, c, t} e w h_{m, n} * p d_{c, a} * Z_{j, m, n, t, a}+\sum_{j, m, n, c, t, a} e m * r l_{a} * p d_{c, a} * Z_{j, m, n, t, a}\right. \\
\left.+\sum_{j, m, n, t}\left(e t c_{j}+e c_{m, n}\right) *\left(\sum_{a} S T P_{j, m, n, t, a}-\sum_{i, r_{2}} U_{i, j, m, n, r_{2}, t}\right)\right\}
\end{gathered}
$$

Subject to:

$$
\begin{array}{ll}
M_{j, c, t}+O D_{j, c, t}=\sum_{m, n, a}\left(1-l q_{a}\right)\left(1-r l_{a}\right) p d_{c, a} Z_{j, m, n, t, a} & \forall j, \forall c, \forall t \\
L_{j, c, t}=\sum_{m, n, a} l q_{a}\left(1-r l_{a}\right) p d_{c, e, a} Z_{j, m, n, t, a} & \forall j, \forall c, \forall t \\
\sum_{c} M_{j, c, t}=d_{j, t} & \\
\sum_{m, n, a} Z_{j, m, n, t, a} \leq g c_{j} & \forall j, \forall t \\
Z_{j, m, n, t, a}=Z_{j, m, n, t-1, a-1}-S T P_{j, m, n, t-1, a-1} & \\
S T P_{j, m, n, t, a}=Z_{j, m, n, t, a} & \forall j, \forall t \\
S T P_{j, m, n, t, a}=Z_{j, m, n, t, a} & \forall m, \forall n, \forall j, \forall t>1, \forall a>1
\end{array}
$$

The second component of the economic objective $\left(O F_{e c o}^{2}\right)$ maximizes total profit of growers, and it is calculated as revenues from sales of final products minus growers' costs. This objective function comprises four terms: (a) revenue from selling (premium quality, surplus, and low quality) mushrooms, (b) costs associated with cultivating substrate, (c) handling costs of a disease outbreak, (d) disposal and transportation costs of (not recovered) waste substrate.

The second component of the environmental objective $\left(O F_{e n v}^{2}\right)$ minimizes total environmental impact associated with growers. It comprises following terms: (a) environmental impact associated with growing, (b) environmental impact associated with a disease outbreak, (c) environmental impact associated with transportation of disposed waste materials and environmental impact associated with disposal of waste materials. 
Constraints (7) and (8) are used to calculate the amount of premium quality, surplus, and low quality mushrooms. Constraints (9) ensure that demand is satisfied by premium quality mushrooms. Constraints (10) ensure capacity restrictions at mushroom growers. Constraints (11) are recursive constraints ensuring that the amount of substrate cultivated for mushroom production in a given period is not larger than in the previous period. Constraints (12) and (13) ensure that the cultivation of a substrate stops in the last considered period, and when substrate has been cultivated for the maximal allowed number of days. The two defined components are aggregated in a single model, which is used to support decision making in the considered closed-loop mushroom supply chain.

\subsubsection{Data and setup of the modelling exercise}

The summarized model components presented in the previous subsections are combined into a bi-objective optimization model by adding the objective functions of economic performance (i.e. $O F_{\text {eco }}^{1}+O F_{e c o}^{2}$ ) and environmental impact (i.e. $O F_{\text {env }}^{1}+O F_{\text {env }}^{2}$ ), and including all presented constraints in a single model. Constraint (4) links the two model components by ensuring that amount of substrate supplied by substrate production facilities is equal to mushroom growers' demand for substrate. The model is applied to redesign an industrial mushroom supply chain. The studied supply chain comprises of two substrate production factories with fixed (i.e. known) locations. In the current structure of the chain, one factory does not produce casing soil, while the other factory cannot produce phase 1 compost. To compare the operational benefits of opening new facilities (including casing soil production, phase 1 compost production, recycling, and reusing options), we take the fixed costs for opening facilities equal to zero.

Mushroom growers were clustered based on their geographical location into seven grower groups. Transportation costs are calculated by multiplying average fuel consumption $(0.02 \mathrm{~L}$ of diesel per ton of product per kilometre), with price of diesel $(1.2 € / \mathrm{L})$, with the average distance from each factory to each location. The distances are given in Table 4.1. The considered time horizon consists of 365 days to capture the variations in prices and demand for mushrooms throughout a year (Figure 4.2).

Table 4.1 Transportation distances from factories to mushroom growers locations, and demand data as a fraction of total demand

\begin{tabular}{ccccc}
\hline & \multicolumn{2}{c}{ Transportation distance $(\mathrm{km})$} & & Demand \\
\cline { 1 - 2 } \cline { 1 - 1 } zone & Factory 1 & Factory 2 & & \\
\hline 1 & 60 & 70 & & 0.29 \\
2 & 120 & 50 & & 0.25 \\
3 & 140 & 40 & & 0.17 \\
4 & 1000 & 900 & & 0.17 \\
5 & 250 & 200 & & 0.04 \\
6 & 650 & 600 & & 0.04 \\
7 & 500 & 500 & & 0.04 \\
\hline
\end{tabular}




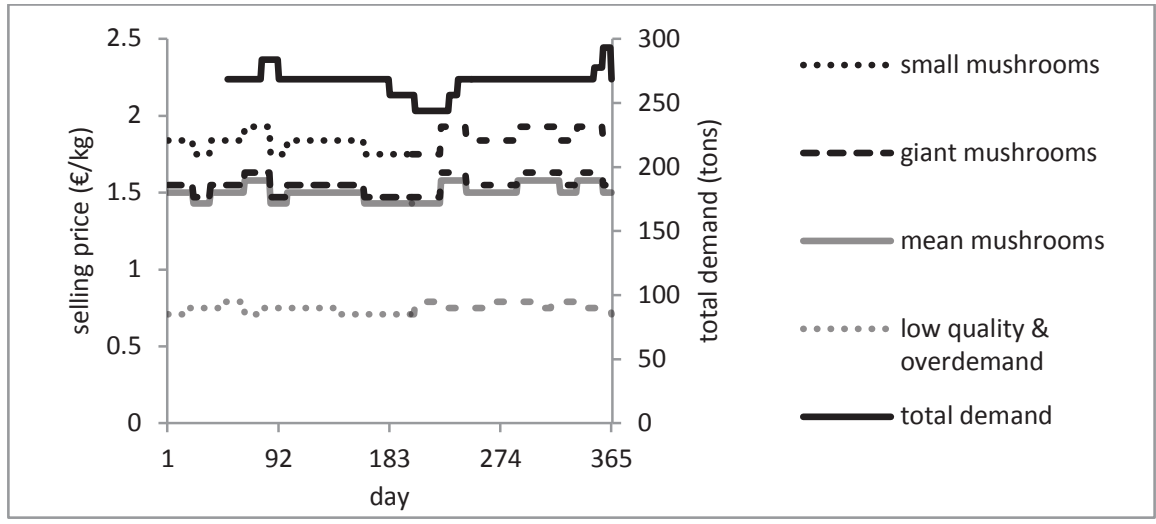

Figure 4.2 Annual fluctuations of prices for small, giant, mean, low quality and over demand mushrooms (primary axis), and aggregated demand for all zones of mushroom growers (secondary axis)

We use total exergy loss as a single metric indicator for environmental performance (Apaiah et al., 2006; Kotas, 1995). Exergy losses of a system have been widely used to express the environmental impact in various fields, including chemical sectors, construction industries, and food industry (Zisopoulos et al., 2017). The advantage of exergy, as an environmental indicator is that it allows to quantify environmental impact of production activities (including energy consumption, fuel consumption and waste generation) and express them in a single unit, i.e. megajoules.

Data on current practice of substrate production and mushrooms cultivation are collected by interviews with industrial partners and collaborating scientists from food processing who quantify the environmental impact of all activities and processes in the mushroom supply chain. Some indicative data are given in Table 4.2 and Table 4.3.

Table 4.2 Average revenues, variable costs, profit and exergy losses associated with mushroom production

\begin{tabular}{llcll}
\hline & $\begin{array}{l}\text { Average revenues } \\
(€ / \text { ton substrate })\end{array}$ & $\begin{array}{l}\text { Average costs } \\
(€ / \text { ton substrate })\end{array}$ & $\begin{array}{l}\text { Profit } \\
(€ / \text { ton substrate })\end{array}$ & $\begin{array}{l}\text { Exergy loss } \\
\text { (MJ/ton substrate) }\end{array}$ \\
1st flush & 270 & 96 & 174 & 6.07 \\
2nd flush & 437 & 122 & 315 & 6.10 \\
3rd flush & 497 & 160 & 337 & 6.11 \\
\hline
\end{tabular}

Table 4.3 Average variable costs associated with substrate production and exergy losses production per ton of substrate

\begin{tabular}{lcc}
\hline Types of substrate & Variable costs $(€ /$ ton substrate) & Exergy (MJ/ton substrate) \\
Current (production) & 80.2 & 5.91 \\
Reused compost & 79.6 & 5.82 \\
Recycled casing soil & 70.7 & 5.94 \\
Reused compost and recycled casing soil & 70.1 & 5.79 \\
\hline
\end{tabular}

To assess the effects of individual technological innovations and potential investment decisions we used the model to calculate an optimal logistical structure in 5 different scenarios (Table 4.4). 
Table 4.4 Investigated scenarios

\begin{tabular}{llllll}
\hline Scenario & 1 & 2 & 3 & 4 & 5 \\
\hline Opening phase 1 production in factory 1 & & $\checkmark$ & $\checkmark$ & $\checkmark$ & $\checkmark$ \\
Opening casing production in in factory 2 & & $\checkmark$ & $\checkmark$ & $\checkmark$ & $\checkmark$ \\
Reusing spent mushroom compost for compost production & & & $\checkmark$ & & $\checkmark$ \\
Recycling spent mushroom compost for casing production & & & & $\checkmark$ & $\checkmark$ \\
\hline
\end{tabular}

Scenario 1 refers to the base case scenario and corresponds to the current structure of the mushroom supply chain. The structure of the factories, i.e. not existing phase 1 compost production in factory 1 and not existing casing soil production in factory 2, imply that all raw materials for compost production need to be transported to factory 2 for phase 1 , and subsequently (after the mixing phase) some phase 1 compost is transported to factory 1 for phases 2 and 3. Analogously, all raw materials for casing soil production are transported to factory 1 and after mixing, the casing soil is transported to all mushroom growers. In scenario 2 it is investigated what is the impact of opening phase 1 production in factory 1 , and opening casing soil production in factory 2 . Scenario 3 investigates the potential added value of reusing spent mushroom compost, and scenario 4 investigates the benefit of recycling the spent mushroom compost.

\subsection{Results}

The primary objective is to demonstrate how the model can be used to explore the effects of applying closed loop principles on the economic and environmental performance of the mushroom supply chain. This section presents the optimization results.

\subsubsection{Multi-objective optimization}

To increase awareness of decision makers regarding trade-offs between economic and environmental objectives, and to provide insights into costs associated with improving environmental performance we derive a set of Pareto-optimal solutions for which it is impossible to improve one objective without worsening the other.

The set of Pareto-optimal solutions in multi-objective optimization can be calculated using the $\varepsilon$-constraint method (Ehrgott 2005). To quantify the set of efficient solutions, one of the objective functions is optimized while the other objective functions are represented by goal constraints. The efficient solutions are obtained by parametrical variation of the right hand side of the goal constraints. An important advantage of the $\varepsilon$-constraint method is that non-extreme solutions for the original multi-objective problem are generated. For the problem considered here, the Pareto-optimal solutions are generated by minimizing the environmental objective and varying parametrically (in 10 iterations) a lower bound on the profit objective function value in the constraint set. This is performed for each scenario. The developed model was solved using Xpress-IVE version 7.2. The sets of Pareto-optimal solutions for each considered scenario are presented in Figure 4.3. 


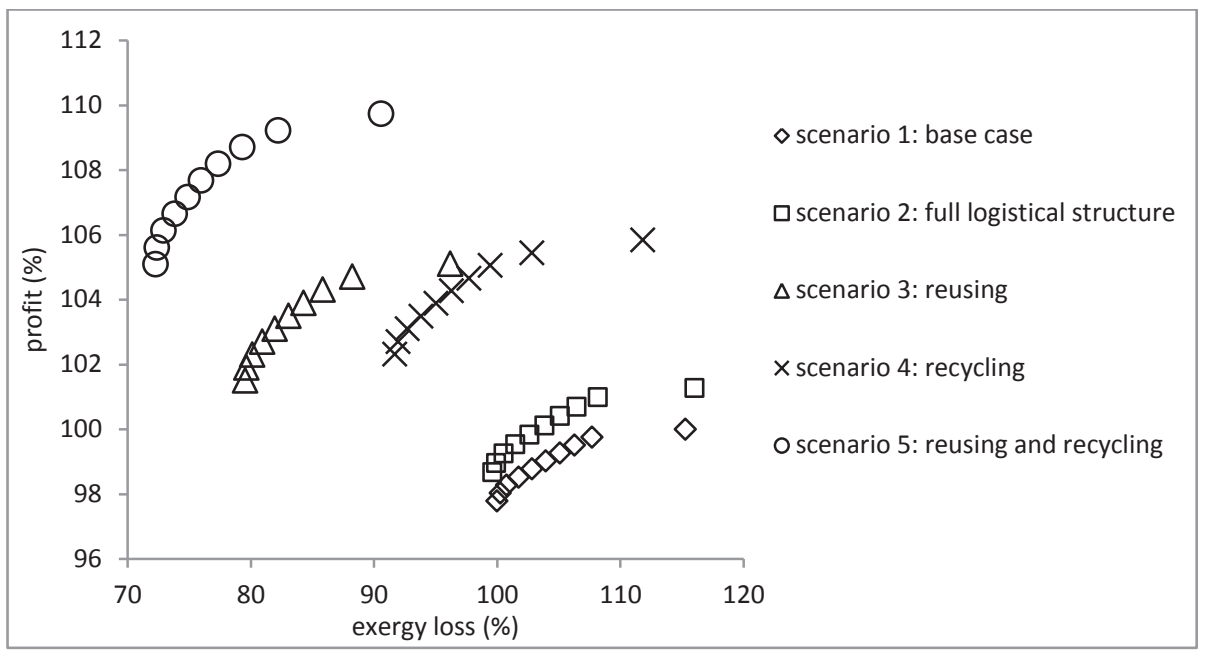

Figure 4.3 Pareto-optimal solutions for the mushroom supply chain; values on the axes are given as compared to best environmental and best economic solutions of the base case

The derived Pareto solutions for each considered scenario represent the trade-off relationship between profit and cumulative exergy losses. For each scenario it is observed that mushroom growers gradually change from cultivating mostly three flushes for best environmental solution, to cultivating two flushes for best economic solution. Additionally, for scenarios 3, 4, and 5, where recycling or reusing waste material is allowed, we observe a gradual change in the amount of recycled or reused material, i.e. the more environmentally friendly the solution, the lower the absolute value of amount of product recycled or reused. The reason is that more environmentally friendly solutions require lower amounts of substrate (substrate is used for three instead of two flushes). Lower substrate requirements result in less recovered material. Nevertheless, the total amount of waste produced decreases with improving the environmental impact expressed in cumulative exergy losses.

Additionally, the illustration of Pareto solutions for each scenario visualises what the quantified benefits are for potential changes in the design of the supply chain. Comparisons of the Pareto solutions show that allowing recycling and reusing spent mushroom compost provides the most promising solutions. For this case study we observe that the possibility to valorise waste material from mushroom production (scenarios 3, 4, 5) brings substantially larger benefits compared to an alternative logistical structure as considered by the industry (i.e. in scenario 2 ). It can be observed that every efficient solution for the scenarios 3 and 5 is better with respect to both: the economic and environmental objectives compared to all solutions in the scenarios 1 and 2 .

It should be mentioned that scenario 2 introduces two aspects simultaneously, i.e. opening phase 1 facility in factory 1 , and opening casing soil production in factory 2 . We observe that the shift of the trade-off curve upwards is caused primarily by opening phase 1 facility in factory 1 , and opening casing soil production in factory 2 only provides for a marginal improvement, i.e. opening casing soil production in factory 2 in addition to scenario 1 improves 
the best economic solution of scenario 1 by $0.01 \%$, and the best environmental solution is comparable to scenario 1 .

The set of efficient solutions provides managerial insights as it ensures finding a solution compromising economic and environmental objectives. Based on the efficient solutions the costs of improving the environmental performance in the analysed supply chain can be calculated. As can be observed, for instance, in the base case the environmental impact of the best economic solution can be improved by $10 \%$ at the expense of $1 \%$ profit. Additionally, the trade-off curve can serve as a tool to analyse how much money can be invested in technological innovations focusing on reusing and recycling the waste materials.

\subsubsection{Single objective optimization}

Each scenario of the model is optimized with respect to one objective at a time to examine the best economic and environmental solutions. This is done to investigate the differences between different solutions with respect to the amount of compost cultivated and waste produced. The results of the model are summarized in Table 4.5.

Table 4.5 Summary results for each scenario when optimizing each considered objective separately

\begin{tabular}{|c|c|c|c|c|c|c|c|c|c|c|}
\hline \multirow[b]{2}{*}{ 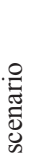 } & \multicolumn{5}{|c|}{ Profit maximization } & \multicolumn{5}{|c|}{ Exergy loss minimization } \\
\hline & $\begin{array}{l}\text { Compost } \\
\text { cultivated } \\
\text { (tons) }\end{array}$ & $\begin{array}{l}\text { Waste } \\
\text { produced } \\
\text { (tons) }\end{array}$ & $\begin{array}{l}\text { Share } \\
\text { of } 1^{\text {st }} \\
\text { flush }\end{array}$ & $\begin{array}{l}\text { Share } \\
\text { of } 2^{\text {nd }} \\
\text { flush }\end{array}$ & $\begin{array}{l}\text { Share } \\
\text { of } 3^{\text {rd }} \\
\text { flush }\end{array}$ & $\begin{array}{l}\text { Compost } \\
\text { cultivated } \\
\text { (tons) }\end{array}$ & $\begin{array}{l}\text { Waste } \\
\text { produced } \\
\text { (tons) }\end{array}$ & $\begin{array}{l}\text { Share } \\
\text { of } 1^{\text {st }} \\
\text { flush }\end{array}$ & $\begin{array}{l}\text { Share } \\
\text { of } 2^{\text {nd }} \\
\text { flush }\end{array}$ & $\begin{array}{l}\text { Share } \\
\text { of } 3^{\text {rd }} \\
\text { flush }\end{array}$ \\
\hline 1 & 339383 & 339383 & $1 \%$ & $96 \%$ & $3 \%$ & 294157 & 294157 & $2 \%$ & $18 \%$ & $79 \%$ \\
\hline 2 & 343029 & 343029 & $1 \%$ & $97 \%$ & $3 \%$ & 294157 & 294157 & $2 \%$ & $18 \%$ & $79 \%$ \\
\hline 3 & 357502 & 220900 & $0 \%$ & $97 \%$ & $3 \%$ & 295036 & 183145 & $3 \%$ & $19 \%$ & $79 \%$ \\
\hline 4 & 360348 & 321575 & $1 \%$ & $97 \%$ & $3 \%$ & 294498 & 263515 & $2 \%$ & $18 \%$ & $79 \%$ \\
\hline 5 & 372519 & 190119 & $1 \%$ & $97 \%$ & $2 \%$ & 295448 & 152740 & $3 \%$ & $19 \%$ & $78 \%$ \\
\hline
\end{tabular}

\subsubsection{Economic objective maximization}

When the economic objective is maximized, we observe that in the optimal solutions for each scenario all mushroom growers cultivate mainly two flushes of mushrooms to maximize the overall profit of the supply chain. In scenario 2, where the impact of opening additional facilities is investigated, we observe that the economic objective is improved by $1.3 \%$ compared to scenario 1 . This is primarily due to increased capacity that allows producing more substrate. It enables mushroom growers to produce more mushrooms in seasons of peak mushroom prices. As observed in Table 4.5, the amount of compost cultivated has increased by over $1 \%$. We also observe a decrease in costs associated with transportation of compost and casing soil to growers by $24 \%$. In scenario 3 , which allows to reuse the bottom layer of spent mushroom compost for compost production, the total profit in the supply chain for the best economic solution increases by $5.1 \%$ compared to the base case. The majority of compost produced includes spent mushroom compost as a raw material $(83 \%)$ and the total amount of waste produced decreases by $35 \%$ compared to scenario 1 . Recycling spent casing soil (studied in scenario 4) improves the best economic solution by $5.8 \%$ compared to scenario 1 . This improvement is due to a substantial reduction of required (expensive) raw materials for casing production, and as a result 
total costs of raw materials are $23 \%$ lower than in scenario 1 (compared to $8 \%$ reduction of raw material costs in scenario 3). The total amount of waste produced is $5 \%$ lower compared to scenario 1 . In scenario 5 , the best economic solution is improved by $11 \%$ compared to scenario 1 , and the total amount of waste produced, i.e. spent mushroom substrate, is reduced by $44 \%$.

\subsubsection{Environmental objective minimization}

Results presented in Table 4.5 show that mushroom growers cultivate mainly three flushes of mushrooms in each considered scenario to minimize the environmental impact. This is due to a large value of chemical exergy of waste material. Minimizing cumulative exergy losses forces mushroom growers to reduce the total amount of waste. In the scenarios 1 and 2 , all components except exergy losses for transportation, remain at the same level. In scenario 2 (including the possibility to use all facilities for the production of phase 1 compost and casing), transportation exergy losses decrease by $17 \%$ resulting in $1 \%$ decrease of the optimal objective function value. Total exergy losses in scenario 3 decrease by $20 \%$ compared to scenario 1 , and the greatest improvement is associated with the possibility to avoid chemical exergy losses. Total chemical exergy of disposed material is reduced by $39 \%$ compared to the best environmental solution in scenario 1 . The best environmental solution in scenario 4 is improved by $8 \%$ compared to scenario 1 . Exergy losses associated with waste production are reduced by $10 \%$ compared to scenario 1 , whereas the greatest relative improvement in exergy losses is associated with transportation of raw materials, and amounts for a decrease of $26 \%$. The best environmental solution in scenario 6 improves compared to the one in scenario 1 by $28 \%$, and the total amount of waste produced decreases by $48 \%$. These figures show how large the benefits can be of applying the concepts of circular economy to an FSC with respect to economic performance and environmental impact.

We note that the amount of substrate produced differs greatly depending on the overriding objective. This difference is a result of mushroom growers' decision concerning the number of flushes. It is observed that in all environmental solutions mostly three flushes are used, and in all economic solutions two flushes are used to cultivate mushrooms.

\subsubsection{Sensitivity analysis}

Sensitivity analysis is conducted to explore the effects of possible changes in input parameters for the current logistical structure of the mushroom supply chain, i.e. scenario 1 in the previous section. Based on discussions with industrial partners, sensitivity analysis is conducted on the most relevant technical and monetary parameters that are associated with 1) uncertainty, i.e. yield for mushrooms per ton of substrate $\left(p d_{c, a}\right)$, and mushroom demand $\left(d_{j, t}\right)$; and 2$)$ expected change in the (near) future, i.e. spent mushroom substrate disposal costs $\left(t c h_{j}\right)$, prices of raw materials $\left(c o_{r, i}\right)$, and mushroom selling prices $\left(p p_{c, t}, p s_{c, t}, p l_{c, t}\right)$.

Effects of change in technical parameters: Due to observed fluctuations in mushroom yields per ton of substrate it was advised to investigate the sensitivity of solutions for different levels of this parameter. The total yield was varied between decrease and increase of $10 \%$, which corresponds to the fraction of low quality mushrooms in the base case. The findings presented 
in Table 4.6 show that in the economic solution an increase in productivity entails more production of compost. This results in higher environmental impact compared to the base scenario because more waste is produced. On the contrary, a reduction of compost cultivated is observed until the productivity decreases by $3 \%$. For a larger decrease, the amount of compost cultivated increases due to the need of fulfilling the demand for mushrooms. In the environmental solution, higher productivity allows reducing the amount of substrate cultivated to meet the demand. Nonetheless, the shape of the Pareto frontier is not affected.

In line with the observation that 3-flush cultivation, which is associated with highly uncertain yields, is more environmentally friendly compared to 2-flush cultivation, we investigated the required increase in these yields, such that the majority of compost in the best economic solution is cultivated for three flushes of mushrooms. It is observed that increase in the yields in the third flush by $16 \%$, which corresponds to only $2 \%$ increase in total yield, entails the increase in share of the third flush cultivation to $62 \%$. This results in $8 \%$ decrease in exergy losses of the best economic solution, showing that the environmental performance can be improved substantially due to an increase of the yield in the third flush. It is concluded that yields of substrate have a major impact on the economic and environmental performance of the mushroom supply chain.

The impact of a change in the demand data is examined by varying this parameter's value between $10 \%$ increase and decrease, what corresponds to the (maximal) yearly annual variations in this data. Results presented in Table 4.6 suggest that the examined changes in demand do not affect the solutions substantially, but result in a shift of the Pareto frontier.

Effects of change in monetary parameters: Changes in price parameters do not affect the best environmental solution. The results are therefore discussed only for the best economic solution.

Industrial partners were keen on investigating the consequences of the expected increase in disposal costs (associated with transportation), and the increase in raw material costs. We found that even a large $(100 \%)$ increase in these costs does not have a major impact on the production plan, although, as expected, substantially reduces the total profit. The reduction in the total profit due to expected increase in costs strengthens the need for more (research on) technological innovations that aim to reduce the amount of disposed waste, and aim to reduce the amount of ingredients required for production. Such technological innovations will reduce the economic effects of increase in costs, and at the same time will contribute to improvement of environmental performance by producing less waste. 
Table 4.6 Results for sensitivity analysis

\begin{tabular}{|c|c|c|c|c|c|c|}
\hline & \multicolumn{6}{|c|}{ Profit maximization } \\
\hline & $\begin{array}{l}\text { Economic } \\
\text { objective }\end{array}$ & $\begin{array}{l}\text { Environmental } \\
\text { objective }\end{array}$ & $\begin{array}{l}\text { Compost } \\
\text { cultivated } \\
\text { (tons) }\end{array}$ & $\begin{array}{l}\text { Share of } \\
1^{\text {st }} \text { flush }\end{array}$ & $\begin{array}{l}\text { Share of } \\
2^{\text {nd }} \text { flush }\end{array}$ & $\begin{array}{l}\text { Share of } \\
3^{\text {rd }} \text { flush }\end{array}$ \\
\hline base case & 1.00 & 1.15 & 339383 & $1 \%$ & $96 \%$ & $3 \%$ \\
\hline $10 \%$ total yield increase & 1.14 & 1.28 & 375056 & $1 \%$ & $96 \%$ & $4 \%$ \\
\hline $10 \%$ total yield decrease & 0.85 & 1.20 & 354331 & $2 \%$ & $95 \%$ & $3 \%$ \\
\hline $10 \%$ demand increase & 1.10 & 1.23 & 360991 & $1 \%$ & $95 \%$ & $4 \%$ \\
\hline $10 \%$ demand decrease & 0.90 & 1.08 & 316775 & $1 \%$ & $96 \%$ & $3 \%$ \\
\hline $10 \%$ selling price increase & 1.24 & 1.29 & 378178 & $1 \%$ & $95 \%$ & $4 \%$ \\
\hline \multirow[t]{3}{*}{$10 \%$ selling price decrease } & 0.77 & 1.09 & 319431 & $1 \%$ & $96 \%$ & $3 \%$ \\
\hline & \multicolumn{6}{|c|}{ Exergy loss minimization } \\
\hline & $\begin{array}{l}\text { Economic } \\
\text { objective }\end{array}$ & $\begin{array}{l}\text { Environmental } \\
\text { objective }\end{array}$ & $\begin{array}{l}\text { Compost } \\
\text { cultivated } \\
\text { (tons) }\end{array}$ & $\begin{array}{l}\text { Share of } \\
1^{\text {st }} \text { flush }\end{array}$ & $\begin{array}{l}\text { Share of } \\
2^{\text {nd }} \text { flush }\end{array}$ & $\begin{array}{l}\text { Share of } \\
3^{\text {rd }} \text { flush }\end{array}$ \\
\hline base case & 0.98 & 1.00 & 294157 & $2 \%$ & $18 \%$ & $79 \%$ \\
\hline $10 \%$ total yield increase & 1.10 & 0.90 & 264163 & $2 \%$ & $5 \%$ & $93 \%$ \\
\hline $10 \%$ total yield decrease & 0.84 & 1.16 & 340179 & $2 \%$ & $59 \%$ & $39 \%$ \\
\hline $10 \%$ demand increase & 1.08 & 1.14 & 335441 & $2 \%$ & $55 \%$ & $43 \%$ \\
\hline $10 \%$ demand decrease & 0.88 & 0.89 & 261470 & $2 \%$ & $5 \%$ & $93 \%$ \\
\hline
\end{tabular}

It is observed that changes in selling prices entail the shift of Pareto frontier (upwards for price increase, and downwards for price decrease). While the total profit of the chain changes, there are no substantial difference in the shares of different flushes used for mushroom production, and the trade-off relationship between the economic and environmental performance is hardly affected.

\subsection{Discussion}

This chapter presents an example of a closed-loop agri-food supply chain, where the medium used for growing mushrooms can be recovered and used as a raw material for the production of a new (or alternative) growing medium. To the best of our knowledge, we present the first model for a closed-loop agri-food supply chain, where material used for production, instead of the product itself, is recovered.

The considerations in this chapter differ from traditional closed-loop supply chains. In a framework for a traditional Closed Loop Supply Chain (CLSC), products or materials after usage are returned by the customer, and subsequently reused, repaired, refurbished, disassembled and serviced, remanufactured or recycled (Bloemhof and van der Vorst, 2014). Such a general class of CLSCs does not fit agricultural products as most of the components cannot be reused or recycled (i.e. food is consumed). Instead, production inputs, which are 
related to agri-food products, can provide potential to close a nutrient cycle. Consequently, the framework for CLSCs needs to be adjusted to fit the agri-food products.

Agri-food supply chains stretch from agricultural producers to consumers, and may comprise multiple actors (Bloemhof and van der Vorst, 2014; Akkerman et al., 2010). Traditionally, agrifood supply chains involve three main stages as presented: (i) raw material providers, (ii) manufacturing and (iii) retailing to consumers. Transportation is involved throughout the chain in order to transfer raw materials from suppliers to manufacturers, and final agri-food products from manufacturers to consumers. In general, food waste occurs primarily in the beginning and at the final stage in a supply chain. Although valorisation options are available for food waste (including e.g. energy and animal feed production) and provide for waste reduction, these options do not correspond to the concept of a CLSC in which after-use materials are recovered in the same chain. For this reason we exclude food waste arising at stages associated with raw material providers and retailing to customers, and solely focus on waste reduction at manufacturing stages which correspond to the recovery of components in material flows for production.

Closing the loops in agri-food supply chains involves adaptation of new processing technologies that focus on valorising waste streams and by-products. In this sense, the design of a CLSC involves additional processing steps that increase complexity compared to traditional agri-food supply chains. Figure 4.4 proposes a general structure of closed loops in agri-food supply chains. The middle part of the figure may comprise multiple manufacturing stages $(k=1, \ldots, K)$ depending on a specific supply chain, including producers, growers, distribution centres, etc. Each manufacturing stage results in an intermediate product. Moreover, each manufacturing stage $k$ can comprise alternative production options $\left(M_{k}\right)$, e.g. in this chapter four alternative production options to produce substrate are considered: 1) no recovered material 2) reused waste for compost production, 3) recycled waste for casing production, 4) reused waste for compost production and recycled waste for casing production. Production options can take place in various locations, and each alternative production option can be associated with different characteristics, e.g. production time, costs, and environmental impact. After the final manufacturing stage, the food products are distributed to consumers, and the material used for production (e.g. a growing medium) is typically disposed. The downstream supply chain in the figure represents wholesalers, retailers, and consumers. The main difference compared to a framework for a CLSC is that (recoverable) end-of-life products arise not from the customers, as in discrete part industry, but from any of the manufacturing stages. 


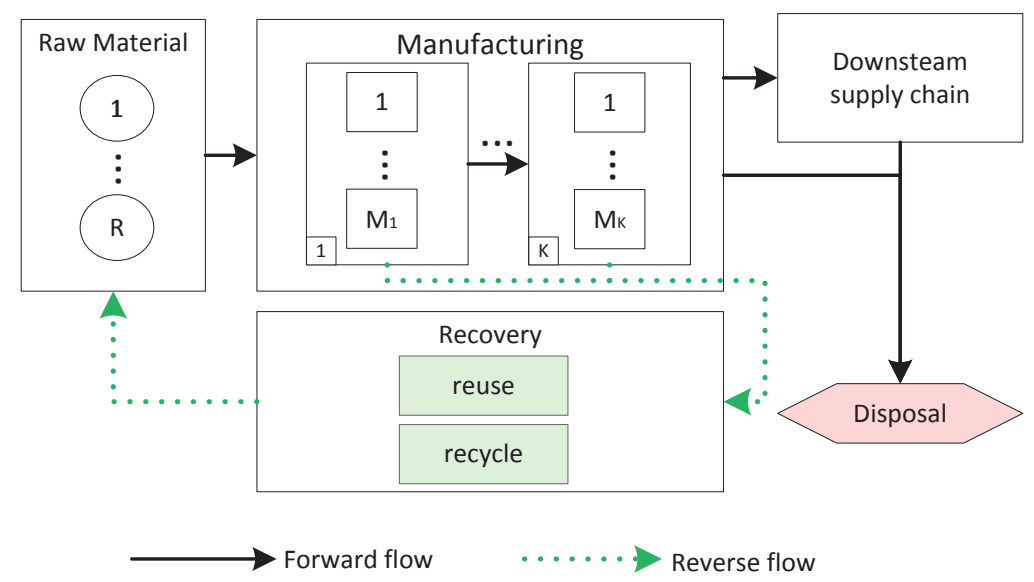

Figure 4.4 Overview of an agri-food (closed-loop) supply chain

New developments and technologies emerge that are able to process waste material from agrifood production into new materials that can be used for production in the same chain. Therefore, in a closed-loop agri-food supply chain recovery stages exist, such as reuse, in which waste material is used directly in the same chain, or recycling, in which waste material is used again after some processing steps. These recovery stages, therefore, provide input in the form of raw materials for other stages by converting waste into usable new (raw) materials. Bread production can be given as an example where wasted bread loafs are recycled by treatment with enzymes, and subsequently used as a raw material in production replacing some of the ingredients (see e.g. Chapter 3 or Zisopoulos et al. (2015)). Another example providing an opportunity to close a mineral cycle concerns production of white sugar from sugar beet. Byproducts from sugar production can be processed (i.e. recycled) and used as fertilizers to supply minerals for growing sugar beets (Kolfschoten et al., 2014). Additionally, as given in this chapter, part of the medium used for growing mushrooms can be recovered (i.e. reused and recycled) and used as a material for production of new growing medium.

\subsection{Conclusions}

The large amount of losses in food manufacturing industry encourage industries to apply concepts of circular economy, such that all materials are valorised and waste is eliminated by using it in new products and applications (Mirabella et al., 2014). Despite the vast body of literature on closed-loop supply chains, to the best of our knowledge no publications exist that present decision support models to evaluate economic and environmental benefits of closing loops in an agri-food supply chain.

The main contribution of this study is the development of a multi-objective model for production and distribution planning in industrial mushroom production, with a particular focus on the valorisation of waste in the form of a closed-loop supply chain. The mushroom supply chain illustrates potential benefits of applying concepts of circular economy in food production. The presented closed-loop mushroom supply chain fills the gap identified by Mirabella et al. 
(2014), on the need for specific case studies related to logistical concerns of industrial symbiosis. By using realistic data, which is usually not the case in literature on sustainable supply chain management (Seuring, 2013), we show that opening new facilities has the potential to improve both the economic and the environmental performance. The greatest benefits and win-win solutions, however, from both economic and environmental perspective are brought in scenarios that focus on using materials to their full potential by valorising waste streams as much as possible. With all (potential) technological innovations that allow for reusing and recycling the waste stream in mushroom production, economic and environmental performance can be improved by $11 \%$, and $28 \%$ respectively. The presented case study illustrates that it is worthwhile to invest in research on technological innovations (and their development) for closing loops in agri-food supply chains.

In contrast to closed-loop studies in discrete parts industry, in agri-food supply chains the value of the final products itself cannot be regained (i.e. food is consumed). Instead, value of spent components used for production can be recovered. These spent production components may arise in any of the manufacturing stages. Therefore, decision support models for closed-loop agri-food supply chains require very specific characteristics. However, if more case studies on closed-loop agri-food supply chains are available, it may be possible to generalize the developed decision support model to be applicable to a more general class of closed-loop agrifood supply chains. Moreover, more case studies are needed to confirm or further adapt the proposed framework for a closed-loop agri-food supply chain.

In the developed model all data are assumed to be deterministic. In real-world optimization problems, however, the data are not exactly known at the time the problem is being solved. To deal with uncertainty in parameters, sensitivity analysis was performed to investigate the impact on the solutions. Future research can include stochasticity in parameters to arrive at solutions that optimize the expected value of the objective functions. It will then be possible to examine the impact of uncertainty on each link of the chain and on the Pareto-optimal solutions.

New processes in the agri-food supply chain, which are associated with recovering materials, mean that more activities need to be carried out and (more) actors will have a different role in the production process. These new closing loop structures, therefore, give the potential of additional employment and income of societies, and can impact other representative indicators for the social dimension of sustainability in an agri-food supply chain. This social aspect of sustainability requires further investigation and can be considered in future studies.

Environmental impact is expressed in this study in exergy losses. Using this environmental indicator enables to consider multiple indicators simultaneously, at the same time simplifying the calculation of the Pareto frontier, and enabling its intuitive graphical representation, which is much easier to communicate to the involved decision makers.

To conclude, this study serves as an illustration on how decision support models can be used to quantify the benefits of potential innovations that focus on the application of concepts of circular economy. Careful planning and designing of closing the loops is essential, and decision 
support models that optimize simultaneously managerial decisions at strategic and tactical level are required (Mota et al., 2015a) to comprehensively evaluate the impact of closing these loops. 

Chapter 5

\section{Accounting for uncertainty in eco-efficient agri-food supply chain: a multi-objective two-stage stochastic optimization model for mushroom production planning}

This chapter is based on the submitted journal article (under review):

A. Banasik, A. Kanellopoulos, J. M. Bloemhof-Ruwaard, G.D.H. Claassen Accounting for uncertainty in eco-efficient agri-food supply chain: a multi-objective two-stage stochastic optimization model for mushroom production planning 


\begin{abstract}
Until recently, food production focused mainly on delivering high quality products at low costs and hardly paid attention to environmental impact and depletion of natural resources. Due to the growing awareness of climate change, shrinking resources, and increasing world population, this trend is changing. Multi-objective optimization models have been proposed in literature to quantify trade-offs between conflicting objectives and to derive eco-efficient solutions, i.e. solutions for which environmental performance can only be improved at higher costs. Often these models are developed under the assumption that all information required for model parameterization is known in advance. In practice, however, not all the required information is available in advance due to various sources of uncertainty in food supply chains. In this research a multi-objective two-stage stochastic programming model is proposed to analyse and evaluate the economic and environmental impacts to account for uncertainty in agri-food supply chains. A mushroom supply chain in the Netherlands is presented as an illustrative case study. Optimal production planning decisions calculated with a two-stage stochastic programming model are compared with the results of an equivalent deterministic model. It is clearly demonstrated that taking uncertainty into account at production planning phase in an agri-food supply chain can bring substantial economic and environmental benefits.
\end{abstract}




\subsection{Introduction}

Until recently, food production focused mainly on delivering high quality products at low costs and gave only secondary attention, if any, to environmental impact and depletion of natural resources (Soysal et al., 2015). Due to the growing awareness of food losses, shrinking resources, and increasing world population, society puts more pressure on companies to use sustainable practices. To remain competitive, companies in the agri-food sector are challenged to redesign the current logistical structures. Decision support models are needed to evaluate the economic and environmental performance of agri-food supply chains quantitatively. Such evaluations require not only the assessment of environmental and economic performance but also the relationship and trade-offs between these conflicting objectives (Wang et al., 2011). Only a limited number of initiatives for environment-friendly production have proved to be profitable (Quariguasi Frota Neto et al., 2008).

Multi-objective optimization is particularly suitable for finding the best compromise between economic and environmental dimensions of sustainability (Chaabane et al., 2011), and for determining eco-efficient solutions, i.e. solutions in which it is not possible to decrease environmental damage unless increasing costs (Quariguasi Frota Neto et al., 2009). In many cases multi-objective optimization models, developed to support decision making in agri-food chains, are deterministic. This implies that it is implicitly assumed that all model parameters are known in advance. However, in practice not all the required information for parameterization of production planning models is deterministic. Main sources of uncertainty in agri-food supply chains are related to productivity (yields), estimated supply and demand patterns, processing parameters, and prices (Soysal et al., 2012; Ahumada and Villalobos, 2009). Often uncertainty is explored with sensitivity analysis and scenario studies to address what-if questions as done in e.g. Chapter 3, or in Ahumada and Villalobos (2011). However, even in these cases, uncertainty is not included explicitly in the optimization phase. This may lead to calculated production planning decisions, which if implemented, result in lower than expected overall economic and environmental performance. Despite that the importance of accounting for uncertainty in decision support models has been stressed in existing literature (Brandenburg et al., 2014; Ahumada and Villalobos, 2009), to the best of our knowledge there are no studies that quantify the consequences of uncertainty in data including its impact on the overall economic and environmental performance in agri-food supply chains.

The aim of this chapter is to evaluate the impact of uncertainty in agri-food supply chains in a multi-objective context. We investigate the impact of uncertain parameters on optimal economic and environmental solutions, and on the eco-efficient frontier. Particularly in agrifood supply chains, many decisions have to be taken in an early stage while yields, output prices and demand are often revealed later in the production process. To decompose such multiphase production planning decisions in eco-efficient agri-food supply chains we propose a multi-objective two-stage programming model. We use an illustrative real-life mushroom supply chain as a case to demonstrate the potential benefits of treating uncertainty in optimization of production planning decisions in an agri-food supply chain. To compare the 
performance of the generated solutions, a simulation is performed to unravel the different objective values and generated solutions depending on the realization of uncertainty in model parameters.

This chapter is structured as follows: Section 2 presents an overview from literature on publications treating uncertainty in food supply chains and on publications treating uncertainty in multi-objective optimization. Section 3 introduces the case study of a mushroom supply chain, describes the developed bi-objective production planning model, and discusses the data including uncertain model parameters. Section 4 presents the results of the model, and section 5 summarizes the conclusions of the study.

\subsection{Literature review}

Food products are particularly characterized by seasonality, yield variability, products' perishability and high fluctuations in demand and prices (Akkerman et al., 2010; van der Vorst et al., 2009). Food production is therefore unique in its complexity, and optimization models used to support decision making should account for intrinsic characteristics of food production, such as productivity uncertainty and increased risks related to market demands and prices. Despite the increasing use of optimization models in agri-food supply chain planning (see e.g. Brandenburg and Rebs (2015), Brandenburg et al. (2014), Ahumada and Villalobos (2009)), uncertainty in these models is rarely taken into account, as shown in the review of Soysal et al. (2012).

The data in real-world optimization problems are not exactly known at the time the problem is being solved due to inevitable estimation, measurement and implementation errors (Ben-Tal et al., 2009), and incorporating uncertainty in some parameters of the model may lead to a better representation of the actual problem. To deal with uncertain input parameters in models, a number of approaches can be applied. The most popular approaches include Stochastic Programming (SP) and Robust Optimization (RO). Stochastic programming models are used to determine production plans that optimize the expected value of an objective function based on numerous scenarios for realizations of uncertain data. Robust optimization models are used to obtain robust production plans that are less risky, immune to infeasibilities, and less sensitive to realizations of uncertain data. For a detailed description of SP and RO we refer to Birge and Louveaux (2011) and Ben-Tal et al. (2009), respectively.

In SP some data parameters are uncertain, and an accurate probability distribution of these parameters is assumed to be available (Birge and Louveaux, 2011). The aim of SP is to find the best solution depending on the expected value of an objective function. Variations of SP exist in terms of e.g. number of stages, types of recourses, or the inclusion of probabilistic (chance) constraints. The difficulty of considering continuous distributions is often avoided by introducing a discrete set of (limited) scenarios. However, a large number of scenarios may be necessary to accurately resemble the distributions of parameters, and the more scenarios the harder to solve the considered problem to optimality (Keyvanshokooh et al., 2016). Robust Optimization, on the other hand, is applied whenever there is a need for creating robust 
solutions that are immune for uncertainty within the specified intervals. In other words, with $\mathrm{RO}$, the best feasible solution is found for worst case instances of the problem parameters. Robust optimization is therefore particularly appropriate for situations where the decision maker is concerned with the worst case and to find a sharp lower bound on the objective value(s). The benefits of RO include the fact that exact distributions of uncertain parameters are not necessary, and independently on the number of uncertain parameters the (transformed) model remains computationally tractable. In RO uncertain data is assumed to belong to some pre-defined set with no specific probabilistic distribution (Bohle et al., 2010).

The aforementioned approaches to treat uncertainty are hardly applied in food production context. Pauls-Worm et al. (2016) study lost sales in inventory problems for fresh food products with uncertain and fluctuating demand. A stochastic programming model is developed to find order quantities to meet cycle fill rate service requirements while keeping outdating low. Guan and Philpott (2011) present a production planning problem in dairy industry under uncertain milk supply and formulate a multistage stochastic programming model with a linear pricedemand curve. Soysal et al. (2015) develop a chance-constrained programming model with demand uncertainty for a multi-period generic inventory routing problem for perishable products with specific attention to environmental considerations. Borodin et al. (2014) propose a stochastic optimization model for the annual harvest scheduling problem of cereal crop production. A chance constrained optimization model is proposed to minimize the risk of crop quality degradation under meteorological uncertainty. Bohle et al. (2010) propose a modified robust optimization approach to solve an agricultural planning problem of wine grape harvesting subject to uncertain labors harvesting productivity. Munhoz and Morabito (2014) apply a RO approach to an aggregate production planning model for frozen orange juice concentrates to minimize total costs with uncertainty in juice acidity parameters. We observe that stochasticity in production yields, which are highly uncertain in food production, is not considered in the aforementioned studies. Moreover, hardly any of the above mentioned publications take multiple conflicting objectives into account.

Publications treating environmental and economic performance in multi-objective optimization while including uncertainty in parameters in production planning are very scarce. Mirzapour Al-e-hashem et al. (2013) propose a two-stage stochastic programming model for aggregate production planning with quantity discounts in green supply chain with uncertain demand. Environmental performance is embedded in the presented model by limiting the greenhouse gas emission from transportation and waste produced to a predetermined level. Radulescu et al. (2009) assumes an uncertain amount of pollution emissions per unit of product, and formulate two stochastic programming models for production planning: a maximum expected return problem, and a minimum pollution risk problem. Sazvar et al. (2014) propose a multi-stage stochastic programming model to optimize costs and total GHG emissions for a supply chain with deteriorating products under uncertain demand. Amin and Zhang (2013) investigate the impact of demand and return uncertainties on the closed-loop supply chain network configuration using a multi-objective model. A scenario-based stochastic programming approach is used to minimize costs and an environmental objective. The aforementioned 
publications apply multi-objective optimization in supply chains under uncertainty. However, none of the studies consider (fast moving) food products.

There are multiple calls in literature reviews for more stochastic models on realistic case studies e.g. Brandenburg et al. (2014), and Ahumada and Villalobos (2009). To the best of our knowledge there is a lack of publications considering environmental criteria in multi-objective optimization with uncertain parameters to support food production planning decisions. Moreover, the (quantified) impact of treating uncertainty in optimization on different objectives associated with sustainability is still unclear. This chapter contributes to literature by filling in these gaps. We investigate the effect of treating uncertainty in optimization in an agri-food supply chain while considering conflicting economic and environmental criteria. Additionally, our contribution provides for a real life study for a mushroom production planning problem in practice.

\subsection{Illustrative real-life case study}

This section starts with the description of the mushroom supply chain and the associated production planning problem. The presented case study illustrates that production planning decisions in agri-food supply chains need to be made before the actual values of uncertain production and demand parameters reveal. This gives rise to decompose the decision making process into multiple steps, providing therefore a typical example in which multi stage decision making may have an added value above a commonly applied deterministic approach. After the case description, a bi-objective model comprising economic and environmental criteria for the mushroom production planning is given. Subsequently, data used in the model are presented. Finally, the setup of numerical analysis is discussed.

\subsubsection{Case description}

Mushrooms are grown on industrially prepared substrate that consists of two layers: compost as a bottom layer, and casing soil as a top layer. Compost ingredients commonly include horse manure, chicken manure, straw, gypsum, water, and ammonium sulphate. Casing soil is usually produced from peat and limestone. All raw materials for substrate production are processed in substrate producing factories. Production of compost takes place in multiple phases as illustrated in Figure 5.1, and total duration of compost production takes a few weeks. The final product must be produced just-in-time, because compost can be stored for at most 24 hours at factory level and becomes waste afterwards due to biological processes taking place in the compost inoculated with mycelium.

Substrate is transported to mushroom producers who provide for appropriate growing conditions for mushrooms. The same substrate can be used for at most three subsequent flushes of mushrooms due to increasing risks for pests and diseases. Productivity of substrate decreases with each flush. Different mushroom sizes are distinguished based on the cap size, which determines the selling price of fresh mushrooms. After the last harvest, spent mushroom substrate is discarded on agricultural land. Discarding the substrate involves substantial disposal 
costs, mainly associated with transportation costs. Additionally, spent mushroom substrate is rich in nutrients that are wasted once the material is discarded. For instance in the Netherlands over 800000 tons of spent mushroom substrate is produced annually (Phan and Sabaratnam, 2012), and need to be transported hundreds of kilometres just to be used as fertilizer. This shows that activities related to disposal are neither economically nor environmentally attractive.

Mushroom producers commonly cultivate two flushes of mushrooms. Changing over to a three flush cultivation scheme would reduce the amount of disposed substrate, but at the expense of the yearly production yield. Additionally, various sources of uncertainty including production yields and demand patterns, complicate decision making in the mushroom supply chain considerably. The impact of uncertainty and the implications of production planning decisions on environmental and economic performance should be evaluated quantitatively to support effective decision making in practice.

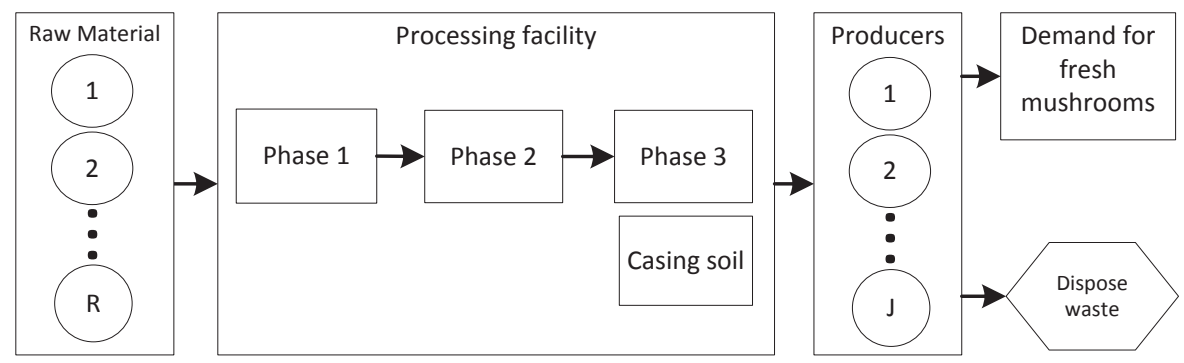

Figure 5.1 A mushroom supply chain

Decision makers in a mushroom supply chain look for ways to optimize interrelated production planning decisions between different links in the chain. Production planning decisions concern the amount of compost produced in each time period under limited production capacity (processing facility), and the amount of compost cultivated in each time period under limited growing capacity (producers). The main objectives include maximization of economic performance expressed by total profit, and minimization of environmental impact expressed by cumulative exergy losses (Apaiah et al., 2006; Kotas, 1995). Exergy losses have been widely accepted to express the environmental impact in various fields, including chemical sectors, construction industries, and food industry (Zisopoulos et al., 2017). The advantage of exergy as an environmental indicator is that it allows to quantify the environmental impact of production activities (including energy consumption, fuel consumption and waste generation) and express them in a single unit, i.e. megajoules.

\subsubsection{Mathematical model for mushroom production planning problem}

A model for production planning in a mushroom supply chain is formulated as a multi-objective linear programming model. The objectives of the model include both an economic and an environmental objective. The model supports production planning and harvesting decisions, i.e. when substrate should be produced and transported to producers, and when to start and finish 
the harvest (i.e. how many flushes to cultivate), such that the production plan will result in the greatest benefits regarding the defined objectives.

We aggregate the two (real-life) production facilities into one, and thus the capacity of the single (aggregated) production facility refers to the total capacity of all substrate facilities. Mushroom producers are also aggregated into a single producer, and thus their growing capacity and demand for mushrooms are combined. For each mushroom size three different selling prices are defined: mushrooms within the specified demand are sold at the highest price, mushrooms produced exceeding the demand are sold at a lower price, and low quality mushrooms are sold to a processing company at the lowest price. Demand for mushrooms is expressed in kilograms and does not depend on mushroom size.

Practitioners emphasized that some of the data to be used in the optimization model are highly uncertain. Firstly, despite all measures taken by the compost production facility to keep the quality of compost standardized, the yield of mushrooms per ton of compost is always different. Exact demand values are neither precisely known.

To treat uncertainty in yield and demand parameters we start from a deterministic model in which expected values of (uncertain) parameters are used. Next, a two-stage stochastic programming model is developed. We follow a common approach to solve the two-stage stochastic programming model by using sample average approximation based on Monte Carlo sampling (Lohndorf, 2016; Birge and Louveaux, 2011). In this method, the expected value of objective function is approximated by solving the problem for a set of scenarios. A discrete set of scenarios is introduced to avoid the complexity of considering continuous distributions.

Any two-stage stochastic programming model comprises first, and second stage decision variables (Birge and Louveaux, 2011). The first stage variables refer to decisions that have to be taken before the actual realization of uncertain parameters are available (Ahmed et al., 2004). After random events have occurred, adjustments can be made by second stage decision variables. In the developed mushroom production planning model first stage variables include the amount of compost cultivated in each time period. Second stage variables, which correspond to decisions that can be postponed until the revealed uncertainty, include the amount of mushrooms sold at each price, size, and period.

\subsubsection{Notation}

For the mathematical description of the model the following notation is introduced:

Indices

$c \quad$ index for the size of mushroom, $c=1, \ldots, C$

$t \quad$ index for time periods, $t=1, \ldots, T$

$a$ index for the age of cultivated compost, $a=1, \ldots, A$

$s \quad$ index for the number of scenarios, $s=1, \ldots, s$ 


\section{Monetary parameters}

$c s_{a} \quad$ variable, labour, and disposal costs per ton of substrate at age $a$

$\quad p l_{c, t} \quad$ selling price of one kilogram of low quality mushrooms size $c$ in period $t$

$p p_{c, t} \quad$ selling price of one kilogram of mushrooms size $c$ fulfilling the demand in period $t$

$p s_{c, t} \quad$ selling price of one kilogram of mushrooms size $c$ exceeding the demand in period $t$

\section{Environmental parameters}
$e_{-} p$
environmental impact associated with producing 1 kilogram of mushrooms
e_w environmental impact associated with disposing 1 ton of spent mushroom compost

Technical parameters
cap_fac capacity of processing facility for compost production
cap_gr capacity of mushroom producer for compost cultivation
$d_{t, s} \quad$ demand for mushrooms in time period $t$ in scenario $s$
$l q_{a} \quad$ fraction of low quality mushrooms at age $a$
p_time processing time of raw materials to produce compost
$p d_{c, t, a, s} \quad$ yield (kg) of mushrooms size $c$ per ton of compost in period $t$ at age $a$ in scenario $s$

\section{Decision variables}

$L_{c, t, s} \quad$ the amount of low quality mushrooms of size $c$ sold in period $t$ in scenario $s$

$M_{c, t, s} \quad$ the amount of premium quality mushrooms of size $c$ sold in period $t$ in scenario $s$

$O D_{c, t, s} \quad$ the amount of surplus mushrooms of size $c$ sold in period $t$ in scenario $s$

$S T P_{t, a} \quad$ the amount of compost disposed in time period $t$ at age $a$

$Z_{t, a} \quad$ the amount of compost cultivated in time period $t$ at age $a$

5.3.2.2 Multi-objective linear programming model

The model presented in this section is a two-stage stochastic programming model with $S$ scenarios. The presented model is also used as a deterministic model by considering only one scenario $(S=1)$ and using expected values for the uncertain parameters $p d_{c, t, a, s}$ and $d_{t, s}$. 


$$
\begin{gathered}
\max \left\{O F_{\text {eco }}=\frac{1}{S} * \sum_{c, t, s}\left(p p_{c, t} * M_{c, t, s}+p s_{c, t} * O D_{c, t, s}+p l_{c, t} * L_{c, t, s}\right)-\sum_{t, a} c S_{a} * Z_{t, a}\right\} \\
\min \left\{O F_{\text {env }}=\frac{1}{S} * \sum_{c, t, a, s} p d_{c, t, a, s} * e_{-} p * Z_{t, a}+\sum_{t, a} e_{-} w * S T P_{t, a}\right\}
\end{gathered}
$$

Subject to:

$$
\begin{array}{ll}
\sum_{k=0}^{p_{-} t i m e-1} Z_{t-k, a} \leq c a p_{-} f a c & \forall t, a=1 \\
M_{c, t, s}+O D_{c, t, s} \leq \sum_{a}\left(1-l q_{a}\right) * p d_{c, t, a, s} * Z_{t, a} & \forall c, \forall t, \forall s \\
L_{c, t, s}=\sum_{a} l q_{a} * p d_{c, t, a, s} * Z_{t, a} & \\
\sum_{c} M_{c, t, s} \leq d_{t, s} & \forall c, \forall t, \forall s \\
\sum_{a} Z_{t, a} \leq c a p_{-} g r & \forall t, \forall s \\
Z_{t, a}=Z_{t-1, a-1}-S T P_{t-1, a-1} & \\
S T P_{t, a}=Z_{t, a} & \forall t \\
S T P_{t, a}=Z_{t, a} & \forall t, \forall a \mid t>1, a>1 \\
& t=T, \forall a
\end{array}
$$

The economic objective $\left(O F_{\text {eco }}\right)$ maximizes total profit. This objective function comprises the following terms: (i) total revenue for selling (premium quality, surplus, and low quality) mushrooms, and (ii) total costs associated with cultivating substrate, including the disposal costs for the transportation of spent mushroom substrate. The environmental objective $\left(O F_{\text {env }}\right)$ minimizes cumulative exergy losses. It comprises the following terms: (iii) exergy losses associated with growing, and (iv) exergy losses associated with the disposal of waste materials.

Constraints (1) ensure compost production capacity at processing level. Constraints (2) and (3) are used to calculate the amount of premium quality, surplus, and low quality mushrooms. Constraints (4) ensure that demand is satisfied by premium quality mushrooms. Constraints (5) ensure that periodic capacity restrictions at the producer level are taken into account. Constraints (6) are recursive constraints, which ensure that the amount of substrate cultivated for mushroom production in a given period is not larger than in the previous period. Constraints (7) and (8) ensure the cultivation of compost stops in the last period of the considered planning horizon, and when compost has been cultivated for the maximal allowed number of days (i.e. after at most three flushes). 


\subsubsection{Data}

Data on substrate production and mushrooms cultivation are provided by industrial partners and collaborating scientists from food processing who quantify the environmental impact of all activities and processes in the mushroom supply chain.

Total duration of compost production in the substrate production facility is 27 days. The processing capacity of compost over 27 days is limited to 44415 tons. Processed compost and mixed casing soil ingredients are transported to the mushroom producer. Ingredients, processing, transportation, and disposal costs account for $229 €$ per ton of compost.

Compost can be cultivated for at most three flushes that are equivalent to 43 growing days. The yield variations over production cycle for each size of mushrooms (small, medium, large) are presented in Figure 5.2. Each flush is associated with a given percentage of low quality mushrooms. Low quality mushrooms are sold to a processing company at a lower price. The amount of low quality mushrooms in the first, second, and third flush, accounts for $5 \%, 10 \%$, and $20 \%$ of yield respectively.

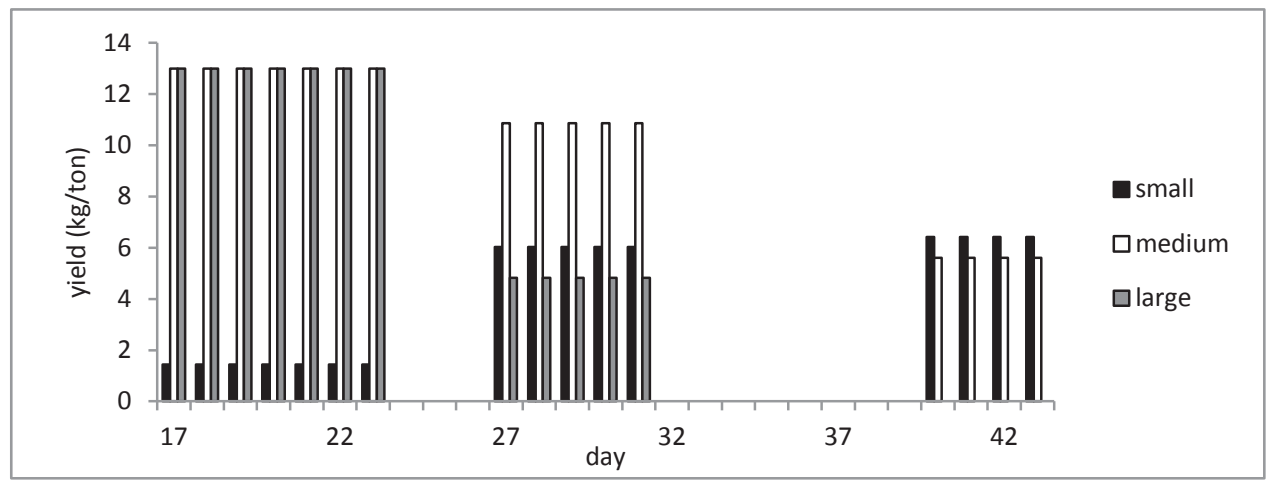

Figure 5.2 Expected yield of small, medium and large mushroom $(\mathrm{kg})$ per ton of compost for maximal duration of a single cultivation round (43 days)

Analysis of historical data, confirmed by chi-squared goodness of fit tests, clearly revealed that yield fluctuations in each flush follow a Gaussian distribution with the following parameters (expressed in kilogram mushrooms/ton of compost per flush): mean yield in the first flush is 192 with standard deviation 17, mean yield in the second flush is 109 with standard deviation 17 , and the mean yield in the third flush is 48 with standard deviation 15 . Uncertainty in yield parameters are assumed to be independent of yields in previous flushes (e.g. the yield in the second flush is independent on the yield in the first flush), and in time periods (e.g. the yield in time $\mathrm{t}$ is independent of yield in time period $\mathrm{t}-1$ ).

The considered time horizon consists of 365 days to capture the variations in prices and demand for mushrooms throughout a year (Figure 5.3). According to domain experts, the demand can deviate from the expected values following a Gaussian distribution with standard deviation of $10 \%$. Uncertainty in demand parameters is assumed to be independent of time periods. 


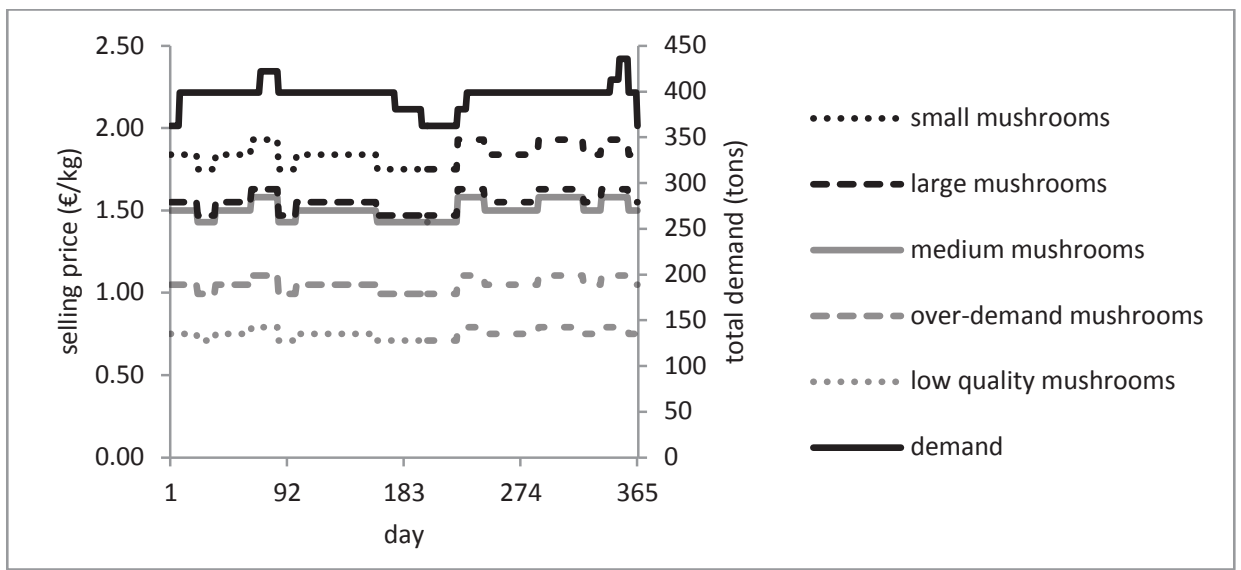

Figure 5.3 Annual fluctuations of prices for small, large, medium, low quality, and over demand mushrooms (primary axis), and expected demand (secondary axis)

Variable and labour cultivation costs for days 1 up to 31 are $3 €$ per ton of compost per day, and for days 32-43 are $5 €$ per ton of compost per day. Additionally, ingredients, processing, transportation, and disposal costs of spent mushroom compost (229€ per ton of compost) are included in variable and labour cultivation costs for the first day of cultivation. The total growing capacity of the (aggregated) mushroom producer is limited to 51975 tons of compost in each time period.

Exergy losses of all activities and processes in the mushroom supply chain have been quantified by collaborating scientists from food processing, and calculations for exergy losses are presented in Zisopoulos et al. (2016). Exergy losses account for 0.3 megajoules per kilogram of grown mushrooms. Exergy losses associated with waste disposal account for 5959 megajoules/ton of spent mushroom compost, and include exergy losses due to transportation and waste stream exergy losses (chemical exergy losses).

\subsubsection{Setup of numerical analysis}

The deterministic and the two-stage stochastic programming models are optimized with respect to the economic and environmental objectives. For the deterministic model the expected values of parameters are used as outlined in the previous subsection. For the two-stage stochastic programming model one hundred scenarios are used to resemble the probability distribution function accurately, and simultaneously to avoid computational difficulty. For each scenario one value is drawn from the given probability distribution functions for each time period for the yields of each flush and for each time period of demand. The optimal objective function values are further referred to as expected values of the deterministic and stochastic model.

After obtaining the solutions for each optimization approach, a simulation is performed to benchmark the generated solutions. Uncertain data parameters are simulated for each time period in 1000 scenarios. The optimal values of first-stage variables are used to examine the objective function values in the simulation. The results obtained from simulations on the 
performance of the objective function values are further called realized values of the objective functions.

To provide insights into costs associated with improving environmental performance we derive a set of efficient solutions for which it is impossible to improve one objective without worsening the other. Efficient frontiers ensure finding a solution that compromises the considered economic and environmental objectives and therefore provide valuable information to decision makers. To obtain efficient solutions we applied the $\varepsilon$-constraint method (Ehrgott, 2005). The efficient solutions for the deterministic problem are generated by maximizing the economic objective, while varying in 10 iterations the allowed level of environmental impact. The same levels of allowed environmental impact were used to derive efficient solutions for the stochastic model.

\subsection{Results}

This section presents the optimization results of the deterministic and the stochastic model as discussed in previous sections. All models are solved using Xpress-IVE version 7.9. The deterministic model comprises 34675 continuous variables and 18960 constraints. The twostage stochastic programming model comprises 359890 continuous variables and 271905 constraints. Optimal solutions for economic performance and environmental impact correspond to a specific production plan, i.e. the amount of compost produced on a given day in the aggregated substrate production facility, the amount of compost cultivated each day at the (aggregated) mushroom producer, and the amount of mushrooms sold at each price level every day.

\subsubsection{Single objective optimization}

According to the results of the deterministic model, compost should be cultivated mostly for two flushes of mushrooms in order to obtain maximal profit. The expected (annual) profit is over 65 million Euros, and corresponds to 3.4 million gigajoules of exergy losses. However, according to the simulation results, the realized value of profit is $3.9 \%$ lower than expected (Table 5.1). The expected profit of the stochastic model turns out to be $1.9 \%$ less compared to the expected profit of the deterministic model, but yields $1.7 \%$ higher realized profit compared to the realized profit of the deterministic model, corresponding to over 1 million euro more profit for the supply chain on a yearly basis. At the same time $4 \%$ more compost is cultivated in the best economic solution obtained for the stochastic model, and therefore this solution is associated with a higher value for exergy losses.

To obtain the best environmental solution, we introduce a lower bound on the amount of profit at $90 \%$ of the best deterministic solution. Results show that the best environmental solution mostly refers to three flushes. Decisions on the number of used flushes determine the total amount of cultivated compost, and therefore also the total amount of waste accounting for the majority of environmental impact. 
Results show hardly any difference in the environmental performance of expected and realized objective function values (Table 5.1). The reason is that the amount of waste, which is not associated with uncertainty in our study, accounts for the majority of environmental impact, i.e. $98.7 \%$ for the best economic solutions found.

Table 5.1 Summary of best economic and best environmental solutions for the deterministic and stochastic models including: expected objective function values, realized objective function values, and amount of compost produced compared to the best economic solution of the deterministic model (shaded cells), and share of each flush in production plans

\begin{tabular}{lccccc}
\hline & \multicolumn{2}{c}{ Profit maximization } & & \multicolumn{2}{c}{ Exergy loss minimization } \\
\cline { 2 - 3 } & $\begin{array}{c}\text { Deterministic } \\
\text { model }\end{array}$ & $\begin{array}{c}\text { Stochastic } \\
\text { model }\end{array}$ & & $\begin{array}{c}\text { Deterministic } \\
\text { model }\end{array}$ & $\begin{array}{c}\text { Stochastic } \\
\text { model }\end{array}$ \\
\hline expected(Profit) & $100.00 \%$ & $98.10 \%$ & & $90.00 \%$ & $90.00 \%$ \\
realized(Profit) & $96.07 \%$ & $97.82 \%$ & & $86.03 \%$ & $89.59 \%$ \\
expected(Exergy loss) & $100.00 \%$ & $104.25 \%$ & & $78.28 \%$ & $82.96 \%$ \\
realized(Exergy loss) & $100.00 \%$ & $104.25 \%$ & & $78.28 \%$ & $82.96 \%$ \\
Compost produced & $100.00 \%$ & $104.25 \%$ & & $78.06 \%$ & $82.81 \%$ \\
& & & & & \\
$2^{\text {nd }}$ flush & $98 \%$ & $97 \%$ & & $18 \%$ & $45 \%$ \\
$3^{\text {rd }}$ flush & $2 \%$ & $3 \%$ & & $82 \%$ & $55 \%$ \\
\hline
\end{tabular}

\subsubsection{Multi-objective optimization}

The sets of eco-efficient solutions for both models (including the best stochastic solution found for the stochastic model), as well as the objective function values based on simulation, are all presented in Figure 5.4.

Each point on the efficient frontier corresponds to a specific production plan, and the extreme solutions of the efficient frontier for the deterministic model are summarized in the previous subsection. It is observed that for each efficient frontier the number of flushes used for cultivation change gradually from mostly two for the best economic solutions, to mostly three for the best environmental solution. This entails a lower amount of cultivated compost resulting in lower environmental impact due to less produced waste.

Simulation results show a substantial reduction of the economic performance for the deterministic cases. The expected profits and the realized profits of the deterministic model (D1 and D2 in Figure 5.4) differ on average by $4.5 \%$. This shows that not accounting for uncertainty in optimization may lead to considerably lower values of economic performance after the values of uncertain parameters reveal. The difference between the expected and realized profit values obtained with stochastic model ( $\mathrm{S} 1$ and $\mathrm{S} 2)$ is on average only $0.3 \%$. 


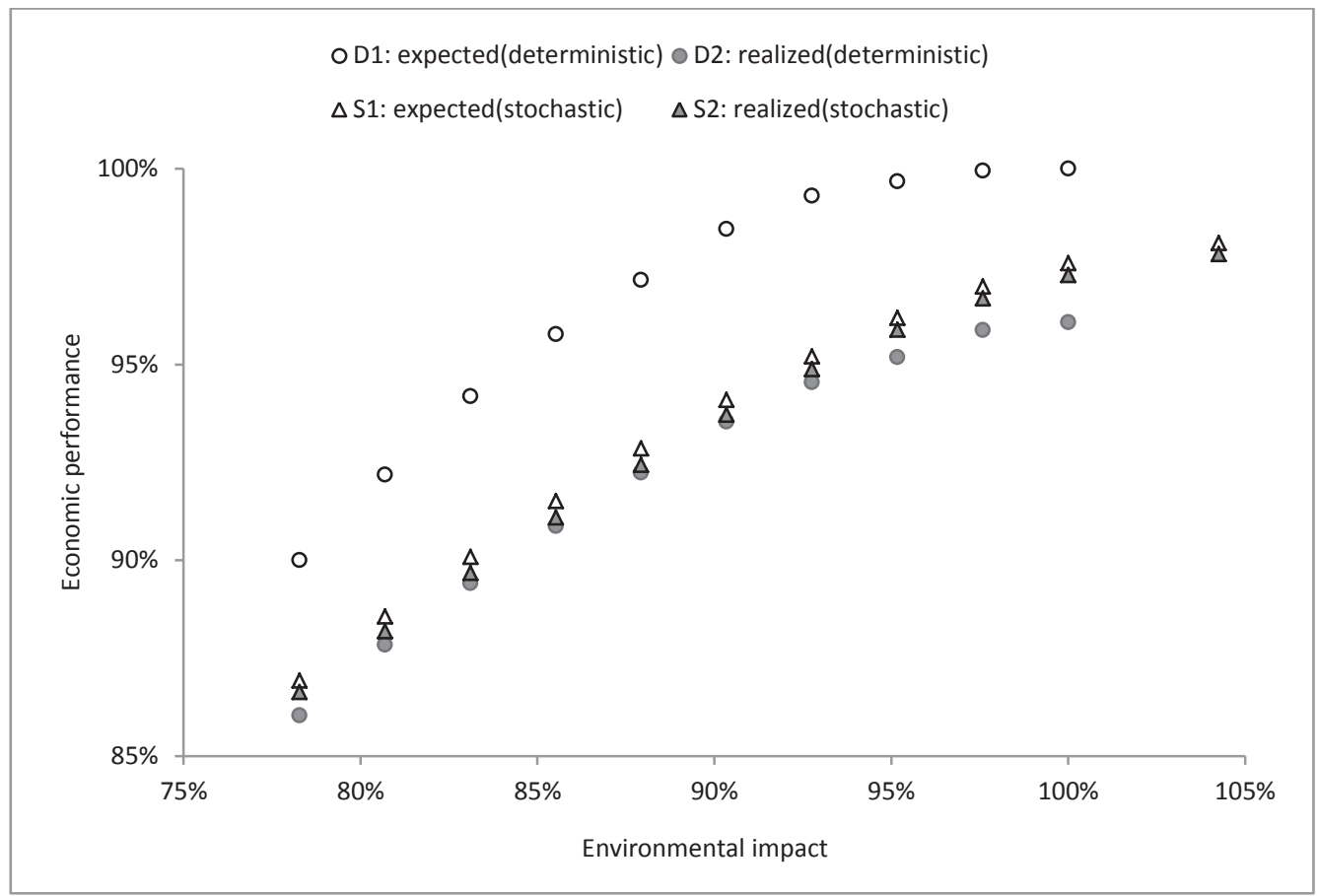

Figure 5.4 Efficient solutions for expected values of objectives functions obtained using deterministic (D1) and stochastic (S1) models; and realized values of objective functions (based on simulation) for deterministic (D2) and stochastic (S2) models

The ten best environmental solutions of D2 and S2 are considered to compare the solutions obtained from the deterministic and stochastic model. The analysis shows that each deterministic solution can be improved by including uncertainty in optimization. The maximum difference between solutions is $1.2 \%$, the minimum difference is $0.2 \%$, and the average difference is $0.5 \%$, which corresponds to over $300000 €$ more profit for the supply chain on a yearly basis. At the same time it can be observed that accounting for uncertainty amounts up to $5 \%$ reduction in environmental impact (i.e. by moving from the best economic solution D2 left until reaching S2 in Figure 5.4).

Eco-efficient solutions allow to quantify the costs associated with improvement of environmental impact. Based on the results in Figure 5.4, it can be calculated that e.g. the environmental impact of the best economic solution obtained with stochastic programming can be improved by $9 \%$ at the expense of $2 \%$ decrease in total profit.

\subsection{Discussion and conclusions}

Due to various sources of uncertainty in agri-food supply chains, not all the required information for optimization is known at the moment that important production planning decisions are made. We confirmed that including uncertain model parameters in agri-food supply chain optimization models is important and can lead to a better representation of the actual decision problem. Based on the numerical results of the case study we conclude that 
using expected (deterministic) parameter values in optimization leads to an overestimated economic performance that will hardly be realized in practice. It is found that accounting for the main uncertain model parameters (i.e. yield and demand) leads to more realistic results, where the solutions of the model are on average much closer to the realized (i.e. after uncertainty has revealed) optimal solutions.

As observed by Dekker et al. (2012), eco-efficient solutions illustrate that improvement of environmental performance comes at a cost, and observe that the use of multi-objective models to derive eco-efficient solutions is rather new. We show how a stochastic multi-objective optimization model can be used to derive efficient solutions for real-life production planning problems. We quantified the stochastic trade-offs between economic and environmental criteria, which can be very different from the corresponding deterministic. Using the stochastic trade-off to support decision making in agri-food supply chains may bring substantial economic and environmental benefits and also a more accurate representation of the trade-off between conflicting objectives. It is therefore concluded that accounting for uncertainty in agri-food supply chains is important, especially when sustainability concerns occur.

In agri-food chains there are situations where infeasibilities are not acceptable, for instance when the demand must be met exactly due to strict periodic delivery contracts with customers, hard restrictions related to quality requirements and safety regulations of perishable products, or in the presence of penalty systems for upper limits on production amounts and the level of environmental impact. In such cases Robust Optimization (RO) is an appropriate approach. Robust optimization provides for solutions that are immune to infeasibilities but are more conservative. In the specific case presented in this chapter, infeasible solutions are hardly an issue as there are no hard constraints on demand (over and under achievement of demand is allowed at different price levels). The conservatism of RO was confirmed in our analysis, in which we assumed a polyhedral uncertainty set for each uncertain parameter (i.e. each uncertain parameter has a value from a pre-specified interval). The solution of such a model turned out to be comparable with the results of a linear optimization problem in which each uncertain parameter was fixed at its worst case value (as presented already by Soyster (1973)). Therefore, RO provided limited added value for the presented mushroom production planning problem. This observation might be very different for other real-life cases in which the achievement of hard constraints are of crucial importance.

This research shows that decomposing decision making into multiple stages has the potential to improve the economic performance of agri-food supply chains. This is because in agri-food supply chains there exists a substantial time lag between production decisions and the revealed uncertainty of production parameters. We provided an example where multistage decision making has an added value above the deterministic approach. Future case based research is needed to confirm the findings in general. It will be interesting to explore which uncertain parameters play a crucial role in other real-life cases, and to examine the impact of other realistic probability distribution functions for those uncertain model parameters. 
Chapter 6

Conclusions and general discussion 



\subsection{Conclusions}

The aim of this thesis is to contribute to improved decision making in Food Supply Chains (FSCs) by developing dedicated multi-objective models to optimize and re-design FSCs by balancing economic and environmental criteria. The emphasis is directed towards the valorization of product flows by means of closing loops and waste management at chain level. In line with the aim of this thesis, the following research questions have been formulated:

RQ1: What is the state of the art and what are the research challenges in MCDM approaches applied to eco-efficient supply chains?

RQ2: What type of MCDM models can be used to evaluate the effects of new technologies and logistical structures on eco-efficiency in food supply chains?

RQ3: What is the added value of using a single metric indicator based on exergy analysis to account for the environmental performance of a food supply chain?

RQ4: What is the impact of including uncertainty of data in optimization models on ecoefficient solutions in a food supply chain?

This chapter starts with providing answers to the research questions, which are addressed in Chapters 2 to 5. Each of the following four subsections in Section 6.1 answers one research question. Section 6.2 presents the integrated findings and discussion. Section 6.3 gives managerial impacts. Section 6.4 provides some challenging directions for future research.

\subsubsection{Research challenges}

RQ1 is addressed in Chapter 2, which focuses on reviewing and identifying research challenges in the field of MCDM approaches applied to support decision making in eco-efficient supply chains. A theoretical framework is developed in Figure 2.1 to find relevant publications and to categorize them with respect to supply chain decision problems, key performance indicators, and the proposed MCDM approach.

Analysis of the literature shows that research on eco-efficient supply chains analysed with MCDM approaches is a relatively new but emerging field. Few publications considered forward and reverse logistics simultaneously to support decision making in a closed-loop supply chain in a multi-criteria context. Not much work has been published in relation to FSCs. Moreover, there is a lack of studies focusing on assessing technological innovations to close loops in FSCs, and no attention has been given to minimization of food waste. Chapter 2 points out that most of the models developed do not take into account stochasticity in parameters despite the inherent uncertainty associated with (food) supply chains, regarding, for example, prices, supply, processing parameters, or demand.

Chapter 2 concludes that despite the growing interest in MCDM approaches to support decision making in eco-efficient supply chains, more attempts to balance economic and environmental criteria in production, distribution, and inventory problems are needed. The study presented 
identifies the need for more multi-criteria models focusing on FSCs, real-life case studies, and inclusion of data uncertainty in optimization models for eco-efficient supply chains.

\subsubsection{MCDM models to evaluate new technologies in FSCs}

RQ2 is addressed in Chapters 3 and 4. These two chapters illustrate how to quantify the effects of new technologies, which allow for waste management and prevention, on the economic and environmental performance of FSCs. Two case studies are considered: Chapter 3 focusses on a bread supply chain and Chapter 4 concentrates on a mushroom supply chain. For each case study, multi-objective models are developed and necessary data for model are collected. The data required for model parametrization include environmental and economic impacts of all processes, including technological innovations and distribution activities. The models developed are used to derive eco-efficient solutions that illustrate the best solutions from an economic and environmental point of view and the quantified trade-off between economic performance and environmental impact.

Chapter 3 presents a mathematical model to quantitatively assess alternative production options that are associated with different ways to deal with food waste, namely disposal, recycling, and prevention of food waste. The multi-objective mixed integer linear programming model developed is applied to a case study of a bread supply chain. Three options to produce a bread product are considered, and each production option is associated with a different way of dealing with waste, i.e. freshly baked bread (waste disposal), fermented breadcrumb bread (waste recycling), and par-baked bread (waste prevention). The results show that prevention of waste is beneficial from an economic point of view for a fraction of all bread types, and is the most beneficial solution from an environmental perspective for all bread types. A shift to par-baked bread production implies that the shelf life of a product can be substantially extended, and this offers a change in the design of a bread supply chain.

Chapter 4 presents a dedicated model to support decision making and to assess alternative production options in a mushroom supply chain. In the mushroom supply chain, new technologies allow for alternative production options to reduce, reuse, and recycle the amount of waste in the form of the growing medium (i.e. spent mushroom compost), which arises due to production of mushrooms. Multi-objective optimization is used to evaluate the effects of these technologies by formulating a set of scenarios and deriving eco-efficient frontiers to explore quantitatively alternative recycling options. It is found that adoption of closing loop technologies has the potential to improve substantially both the economic and environmental performance of the chain. This is achieved by reducing the need for raw materials and reducing transportation.

The case studies presented illustrate the potential of studying food production planning decision problems in a multi-objective context. The models developed provide insights on the assessment of alternative production options and alternative logistical structures. It is concluded that a comprehensive evaluation of recycling technologies and re-designing logistical structures 
requires quantitative tools that optimize managerial decisions simultaneously at strategic and tactical levels.

\subsubsection{Indicator based on exergy analysis to account for environmental performance of an FSC}

In Chapters 3, 4 and 5, the environmental impact is expressed by exergy losses, an indicator based on exergy analysis. Exergy analysis has the potential to capture other commonly used indicators, such as energy consumption, fuel consumption, and waste generation, and express them in a single metric. This allows the environmental impacts of production activities (including energy consumption, fuel consumption and waste generation) to be quantified by a single indicator. The use of a single indicator to quantify the environmental performance of a food chain simplifies the calculation of the eco-efficient frontier, and enables its intuitive graphical representation. This has been proven to facilitate the communication of the results with decision makers in practice.

The case study in Chapter 3 demonstrates that the optimal solutions obtained are different when exergy losses are used as an environmental indicator compared with a scenario in which the most commonly applied indicator, i.e. $\mathrm{CO}_{2}$ equivalents $\left(\mathrm{CO}_{2} \mathrm{e}\right)$, is used. $\mathrm{CO}_{2} \mathrm{e}$ focuses only on particular issues and does not always provide an integrated assessment of environmental impact. Using $\mathrm{CO}_{2} \mathrm{e}$, therefore, may point to solutions that are not environmentally friendly overall. However, using total waste produced as an environmental indicator results in a comparable eco-efficient frontier, whereas total waste produced is the main concern in the case studies considered here. This finding confirms that exergy is able to capture the impact of both waste and energy and provides evidence that exergy analysis offers an objective assessment for environmental impact in the case studies.

\subsubsection{Accounting for uncertainty in optimizing production planning decisions in FSCs}

Chapter 5 proposes a multi-objective two-stage stochastic programming model that enables production planning decisions in FSCs to be decomposed into two phases. Particularly in FSCs, many decisions have to be taken at an early stage, whereas yields, output prices and demand are often revealed later in the production process. Not accounting for these sources of uncertainty in the optimization may lead to production planning decisions that result in lower than expected overall economic and environmental performance. The model developed in Chapter 5 is used to analyse and evaluate the economic and environmental impacts of accounting for uncertainty in FSCs. As a case study, an illustrative real-life mushroom production planning problem is presented in which a substantial time lag exists between production decisions and the revealed uncertainty of production parameters. The illustrative case study demonstrates the potential benefits of treating uncertainty in optimizing production planning decisions in an FSC. It is clearly demonstrated that taking uncertainty into account at the production planning level in an FSC has substantial economic and environmental benefits. 


\subsection{Scientific contribution and integrated findings}

The research presented in this thesis contributes to the scientific literature on eco-efficient FSCs by providing decision support models used by decision makers to assess alternative logistical structures, quantify the economic and environmental implications of closing loop technologies, and improve their economic and environmental performance by closing loops. In the previous section, the answers to the individual research questions are presented. This section provides integrated findings and shows how the overall research objective is attained. The overall research objective of this thesis is to support decision making by developing dedicated multiobjective models to optimize and re-design FSCs by balancing economic and environmental criteria.

A thorough literature review on the new and emerging field of MCDM approaches for ecoefficient supply chains is presented in Chapter 2. This chapter contributes to the scientific literature by identifying research challenges in the study domain. In addition, Chapters 4 and 5 present literature reviews that highlight the gaps and justify the contributions of the studies. These literature reviews clearly show that more applications of multi-objective optimization to real-life case studies are needed to investigate the relationship between the economic and environmental dimensions of sustainability, and that determining eco-efficient solutions with multi-objective optimization models is quite new. Moreover, studies applying multi-objective optimization to eco-efficient FSCs have given little attention to food waste. Qualitative studies are available that identify and prioritize the most appropriate waste management and prevention options (Papargyropoulou et al., 2014), but quantitative evidence on case studies is missing. Furthermore, according to Govindan et al. (2015d) and Stindt and Sahamie (2014), assessments of technological innovations allowing for closing loops in supply chains are rare with respect to multiple criteria of economic and environmental performance. In addition, no studies applying the concept of closed-loop supply chains within the context of food products were found.

\subsubsection{Decision support models for eco-efficient FSCs}

Eco-efficient FSCs require new decision support models that are capable of assessing the impact of alternative production options and technological innovations on economic and environmental performance. The mathematical models used in this $\mathrm{PhD}$ thesis provide decision support tools for production and distribution planning problems. The models are based on known mathematical formulations of lot sizing and location/allocation models, adjusted to make them suitable for the specific problem setting. Chapter 3 formulates a multi-item capacitated lot-sizing model in a multi-objective context. The model is tuned to compare alternative production options to determine different ways of dealing with waste. Chapter 4 combines a location/allocation model and a harvesting planning model to consider the complete supply chain simultaneously. Although the first component of the proposed model (i.e. the location/allocation model) is a well-known concept in Operations Research, the second model component (i.e. the harvesting planning model) has been designed specifically for the mushroom supply chain. In addition, the model has been adjusted to include the possibility of closing a loop. The model developed is used to perform ex ante quantitative assessment of 
technological innovations, which allow valorization of waste, on the economic and the environmental performance of the chain. The optimization models developed in this thesis are used to support managerial decisions for alternative logistical structures that result in lower production costs and environmentally friendly food production.

Food production is intrinsically associated with uncertainty. The impact of uncertainty in supply chain studies is commonly explored by scenario studies or sensitivity analysis, i.e. by investigating the impact of a change in the (uncertain) parameters on the solutions obtained. In these cases, uncertainty is not included explicitly in the optimization phase and may lead to production planning decisions, which, if implemented, would result in lower than expected overall economic and environmental performance. To deal with uncertain input parameters in models, a number of approaches can be applied, such as stochastic programming, fuzzy programming, or robust optimization. Multi-stage stochastic programming is particularly suitable for FSCs, in which a substantial time lag commonly exists between production decisions and the revealed uncertainty of (production) parameters. Decomposing the decisionmaking process into multiple stages, therefore, has an added value above the deterministic approach, in which all decisions are optimized once, i.e. at the beginning of a planning horizon. In Chapter 5, a multi-objective two-stage stochastic programming model is applied to an FSC in which some decisions can be postponed. The results show that accounting for uncertainty in optimizing production planning decisions in FSCs can bring substantial benefits from economic and environmental perspectives. The study presented in Chapter 5 is, to the best of our knowledge, the first attempt to model a production planning problem in a multi-objective context while taking into account yield and demand uncertainty in food production.

All models developed in this thesis are formulated in a multi-objective context to derive sets of Pareto-efficient solutions that are used to inform decision makers on the trade-offs between important economic and environmental criteria. To derive the set of Pareto-efficient solutions, a number of methods are available, as discussed in Chapter 2, including the $\varepsilon$-constraint method, weighted sum method, a multi-objective genetic algorithm, or other heuristics. It is important to identify the appropriate solution approaches based on the problem context and complexity. Pareto-efficient solutions are determined using the $\varepsilon$-constraint method because, unlike the weighted sum method, it is capable of finding all Pareto-efficient points when the solution space is not convex.

This thesis contributes to the scientific literature on MCDM from an application point of view by providing two real-life case studies. In the case studies, the reduction of waste materials produced is enabled by technological innovations. The applicability of the lot-sizing model developed in Chapter 3 is demonstrated on a real-life bread supply chain in the Netherlands. The model is used to assess alternative production options with particular attention to different ways of dealing with the issue of food waste. The location/allocation and harvesting planning model developed in Chapter 4 is tailored to support decision making in an industrial mushroom supply chain in which possibilities exist to recover part of the waste material, thereby reducing the total amount of waste stream produced. This thesis, therefore, contributes to the scientific literature by developing industry-specific FSC models based on real-life case studies and by 
deriving eco-efficient solutions to assess and quantify the effect of alternative production options.

\subsubsection{Closing the loop}

Another area in which this thesis contributes to science is the reduction of food waste by closing the loop. The issue of food waste is addressed in a food waste hierarchy framework proposed by Papargyropoulou et al. (2014). Food waste hierarchy identifies and prioritizes the most appropriate options for prevention and management of food waste. The food waste hierarchy framework concludes that prevention is the most advantageous option from environmental and economic perspectives. Prevention is followed by reuse, recycle, recovery, and disposal, which is the least favourable option for managing food waste. However, quantitative evidence for the food waste hierarchy is missing and it needs to be confirmed. Chapter 3 proposes a model to assess alternative production options associated with different ways of dealing with waste materials. The model developed is applied to a bread supply chain in the Netherlands, and the results confirm the finding of Papargyropoulou et al. (2014) that prevention is the most beneficial option from an environmental point of view, and can also be beneficial from an economic point of view. Moreover, one of the production options in the bread supply chain allows recycling of bread waste and using it as a raw material in bread production. To the best of our knowledge, this feature is the first example in FSCs in which there is a possibility of closing the loop. We therefore not only provide a model that can be used to assess alternative production options associated with different ways of dealing with waste but also provide a reallife case example of a closed-loop FSC.

The mushroom supply chain, discussed in detail in Chapter 4, provides another example in which there is potential to close the loop in an FSC. In Chapter 4, the quantified impact of closing loops in an industrial mushroom supply chain is examined with multi-objective optimization. All potential innovations allow the amount of waste to be reduced, thereby improving the economic and environmental performance by $11 \%$ and $28 \%$, respectively. It is concluded that valorization of materials and closing loops in FSCs can have a positive effect on both economic and environmental performance. Chapter 4 contributes to the scientific literature by proposing a multi-objective model to quantitatively assess closing loop technology in an FSC with respect to economic and environmental performance. In addition, both case studies confirm that prevention of waste is the most desirable way of reducing the environmental impact of food production.

\subsubsection{Environmental assessment}

Another finding concerns the indicators used to account for the environmental performance of FSCs. It has been argued by Kaipia et al. (2013) that the amount of waste produced is the key factor contributing to the environmental impact of food production, and the environmental impact is not caused solely in the phase where the product is wasted; food products that end up not being consumed have an environmental impact without adding value. One of the causes of waste production is the selection of key performance indicators, because the indicators currently 
used focus on cost efficiency (Kaipia et al., 2013). To reduce environmental impact, it is crucial to consider appropriate environmental indicators for the supply chain under consideration, as well as the economic indicators currently considered. Environmental impact can be objectively assessed using exergy analysis (Zisopoulos et al., 2017), which has the potential to capture multiple environmental indicators simultaneously. Both case studies considered in this thesis, however, show that using cumulative exergy loss (an indicator based on exergy analysis) or the amount of waste produced yields nearly the same solutions. Performing exergy analysis can be time consuming and requires detailed information on processes and activities. Quantifying the exergy losses of all (additional) processing steps can be difficult when technological innovations allowing for valorization of materials have not yet been implemented. Based on the results presented in this thesis, it is concluded that the amount of waste produced is an appropriate environmental indicator of FSCs, and the two case studies confirm that waste is the main factor contributing to exergy losses in food production.

\subsection{Managerial impact}

Most companies pursue environmental programmes only when improvements in economic performance are measurable and attainable (Pullman et al., 2009). The case studies clearly illustrate that technological innovations that allow for reuse and recycling of waste streams in the form of a closed-loop supply chain, can substantially improve the economic and environmental performance of an FSC. The greatest benefits are attained by using materials to their full potential by valorizing waste streams as much as possible. The case studies illustrate that it is worthwhile investing in research on technological innovations (and their development) for closing loops in FSCs. Although the economic and environmental performance can be improved by implementing these technological innovations, trade-off between these criteria still exists. This confirms that simultaneous consideration of economic and environmental criteria is important to inform decision makers on the trade-off between these criteria.

The impact of alternative production options is quantified with the help of the decision support models developed in this thesis. A decision support model is developed for each case study. The models are used to derive sets of eco-efficient solutions (i.e. Pareto-efficient solutions that consider economic and environmental objectives). The sets of eco-efficient solutions made decision makers aware of their own trade-offs in practice, and proved to be especially informative in facilitating discussions with industrial partners.

The proposed realistic variants of production and distribution planning models can be used to assess alternative production options associated with different ways to address the issue of waste, i.e. prevention, recycling, or disposal. The proposed models can also be used for other case studies to assess production options with respect to economic and environmental performance. However, a generic model often requires adjustment to make it suitable for a particular case study. To operationalize the models for other case studies, detailed information is required and the necessary data on the economic and environmental impact of all processing steps and distribution activities must be quantified. Ongoing research is already using the 
models for other supply chains, including a potato supply chain and a biscuit supply chain, showing their general applicability.

The models developed in this thesis have been applied to two case studies: a bread supply chain and a mushroom supply chain. In each case study, technological innovations enabled reduction of the total amount of waste produced along the supply chain. The case studies were selected based on their differences with respect to the type of waste material produced. In the bread supply chain, the focus is directed towards product waste, i.e. bread loafs that are not sold on the day of production. In the mushroom supply chain, on the other hand, the focus is directed towards process waste, i.e. waste that arises as a result of mushroom production, and corresponds to the growing medium (i.e. substrate used for growing mushrooms), which needs to be discarded after mushroom cultivation. The results for the bread supply chain considered in Chapter 3 show that prevention of waste, associated with the par-baking production option, can be favourable from both an economic and environmental perspective. The possibility of storing par-baked bread and selling it when it is needed gives additional flexibility and reduces the setup costs substantially. A shift to par-baked bread production implies that the shelf life of the product can be extended substantially, and this offers a change in the design of the bread supply chain. These findings encouraged our industrial partners to carry out follow-up research to investigate the potential alternative logistical structures, including the location and size of distribution centres, and inventory management-related issues, including alternative reviewing policies, and safety stock levels of frozen breads.

According to experts, based on the set of eco-efficient solutions, a production option that is associated with recycling bread waste provides a good balance between economic and environmental objectives. Recycling of bread rejects is already common practice within the boundaries of a bakery, i.e. breads that are rejected because of e.g. their shape or weight, can be processed and used as a raw material for production. However, to implement recycling at a supply chain level (i.e. to collect the bread not sold from supermarkets and transport it back to industrial bakeries for processing), additional food safety measures are necessary to prevent any potential contamination of products. The results provided by this study encouraged our industrial partners to carry out follow-up research to investigate the feasibility of recycling bread waste in terms of food security issues, food safety, and marketing research to investigate the customers' acceptability of products produced from recycled bread.

Chapter 4 presents a detailed integrated model with location/allocation and harvesting decisions. The results for the mushroom supply chain presented in Chapter 4 show that the (potential) technological innovations, which allow for recycling and reusing the waste stream in the form of spent mushroom substrate, can substantially improve the chain's economic and environmental performance. The results of the study presented in this thesis encouraged our industrial partners to further investigate the technical feasibility of the recovery options of the waste material. Ongoing research is being carried out on the possibility of recovering spent mushroom substrate as a peat replacement for casing soil production. Recovery of spent mushroom compost reduces the need for raw materials, providing substantial economic and environmental benefits. Moreover, the model developed for the case study is currently being 
used by our industrial partners to test various what-if scenarios, including the implications of increased compost production capacity and reduced availability of raw materials.

Although the research presented in this thesis does not have the capacity to support the claim that valorizing waste materials from food production brings benefits with respect to ecoefficiency independently of the supply chain, it does provide tools for the assessment of alternative production options associated with different waste management and prevention options. Sustainability research is not easily generalized across industries, and industry-specific sustainability research may yield more practical findings than cross-industry studies (Pullman et al., 2009). Future research on real-life case studies should be carried out to provide more evidence on the implications of valorizing raw materials in FSCs.

\subsection{Future research directions}

\subsubsection{Decision support models for eco-efficient FSCs}

As discussed in Chapter 2, existing approaches within the MCDM field are divided into two categories: MADM and MODM. This thesis explores only one of these categories (MODM) in case studies to optimize production and distribution planning decisions and derive eco-efficient solutions. Future case studies can build on the models developed in this thesis by additionally using MADM approaches to recover stakeholders' weights associated with different objectives, such that a single (preferred) solution is selected from the eco-efficient set.

Despite the increased interest in the scientific literature in using MCDM approaches for ecoefficient supply chains as presented in Chapter 2, only a few studies have focused on food products. It is clear that FSCs are unique in their complexity, and food products are characterized by seasonality, yield variability, product perishability and high fluctuations in demand and price (Akkerman et al., 2010; van der Vorst et al., 2009). Eliminating current inefficiencies and improving economic and environmental performance, therefore, requires sophisticated decision support models that account for the intrinsic characteristics of food products, including market and productivity uncertainty and perishability. Although the models proposed in this research account for market and productivity uncertainty, perishability issues are not explicitly included. However, perishability is implicitly included in the models by assuming that the products (bread and spent mushroom substrate) become waste if not sold or recycled on the day of production. Future research should explore the impact of inclusion of the limited shelf life of food products (i.e. longer than one day as assumed here) in a multi-criteria context.

This thesis provides tools for estimating the impact of alternative production options associated with different ways of valorizing (waste) materials. To operationalize the planning models in practice and to determine the impacts of new production technologies, the models should be further adjusted to include more realistic characteristics of the problems under study (e.g. including production in batches and considering different vehicles and their load) that have an impact on the economic and environmental performance. Future case studies should also 
consider multi-stage stochastic programming to better resemble reality by allowing more stages for decision making. Moreover, uncertainty associated with environmental impact of production processes, omitted in this work, should be considered in future studies. As shown in Zisopoulos et al. (2016), the values of some environmental parameters can have a critical influence on the overall environmental performance of an FSC.

\subsubsection{Improvement opportunities}

Each case studied in this thesis considers a supply chain as a single entity (from raw material providers to the retail stage) instead of considering each link in the chain separately. In practice, however, different links in the chain tend to maximize their own objectives. The scientific literature shows that collaboration and information sharing can bring economic and environmental benefits in FSCs (Kaipia et al., 2013). This provides potential for future research to investigate how the benefits obtained from collaboration and the benefits obtained by implementing technological innovations in processing can be assigned between different entities in a supply chain. Moreover, future research should also focus on investigating the impact of various sources of uncertainty on each link of the chain separately.

This study breaks away from the traditional view of supply chains in which the so-called take, make, dispose economic model dominates. Disposal of waste materials is the dominant pattern worldwide, leading to a huge loss of resources and causing heavy environmental impacts (Ghisellini et al., 2016). The large amount of waste produced by the food industry, in addition to being a great loss of valuable materials, raises problems both from the economic and environmental points of view (Mirabella et al., 2014). Recently, a new view of waste streams has been emerging, which recognizes waste management as recovery of resources and environmental impact prevention (Ghisellini et al., 2016). As a result of new production technologies in the food industry, valorizing waste materials in the same supply chain becomes possible. This leads to the concept of a closed-loop supply chain, which has not been widely applied to FSCs.

Even though interfirm clusters are considered simultaneously in this work by considering the supply chain as a whole, further improvement of economic and environmental performance could be attained if multiple interrelated supply chains are considered simultaneously. Many residues that cannot be valorized in one supply chain have the potential to be reused in other production systems, e.g. through bio-refineries (Mirabella et al., 2014). This can have an additional positive effect on eco-efficiency. Futures studies should consider more options for valorization of materials by considering more interrelated entities and supply chains in which waste material from processes in one sector can be used as input material in other sectors. A network of companies that exchange by-products and share other common resources corresponds to industrial symbiosis, in which the goal is to take full advantage of by-product utilization while reducing residual products or treating them efficiently (Zhu et al., 2007). In line with Mirabella et al. (2014), the potential direction for future research identified by this study is to perform feasibility studies to classify the type and amount of wastes and to identify which industrial sector might transform and use them. 


\section{Summary}

Until recently, food production focused mainly on delivering high-quality products at low cost and little attention was paid to environmental impact and depletion of natural resources. As a result of the growing awareness of climate change, shrinking resources, and increasing world population, this trend is changing. A major concern in Food Supply Chains (FSCs) is food waste. To remain competitive, FSCs are challenged to adopt new technologies that reduce or valorize food waste. These technologies can contribute to maintaining or increasing economic output and concurrently reduce the environmental impact of current operations, i.e. achieving what has been defined as eco-efficiency. Designing eco-efficient supply chains requires complex decision support models that can deal with multiple dimensions of sustainability while taking into account the specific characteristics of products and their supply chain. Multi-Criteria Decision Making (MCDM), a research field within Operations Research, is particularly suitable to support decision making when multiple and (mostly) conflicting criteria are involved. In this research, multi-objective optimization was used to quantify trade-offs between conflicting objectives and derive eco-efficient solutions, i.e. solutions in which environmental performance can only be improved at higher cost. The overall objective of this thesis was to support decision making in FSCs by developing dedicated decision support models to optimize and re-design FSCs by balancing the economic and environmental criteria. The emphasis is directed towards valorization of product flows by means of closing loops and waste management at a chain level. In line with this overall objective, four research questions were defined, which are addressed in Chapters 2 to 5 .

In Chapter 2, the use of MCDM approaches for designing Green Supply Chains (GSCs) is reviewed; GSCs extend traditional supply chains to include activities that minimize the environmental impact of a product throughout its life cycle. A conceptual framework was developed to find relevant publications and categorize papers with respect to decision problems, indicators, and MCDM approaches. The analysis shows that the use of MCDM approaches for designing GSCs is a new but emerging research field. Most publications focus on production and distribution problems, and there are only a few inventory models with environmental considerations. Most papers assume all data to be deterministic. Moreover, little attention has been given to minimization of waste in studies on FSCs, and numerous indicators are used to account for eco-efficiency, indicating the lack of standards. Chapter 2, therefore, identifies the need for more multi-criteria models for real-life GSCs, especially with respect to supply chains dealing with food production, and with inclusion of uncertainty in parameters.

Environmental concerns and scarcity of resources encourage decision makers in supply chains to consider alternative production options that include preventing the production of waste streams and simultaneously reusing and recycling waste materials. Until now, quantitative modelling approaches on closing loops in FSCs have been rare in the literature. The aim of Chapter 3 was to develop a mathematical model that can be used for quantitative assessment of alternative production options associated with different ways of dealing with waste in FSCs, i.e. 
prevention, recycling, and disposal of food waste. A multi-objective mixed integer linear programming model was developed to derive a set of eco-efficient solutions corresponding to production planning decisions. The environmental performance of the chain is expressed by an indicator based on exergy analysis, which has the potential to capture other commonly used indicators, such as energy consumption, fuel consumption, and waste generation, in a single value. This simplifies the calculation of the eco-efficient frontier and enables its intuitive graphical representation, which is much easier to communicate to the decision makers. The applicability of the model is demonstrated on a real-life industrial bread supply chain in the Netherlands. The results confirm the findings from the literature that prevention is the best waste management strategy from an environmental perspective. The advantages of using exergy as an indicator to capture the environmental performance is demonstrated by comparing the outcomes with other commonly used indicators of environmental performance. The potential of studying food production planning decision problems in a multi-objective context is illustrated and the applicability of the model in the assessment of alternative production options is demonstrated.

In contrast to closed-loop studies in industry involving discrete parts, in FSCs the value of the final product usually cannot be regained. However, the components used for production, such as organic matter or a growing medium, can be recycled. The aim of Chapter 4 was to reveal the consequences of closing loops in a mushroom supply chain. A multi-objective mixed integer linear programming model was proposed to quantify trade-offs between economic and environmental indicators and to explore alternative recycling technologies quantitatively. The model was developed to re-design the logistical structure and close loops in the mushroom supply chain. It was found that adopting closing loop technologies in industrial mushroom production has the potential to increase the total profitability of the chain by almost $11 \%$ and improve the environmental performance by almost $28 \%$. It is concluded that a comprehensive evaluation of recycling technologies and re-designing logistical structures requires quantitative tools that simultaneously optimize managerial decisions at strategic and tactical levels.

Multi-objective optimization models are often developed under the assumption that all information required for model parameterization is known in advance. In practice, however, not all the required information is available in advance because of various sources of uncertainty in FSCs. In Chapter 5, a multi-objective two-stage stochastic programming model was proposed to analyse and evaluate the economic and environmental impacts to account for uncertainty in FSCs. A mushroom supply chain in the Netherlands is presented as an illustrative case study. Optimal production planning decisions calculated with a two-stage stochastic programming model are compared with the results of an equivalent deterministic model. It is demonstrated that taking uncertainty into account at the production planning phase in an FSC can bring substantial economic and environmental benefits.

The research presented in this thesis contributes to the scientific literature on eco-efficient FSCs by providing decision support models for use by decision makers to assess alternative logistical structures and quantify the economic and environmental implications of closing loop technologies. This thesis shows that technological innovations, which allow for reuse and 
recycling of waste streams, have the potential to improve the economic and environmental performance of an FSC substantially. The case studies illustrate that it is worthwhile investing in research on technological innovations (and their development) for closing loops in FSCs. The greatest benefits are brought about by using materials to their full potential by valorizing waste streams as much as possible. 



\section{References}

AHUMADA, O. \& VILLALOBOS, J. R. 2009. Application of planning models in the agri-food supply chain: a review. European Journal of Operational Research, 196, 1-20.

AHUMADA, O. \& VILLALOBOS, J. R. 2011. A tactical model for planning the production and distribution of fresh produce. Annals of Operations Research, 190, 339-358.

AKKERMAN, R., FARAHANI, P. \& GRUNOW, M. 2010. Quality, safety and sustainability in food distribution: a review of quantitative operations management approaches and challenges. OR Spectrum, 32, 863-904.

AKKERMAN, R., WANG, Y. \& GRUNOW, M. MILP approaches to sustainable production and distribution of meal elements. International Conference on Computers and Industrial Engineering, 2009. 973-978.

AKTIN, T. \& GERGIN, Z. 2016. Mathematical modelling of sustainable procurement strategies: three case studies. Journal of Cleaner Production, 113, 767-780.

ALEXANDRATOS, N. \& BRUINSMA, J. 2012. World agriculture towards 2030/2050: the 2012 revision. FAO.

ALMARAZ, S. D. L., AZZARO-PANTEL, C., MONTASTRUC, L. \& DOMENECH, S. 2014. Hydrogen supply chain optimization for deployment scenarios in the Midi-Pyrenees region, France. International Journal of Hydrogen Energy, 39, 11831-11845.

AMIN, S. H. \& ZHANG, G. Q. 2013. A multi-objective facility location model for closed-loop supply chain network under uncertain demand and return. Applied Mathematical Modelling, 37, 4165-4176.

AMORIM, P., GUNTHER, H. O. \& ALMADA-LOBO, B. 2012. Multi-objective integrated production and distribution planning of perishable products. International Journal of Production Economics, 138, 89-101.

ANDRIOLO, A., BATTINI, D., PERSONA, A. \& SGARBOSSA, F. 2015. Haulage sharing approach to achieve sustainability in material purchasing: new method and numerical applications. International Journal of Production Economics, 164, 308-318.

APAIAH, R. K., HENDRIX, E. M. T., MEERDINK, G. \& LINNEMANN, A. R. 2005. Qualitative methodology for efficient food chain design. Trends in Food Science \& Technology, 16, 204-214.

APAIAH, R. K., LINNEMANN, A. R. \& VAN DER KOOI, H. J. 2006. Exergy analysis: a tool to study the sustainability of food supply chains. Food Research International, 39, 111.

ARAMYAN, L., HOSTE, R., VAN DEN BROEK, W., GROOT, J., SOETHOUDT, H., NGUYEN, T. L., HERMANSEN, J. \& VAN DER VORST, J. 2011. Towards sustainable food production: a scenario study of the European pork sector. Journal on Chain and Network Science, 11, 177-189.

ARAMYAN, L., ONDERSTEIJN, C. J., VAN KOOTEN, O. \& LANSINK, A. O. 2006. Performance indicators in agri-food production chains. Quantifying the agri-food supply chain. Springer. 
ASGARI, N., HASSANI, A., JONES, D. \& NGUYE, H. H. 2015. Sustainability ranking of the UK major ports: methodology and case study. Transportation Research Part ELogistics and Transportation Review, 78, 19-39.

ASHBY, A., LEAT, M. \& HUDSON-SMITH, M. 2012. Making connections: a review of supply chain management and sustainability literature. Supply Chain Management-an International Journal, 17, 497-516.

ASHLAGHI, M. J. 2014. A new approach to green supplier selection based on fuzzy multicriteria decision making method and linear physical programming. Tehnicki VjesnikTechnical Gazette, 21, 591-597.

AWASTHI, A., CHAUHAN, S. S. \& GOYAL, S. K. 2011. A multi-criteria decision making approach for location planning for urban distribution centers under uncertainty. Mathematical and Computer Modelling, 53, 98-109.

AWASTHI, A. \& KANNAN, G. 2016. Green supplier development program selection using NGT and VIKOR under fuzzy environment. Computers \& Industrial Engineering, 91, 100-108.

AYOUB, N., ELMOSHI, E., SEKI, H. \& NAKA, Y. 2009. Evolutionary algorithms approach for integrated bioenergy supply chains optimization. Energy Conversion and Management, 50, 2944-2955.

AZADEH, A., RAOOFI, Z. \& ZARRIN, M. 2015. A multi-objective fuzzy linear programming model for optimization of natural gas supply chain through a greenhouse gas reduction approach. Journal of Natural Gas Science and Engineering, 26, 702-710.

AZADNIA, A. H., SAMAN, M. Z. M. \& WONG, K. Y. 2014. Sustainable supplier selection and order lot-sizing: an integrated multi-objective decision-making process. International Journal of Production Research, 53, 383-408.

BAIRAMZADEH, S., PISHVAEE, M. S. \& SAIDI-MEHRABAD, M. 2016. Multiobjective robust possibilistic programming approach to sustainable bioethanol supply chain design under multiple uncertainties. Industrial \& Engineering Chemistry Research, 55, 237-256.

BARATA, J. F. F., QUELHAS, O. L. G., COSTA, H. G., GUTIERREZ, R. H., LAMEIRA, V. D. \& MEIRINO, M. J. 2014. Multi-criteria indicator for sustainability rating in suppliers of the oil and gas industries in Brazil. Sustainability, 6, 1107-1128.

BAUER, J., BEKTAS, T. \& CRAINIC, T. G. 2010. Minimizing greenhouse gas emissions in intermodal freight transport: an application to rail service design. Journal of the Operational Research Society, 61, 530-542.

BEAMON, B. M. 1999. Designing the green supply chain. Logistics Information Management, $12,332-342$.

BELL, J. E., MOLLENKOPF, D. A. \& STOLZE, H. J. 2013. Natural resource scarcity and the closed-loop supply chain: a resource-advantage view. International Journal of Physical Distribution \& Logistics Management, 43, 351-379.

BEN-TAL, A., EL GHAOUI, L. \& NEMIROVSKI, A. 2009. Robust optimization, Princeton, NJ, Princeton University Press. 
BERNARDI, A., GIAROLA, S. \& BEZZO, F. 2012. Optimizing the economics and the carbon and water footprints of bioethanol supply chains. Biofuels Bioproducts \& BiorefiningBiofpr, 6, 656-672.

BIRGE, J. R. \& LOUVEAUX, F. 2011. Introduction to Stochastic Programming, New York, NY, Springer Science+Business Media, LLC.

BLOEMHOF, J. M. \& VAN DER VORST, J. G. A. J. V. D. 2014. Sustainable Food Supply Chain Networks. Markets, Business, and Sustainability. Bentham Science Publishers.

BLONK, H. 2006. Duurzaam broodbakken : werkdocument analysefase bakker Wiltink, [Gouda], [Blonk Milieu Advies].

BOHLE, C., MATURANA, S. \& VERA, J. 2010. A robust optimization approach to wine grape harvesting scheduling. European Journal of Operational Research, 200, 245252.

BOJARSKI, A. D., LAINEZ, J. M., ESPUNA, A. \& PUIGJANER, L. 2009. Incorporating environmental impacts and regulations in a holistic supply chains modeling: an LCA approach. Computers \& Chemical Engineering, 33, 1747-1759.

BOONSOTHONSATIT, K., KARA, S., IBBOTSON, S. \& KAYIS, B. 2015. Development of a Generic decision support system based on multi-Objective Optimisation for Green supply chain network design (GOOG). Journal of Manufacturing Technology Management, 26, 1069-1084.

BORODIN, V., BOURTEMBOURG, J., HNAIEN, F. \& LABADIE, N. 2014. A quality risk management problem: case of annual crop harvest scheduling. International Journal of Production Research, 52, 2682-2695.

BORTOLINI, M., FACCIO, M., FERRARI, E., GAMBERI, M. \& PILATI, F. 2016. Fresh food sustainable distribution: cost, delivery time and carbon footprint three-objective optimization. Journal of Food Engineering, 174, 56-67.

BOUCHERY, Y., GHAFFARI, A., JEMAI, Z. \& DALLERY, Y. 2012. Including sustainability criteria into inventory models. European Journal of Operational Research, 222, 229240 .

BOUCHERY, Y., GHAFFARI, A., JEMAI, Z. \& FRANSOO, J. 2016. Sustainable transportation and order quantity: insights from multiobjective optimization. Flexible Services and Manufacturing Journal, 28, 367-396.

BOUKHERrouB, T., RUIZ, A., GUINET, A. \& FONDREVELLE, J. 2015. An integrated approach for sustainable supply chain planning. Computers \& Operations Research, 54, 180-194.

BOUTKHOUM, O., HANINE, M., BOUKHRISS, H., AGOUTI, T. \& TIKNIOUINE, A. 2016. Multi-criteria decision support framework for sustainable implementation of effective green supply chain management practices. Springerplus, 5, 664.

BOUTKHOUM, O., HANINE, M., TIKNIOUINE, A. \& AGOUTI, T. 2015. Multi-criteria decisional approach of the OLAP analysis by fuzzy logic: green logistics as a case study. Arabian Journal for Science and Engineering, 40, 2345-2359.

BOUZAROUR-AMOKRANE, Y., TCHANGANI, A. \& PERES, F. 2015. Decision evaluation process in end-of-life systems management. Journal of Manufacturing Systems, 37, 715-728. 
BRANDENBURG, M. 2015. Low carbon supply chain configuration for a new product - a goal programming approach. International Journal of Production Research, 53, 6588-6610.

BRANDENBURG, M., GOVINDAN, K., SARKIS, J. \& SEURING, S. 2014. Quantitative models for sustainable supply chain management: developments and directions. European Journal of Operational Research, 233, 299-312.

BRANDENBURG, M. \& REBS, T. 2015. Sustainable supply chain management: a modeling perspective. Annals of Operations Research, 229, 213-252.

BRAUNGART, M., MCDONOUGH, W. \& BOLLINGER, A. 2007. Cradle-to-cradle design: creating healthy emissions - a strategy for eco-effective product and system design. Journal of Cleaner Production, 15, 1337-1348.

BUYUKOZKAN, G. 2012. An integrated fuzzy multi-criteria group decision-making approach for green supplier evaluation. International Journal of Production Research, 50, 28922909.

BUYUKOZKAN, G. \& CIFCI, G. 2011. A novel fuzzy multi-criteria decision framework for sustainable supplier selection with incomplete information. Computers in Industry, 62, 164-174.

BUYUKOZKAN, G. \& CIFCI, G. 2012. A novel hybrid MCDM approach based on fuzzy DEMATEL, fuzzy ANP and fuzzy TOPSIS to evaluate green suppliers. Expert Systems with Applications, 39, 3000-3011.

CAO, Q. W., WU, J. \& LIANG, C. Y. 2015. An intuitionsitic fuzzy judgement matrix and TOPSIS integrated multi-criteria decision making method for green supplier selection. Journal of Intelligent \& Fuzzy Systems, 28, 117-126.

CARTER, C. R. \& ROGERS, D. S. 2008. A framework of sustainable supply chain management: moving toward new theory. International Journal of Physical Distribution \& Logistics Management, 38, 360-387.

CELIK, E., ERDOGAN, M. \& GUMUS, A. T. 2016. An extended fuzzy TOPSIS-GRA method based on different separation measures for green logistics service provider selection. International Journal of Environmental Science and Technology, 13, 1377-1392.

CHAABANE, A., RAMUDHIN, A. \& PAQUET, M. 2011. Designing supply chains with sustainability considerations. Production Planning \& Control, 22, 727-741.

CHAABANE, A., RAMUDHIN, A. \& PAQUET, M. 2012. Design of sustainable supply chains under the emission trading scheme. International Journal of Production Economics, $135,37-49$.

CHAABANE, A., RAMUDHIN, A., PAQUET, M. \& A., B. M. An integrated logistics model for environmental conscious supply chain network design. Americas Conference on Information Systems, 2008. Toronto, ON, Canada.

CHAKRABORTY, P. S., MAJUMDER, G. \& SARKAR, B. 2005. Performance evaluation of existing vendors using Analytic Hierarchy Process. Journal of Scientific \& Industrial Research, 64, 648-652.

CHAN, C. K., LEE, Y. C. E. \& CAMPBELL, J. F. 2013. Environmental performance-Impacts of vendor-buyer coordination. International Journal of Production Economics, 145, 683-695. 
CHEN, H., JIANG, W., YANG, Y., YANG, Y. \& MAN, X. 2017. State of the art on food waste research: a bibliometrics study from 1997 to 2014. Journal of Cleaner Production, $140,840-846$.

CHEN, H. M., CHOU, S. Y., LUU, Q. D. \& YU, T. H. K. 2016. A fuzzy MCDM approach for green supplier selection from the economic and environmental aspects. Mathematical Problems in Engineering.

CHEN, Z. X. \& ANDRESEN, S. 2014. A multiobjective optimization model of productionsourcing for sustainable supply chain with consideration of social, environmental, and economic factors. Mathematical Problems in Engineering.

CHIBELES-MARTINS, N., PINTO-VARELA, T., BARBOSA-POVOA, A. P. \& NOVAIS, A. Q. 2016. A multi-objective meta-heuristic approach for the design and planning of green supply chains - MBSA. Expert Systems with Applications, 47, 71-84.

CHITHAMBARANATHAN, P., SUBRAMANIAN, N., GUNASEKARAN, A. \& PALANIAPPAN, P. L. K. 2015. Service supply chain environmental performance evaluation using grey based hybrid MCDM approach. International Journal of Production Economics, 166, 163-176.

CHOPRA, S. \& MEINDL, P. 2013. Supply chain management : strategy, planning, and operation, Boston, Pearson.

CLAASSEN, G. D. H. \& HENDRIX, E. M. T. 2014. On modelling approaches for planning and scheduling in food processing industry. Lecture Notes in Computer Science (including subseries Lecture Notes in Artificial Intelligence and Lecture Notes in Bioinformatics).

CLARK, A., ALMADA-LOBO, B. \& ALMEDER, C. 2011. Lot sizing and scheduling: industrial extensions and research opportunities. International Journal of Production Research, 49, 2457-2461.

COATANÉA, E., KUUVA, M., MAKKONNEN, P. E., SAARELAINEN, T. \& CASTILLÓNSOLANO, M. O. Analysis of the concept of sustainability: definition of conditions for using exergy as a uniform environmental metric. Proceedings of the 13th CIRP International conference on life cycle engineering, 2006. p. 81-86.

COBULOGLU, H. I. \& BUYUKTAHTAKIN, I. E. 2015. A stochastic multi-criteria decision analysis for sustainable biomass crop selection. Expert Systems with Applications, 42, 6065-6074.

COLICCHIA, C., CREAZZA, A., DALLARI, F. \& MELACINI, M. 2016. Eco-efficient supply chain networks: development of a design framework and application to a real case study. Production Planning \& Control, 27, 157-168.

CORTEZ, L. A. B., LARSON, D. L. \& DASILVA, A. 1997. Energy and exergy evaluation of ice production by absorption refrigeration. Transactions of the Asae, 40, 395-403.

CRUZ, J. M. 2008. Dynamics of supply chain networks with corporate social responsibility through integrated environmental decision-making. European Journal of Operational Research, 184, 1005-1031.

CRUZ, J. M. 2009. The impact of corporate social responsibility in supply chain management: multicriteria decision-making approach. Decision Support Systems, 48, 224-236. 
CRUZ, J. M. 2013. Modeling the relationship of globalized supply chains and corporate social responsibility. Journal of Cleaner Production, 56, 73-85.

CRUZ, J. M. \& MATSYPURA, D. 2009. Supply chain networks with corporate social responsibility through integrated environmental decision-making. International Journal of Production Research, 47, 621-648.

D'AMORE, F. \& BEZZO, F. 2016. Strategic optimisation of biomass-based energy supply chains for sustainable mobility. Computers \& Chemical Engineering, 87, 68-81.

DAI, J. \& BLACKHURST, J. 2012. A four-phase AHP-QFD approach for supplier assessment: a sustainability perspective. International Journal of Production Research, 50, 54745490 .

DE KEIZER, M. 2015. Logistics network design \& control: managing product quality in a blooming sector. Wageningen University.

DEHGHANIAN, F. \& MANSOUR, S. 2009. Designing sustainable recovery network of endof-life products using genetic algorithm. Resources Conservation and Recycling, 53, 559-570.

DEKKER, R., BLOEMHOF, J. \& MALLIDIS, I. 2012. Operations Research for green logistics - an overview of aspects, issues, contributions and challenges. European Journal of Operational Research, 219, 671-679.

DEVIKA, K., JAFARIAN, A. \& NOURBAKHSH, V. 2014. Designing a sustainable closedloop supply chain network based on triple bottom line approach: a comparison of metaheuristics hybridization techniques. European Journal of Operational Research, 235, 594-615.

DOBOS, I. \& VOROSMARTY, G. 2014. Green supplier selection and evaluation using DEAtype composite indicators. International Journal of Production Economics, 157, 273278.

DRAGANOVIC, V., JORGENSEN, S. E., BOOM, R., JONKERS, J., RIESEN, G. \& VAN DER GOOT, A. J. 2013. Sustainability assessment of salmonid feed using energy, classical exergy and eco-exergy analysis. Ecological Indicators, 34, 277-289.

EHRGOTT, M. 2005. Multicriteria optimization, Berlin, Springer.

EKER, S. \& VAN DAALEN, E. 2015. A model-based analysis of biomethane production in the Netherlands and the effectiveness of the subsidization policy under uncertainty. Energy Policy, 82, 178-196.

ESKANDARPOUR, M., DEJAX, P., MIEMCZYK, J. \& PETON, O. 2015. Sustainable supply chain network design: an optimization-oriented review. Omega-International Journal of Management Science, 54, 11-32.

ESKANDARPOUR, M., ZEGORDI, S. H. \& NIKBAKHSH, E. 2013. A parallel variable neighborhood search for the multi-objective sustainable post-sales network design problem. International Journal of Production Economics, 145, 117-131.

FAHIMNIA, B. \& JABBARZADEH, A. 2016. Marrying supply chain sustainability and resilience: a match made in heaven. Transportation Research Part E-Logistics and Transportation Review, 91, 306-324. 
FALATOONITOOSI, E., AHMED, S. \& SOROOSHIAN, S. 2014. A multicriteria framework to evaluate supplier's greenness. Abstract and Applied Analysis.

FAO 2013. Food wastage footprint; Impacts on natural resources.

FLAPPER, S. D. P., VAN NUNEN, J. A. E. E. \& VAN WASSENHOVE, L. N. 2005. Managing closed-loop supply chains.

FLEISCHMANN, M., BLOEMHOF-RUWAARD, J. M., DEKKER, R., VAN DER LAAN, E., VAN NUNEN, J. A. E. E. \& VAN WASSENHOVE, L. N. 1997. Quantitative models for reverse logistics: a review. European Journal of Operational Research, 103, 1-17.

GAlveZ, D., RAKOTONDRANAIVO, A., MOREL, L., CAMARGO, M. \& FICK, M. 2015. Reverse logistics network design for a biogas plant: an approach based on MILP optimization and Analytical Hierarchical Process (AHP). Journal of Manufacturing Systems, 37, 616-623.

GAO, J. Y. \& YOU, F. Q. 2015. Shale gas supply chain design and operations toward better economic and life cycle environmental performance: MINLP model and global optimization algorithm. Acs Sustainable Chemistry \& Engineering, 3, 1282-1291.

GARCIA, D. J. \& YOU, F. Q. 2015a. Life cycle network modeling framework and solution algorithms for systems analysis and optimization of the water-energy nexus. Processes, 3, 514-539.

GARCIA, D. J. \& YOU, F. Q. 2015b. Multiobjective optimization of product and process networks: general modeling framework, efficient global optimization algorithm, and case studies on bioconversion. AIChE Journal, 61, 530-551.

GARG, K., KANNAN, D., DIABAT, A. \& JHA, P. C. 2015. A multi-criteria optimization approach to manage environmental issues in closed loop supply chain network design. Journal of Cleaner Production, 100, 297-314.

GELDERMANN, J., TREITZ, M. \& RENTZ, O. 2007. Towards sustainable production networks. International Journal of Production Research, 45, 4207-4224.

GELDERMANN, J., TREITZ, M., SCHOLLENBERGER, H. \& RENTZ, O. 2006. Evaluation of VOC recovery strategies - Multi Objective Pinch Analysis (MOPA) for the evaluation of VOC recovery strategies. OR Spectrum, 28, 3-20.

GERBER, L., FAZLOLLAHI, S. \& MARECHAL, F. 2013. A systematic methodology for the environomic design and synthesis of energy systems combining process integration, Life Cycle Assessment and industrial ecology. Computers \& Chemical Engineering, $59,2-16$.

GHAYEBLOO, S., TAROKH, M. J., VENKATADRI, U. \& DIALLO, C. 2015. Developing a bi-objective model of the closed-loop supply chain network with green supplier selection and disassembly of products: the impact of parts reliability and product greenness on the recovery network. Journal of Manufacturing Systems, 36, 76-86.

GHISELliNI, P., CIALANI, C. \& ULGIATI, S. 2016. A review on circular economy: the expected transition to a balanced interplay of environmental and economic systems. Journal of Cleaner Production, 114, 11-32.

GIAROLA, S., ZAMBONI, A. \& BEZZO, F. 2011. Spatially explicit multi-objective optimisation for design and planning of hybrid first and second generation biorefineries. Computers \& Chemical Engineering, 35, 1782-1797. 
GIAROLA, S., ZAMBONI, A. \& BEZZO, F. 2012. Environmentally conscious capacity planning and technology selection for bioethanol supply chains. Renewable Energy, $43,61-72$.

GIROTTO, F., ALIBARDI, L. \& COSSU, R. 2015. Food waste generation and industrial uses: a review. Waste Management, 45, 32-41.

GONELA, V., ZHANG, J., OSMANI, A. \& ONYEAGHALA, R. 2015. Stochastic optimization of sustainable hybrid generation bioethanol supply chains. Transportation Research Part E: Logistics and Transportation Review, 77, 1-28.

GONG, J. \& YOU, F. Q. 2015. Value-added chemicals from microalgae: greener, more economical, or both? Acs Sustainable Chemistry \& Engineering, 3, 82-96.

GOVINDAN, K., JAFARIAN, A., KHODAVERDI, R. \& DEVIKA, K. 2014a. Two-echelon multiple-vehicle location-routing problem with time windows for optimization of sustainable supply chain network of perishable food. International Journal of Production Economics, 152, 9-28.

GOVINDAN, K., JAFARIAN, A. \& NOURBAKHSH, V. 2015a. Bi-objective integrating sustainable order allocation and sustainable supply chain network strategic design with stochastic demand using a novel robust hybrid multi-objective metaheuristic. Computers \& Operations Research, 62, 112-130.

GOVINDAN, K., JHA, P. C. \& GARG, K. 2016a. Product recovery optimization in closed-loop supply chain to improve sustainability in manufacturing. International Journal of Production Research, 54, 1463-1486.

GOVINDAN, K., KANNAN, D. \& SHANKAR, M. 2015b. Evaluation of green manufacturing practices using a hybrid MCDM model combining DANP with PROMETHEE. International Journal of Production Research, 53, 6344-6371.

GOVINDAN, K., KHODAVERDI, R. \& JAFARIAN, A. 2013. A fuzzy multi criteria approach for measuring sustainability performance of a supplier based on triple bottom line approach. Journal of Cleaner Production, 47, 345-354.

GOVINDAN, K., KHODAVERDI, R. \& VAFADARNIKJOO, A. 2015c. Intuitionistic fuzzy based DEMATEL method for developing green practices and performances in a green supply chain. Expert Systems with Applications, 42, 7207-7220.

GOVINDAN, K., SARKIS, J., JABBOUR, C. J. C., ZHU, Q. H. \& GENG, Y. 2014b. Ecoefficiency based green supply chain management: current status and opportunities. European Journal of Operational Research, 233, 293-298.

GOVINDAN, K., SHANKAR, K. M. \& KANNAN, D. 2016b. Sustainable material selection for construction industry - A hybrid multi criteria decision making approach. Renewable \& Sustainable Energy Reviews, 55, 1274-1288.

GOVINDAN, K. \& SIVAKUMAR, R. 2016. Green supplier selection and order allocation in a low-carbon paper industry: integrated multi-criteria heterogeneous decision-making and multi-objective linear programming approaches. Annals of Operations Research, $238,243-276$.

GOVINDAN, K., SOLEIMANI, H. \& KANNAN, D. 2015d. Reverse logistics and closed-loop supply chain: a comprehensive review to explore the future. European Journal of Operational Research, 240, 603-626. 
GUAN, Z. \& PHILPOTT, A. B. 2011. A multistage stochastic programming model for the New Zealand dairy industry. International Journal of Production Economics, 134, 289-299.

GUIDE, V. D. R., HARRISON, T. P. \& VAN WASSENHOVE, L. N. 2003. The challenge of closed-loop supply chains. Interfaces, 33, 3-6.

GUILlEN-GOSAlBEZ, G., CABAllerO, J. A. \& JIMENEZ, L. 2008. Application of life cycle assessment to the structural optimization of process flowsheets. Industrial \& Engineering Chemistry Research, 47, 777-789.

GUILLEN-GOSALBEZ, G. \& GROSSMANN, I. 2010. A global optimization strategy for the environmentally conscious design of chemical supply chains under uncertainty in the damage assessment model. Computers \& Chemical Engineering, 34, 42-58.

GUILLEN-GOSALBEZ, G. \& GROSSMANN, I. E. 2009. Optimal design and planning of sustainable chemical supply chains under uncertainty. AIChE Journal, 55, 99-121.

GUILlEN-GOSALBEZ, G., MELE, F. D. \& GROSSMANN, I. E. 2010. A bi-criterion optimization approach for the design and planning of hydrogen supply chains for vehicle use. AIChE Journal, 56, 650-667.

HARRIS, I., MUMFORD, C. L. \& NAIM, M. M. 2014. A hybrid multi-objective approach to capacitated facility location with flexible store allocation for green logistics modeling. Transportation Research Part E-Logistics and Transportation Review, 66, 1-22.

HARRIS, I., NAIM, M., PALMER, A., POTTER, A. \& MUMFORD, C. 2011. Assessing the impact of cost optimization based on infrastructure modelling on $\mathrm{CO} 2$ emissions. International Journal of Production Economics, 131, 313-321.

HASHEMI, S. H., KARIMI, A. \& TAVANA, M. 2015. An integrated green supplier selection approach with analytic network process and improved Grey relational analysis. International Journal of Production Economics, 159, 178-191.

HASSINI, E., SURTI, C. \& SEARCY, C. 2012. A literature review and a case study of sustainable supply chains with a focus on metrics. International Journal of Production Economics, 140, 69-82.

HOMBACH, L. E. \& WALTHER, G. 2015. Pareto-efficient legal regulation of the (bio)fuel market using a bi-objective optimization model. European Journal of Operational Research, 245, 286-295.

HSU, C. H., WANG, F. K. \& TZENG, G. H. 2012. The best vendor selection for conducting the recycled material based on a hybrid MCDM model combining DANP with VIKOR. Resources Conservation and Recycling, 66, 95-111.

HSU, C. W. \& HU, A. H. 2009. Applying hazardous substance management to supplier selection using analytic network process. Journal of Cleaner Production, 17, 255-264.

HSU, C. W., KUO, R. J. \& CHIOU, C. Y. 2014. A multi-criteria decision-making approach for evaluating carbon performance of suppliers in the electronics industry. International Journal of Environmental Science and Technology, 11, 775-784.

HSUEH, S. L. \& YAN, M. R. 2013. A multimethodology contractor assessment model for facilitating green innovation: the view of energy and environmental protection. ScientificWorldJournal, 2013, 624340. 
HugO, A., RUTTER, P., PISTIKOPOUlOS, S., AMORELli, A. \& ZOIA, G. 2005. Hydrogen infrastructure strategic planning using multi-objective optimization. International Journal of Hydrogen Energy, 30, 1523-1534.

HWANG, C. L., PAIDY, S. R., YOON, K. \& MASUD, A. S. M. 1980. Mathematicalprogramming with multiple objectives - a tutorial. Computers \& Operations Research, $7,5-31$.

IGARASHI, K., YAMADA, T., GUPTA, S. M., INOUE, M. \& ITSUBO, N. 2016. Disassembly system modeling and design with parts selection for cost, recycling and $\mathrm{CO} 2$ saving rates using multi criteria optimization. Journal of Manufacturing Systems, $38,151-164$.

INGHELS, D., DULLAERT, W. \& BLOEMHOF, J. 2016. A model for improving sustainable green waste recovery. Resources Conservation and Recycling, 110, 61-73.

JAKHAR, S. K. 2015. Performance evaluation and a flow allocation decision model for a sustainable supply chain of an apparel industry. Journal of Cleaner Production, 87, 391-413.

JAMSHIDI, R., GHOMI, S. M. T. F. \& KARIMI, B. 2012. Multi-objective green supply chain optimization with a new hybrid memetic algorithm using the Taguchi method. Scientia Iranica, 19, 1876-1886.

JANS, R. \& DEGRAEVE, Z. 2008. Modeling industrial lot sizing problems: a review. International Journal of Production Research, 46, 1619-1643.

JAYARAMAN, V. 2006. Production planning for closed-loop supply chains with product recovery and reuse: an analytical approach. International Journal of Production Research, 44, 981-998.

JIA, P., GOVINDAN, K., CHOI, T. M. \& RAJENDRAN, S. 2015. Supplier selection problems in fashion business operations with sustainability considerations. Sustainability, 7, 1603-1619.

KAIPIA, R., DUKOVSKA-POPOVSKA, I. \& LOIKKANEN, L. 2013. Creating sustainable fresh food supply chains through waste reduction. International Journal of Physical Distribution \& Logistics Management, 43, 262-276.

KANNAN, D., GOVINDAN, K. \& RAJENDRAN, S. 2015. Fuzzy Axiomatic Design approach based green supplier selection: a case study from Singapore. Journal of Cleaner Production, 96, 194-208.

KANNAN, D., KHODAVERDI, R., OLFAT, L., JAFARIAN, A. \& DIABAT, A. 2013. Integrated fuzzy multi criteria decision making method and multi-objective programming approach for supplier selection and order allocation in a green supply chain. Journal of Cleaner Production, 47, 355-367.

KANNEGIESSER, M. \& GUNTHER, H. O. 2014. Sustainable development of global supply chains-part 1: sustainability optimization framework. Flexible Services and Manufacturing Journal, 26, 24-47.

KANNEGIESSER, M., GUNTHER, H. O. \& AUTENRIEB, N. 2015. The time-tosustainability optimization strategy for sustainable supply network design. Journal of Cleaner Production, 108, 451-463. 
KANNEGIESSER, M., GUNTHER, H. O. \& GYLFASON, O. 2014. Sustainable development of global supply chains-part 2: investigation of the European automotive industry. Flexible Services and Manufacturing Journal, 26, 48-68.

KANZIAN, C., KUHMAIER, M., ZAZGORNIK, J. \& STAMPFER, K. 2013. Design of forest energy supply networks using multi-objective optimization. Biomass \& Bioenergy, 58, 294-302.

KEYVANSHOKOOH, E., RYAN, S. M. \& KABIR, E. 2016. Hybrid robust and stochastic optimization for closed-loop supply chain network design using accelerated Benders decomposition. European Journal of Operational Research, 249, 76-92.

KOLFSCHOTEN, R. C., BRUINS, M. E. \& SANDERS, J. P. M. 2014. Opportunities for small-scale biorefinery for production of sugar and ethanol in the Netherlands. Biofuels Bioproducts \& Biorefining-Biofpr, 8, 475-486.

KONUR, D. \& SCHAEFER, B. 2016. Economic and environmental comparison of grouping strategies in coordinated multi-item inventory systems. Journal of the Operational Research Society, 67, 421-436.

KOOPMAN, R., LANEY, K., T.P., M., BOONE, P., GREENFIELD, S. \& COLEMAN, J. 2010. Mushrooms; Industry \& Trade Summary.

KOStiN, A., GUILlEN-GOSALBEZ, G. \& JIMENEZ, L. 2015. Dimensionality reduction applied to the simultaneous optimization of the economic and life cycle environmental performance of supply chains. International Journal of Production Economics, 159, 223-232.

KOTAS, T. J. 1995. The exergy method of thermal plant analysis, Malabar, FL, Krieger Publishing.

KRAVANJA, Z. 2010. Challenges in sustainable integrated process synthesis and the capabilities of an MINLP process synthesizer MipSyn. Computers \& Chemical Engineering, 34, 1831-1848.

KRAVANJA, Z. \& CUCEK, L. 2013. Multi-objective optimisation for generating sustainable solutions considering total effects on the environment. Applied Energy, 101, 67-80.

KRIKKE, H., BLOEMHOF-RUWAARD, J. \& VAN WASSENHOVE, L. N. 2003. Concurrent product and closed-loop supply chain design with an application to refrigerators. International Journal of Production Research, 41, 3689-3719.

KRIKKE, H. R., VAN HARTEN, A. \& SCHUUR, P. C. 1999. Business case Océ: reverse logistic network re-design for copiers. OR Spektrum, 21, 381-409.

KUCUKVAR, M., EGILMEZ, G. \& TATARI, O. 2016. Life cycle assessment and optimization-based decision analysis of construction waste recycling for a LEEDcertified university building. Sustainability, 8.

KUHMAIER, M. \& STAMPFER, K. 2012. Development of a multi-criteria decision support tool for energy wood supply management. Croatian Journal of Forest Engineering, 33, 181-198.

KUO, R. J., WANG, Y. C. \& TIEN, F. C. 2010. Integration of artificial neural network and MADA methods for green supplier selection. Journal of Cleaner Production, 18, 1161-1170. 
LAUKKANEN, S., PALANDER, T. \& KANGAS, J. 2004. Applying voting theory in participatory decision support for sustainable timber harvesting. Canadian Journal of Forest Research-Revue Canadienne De Recherche Forestiere, 34, 1511-1524.

LIN, C. S. K., PFALTZGRAFF, L. A., HERRERO-DAVILA, L., MUBOFU, E. B., ABDERRAHIM, S., CLARK, J. H., KOUTINAS, A. A., KOPSAHELIS, N., STAMATELATOU, K., DICKSON, F., THANKAPPAN, S., MOHAMED, Z., BROCKLESBY, R. \& LUQUE, R. 2013. Food waste as a valuable resource for the production of chemicals, materials and fuels. Current situation and global perspective. Energy \& Environmental Science, 6, 426-464.

LiOU, J. J. H., TAMOSAITIENE, J., ZAVADSKAS, E. K. \& TZENG, G. H. 2016. New hybrid COPRAS-G MADM Model for improving and selecting suppliers in green supply chain management. International Journal of Production Research, 54, 114-134.

LIU, C. G., YANG, J., LIAN, J., LI, W. J., EVANS, S. \& YIN, Y. 2014a. Sustainable performance oriented operational decision-making of single machine systems with deterministic product arrival time. Journal of Cleaner Production, 85, 318-330.

LIU, Y., DONG, H. B., LOHSE, N. \& PETROVIC, S. 2015. Reducing environmental impact of production during a Rolling Blackout policy - A multi-objective schedule optimisation approach. Journal of Cleaner Production, 102, 418-427.

LIU, Y., DONG, H. B., LOHSE, N., PETROVIC, S. \& GINDY, N. 2014b. An investigation into minimising total energy consumption and total weighted tardiness in job shops. Journal of Cleaner Production, 65, 87-96.

LOHNDORF, N. 2016. An empirical analysis of scenario generation methods for stochastic optimization. European Journal of Operational Research, 255, 121-132.

LU, L. Y. Y., WU, C. H. \& KUO, T. C. 2007. Environmental principles applicable to green supplier evaluation by using multi-objective decision analysis. International Journal of Production Research, 45, 4317-4331.

MANSOURI, S. A., AKTAS, E. \& BESIKCI, U. 2016. Green scheduling of a two-machine flowshop: trade-off between makespan and energy consumption. European Journal of Operational Research, 248, 772-788.

MANZARDO, A., REN, J. Z., PIANTEllA, A., MAZZI, A., FEDELE, A. \& SCIPIONI, A. 2014. Integration of water footprint accounting and costs for optimal chemical pulp supply mix in paper industry. Journal of Cleaner Production, 72, 167-173.

MARTI, J. M. C., TANCREZ, J. S. \& SEIFERT, R. W. 2015. Carbon footprint and responsiveness trade-offs in supply chain network design. International Journal of Production Economics, 166, 129-142.

MARTINEZ-GUIDO, S. I., GONZALEZ-CAMPOS, J. B., DEL RIO, R. E., PONCEORTEGA, J. M., NAPOLES-RIVERA, F., SEMA-GONZALEZ, M. \& ELHALWAGI, M. M. 2014. A multiobjective optimization approach for the development of a sustainable supply chain of a new fixative in the perfume industry. Acs Sustainable Chemistry \& Engineering, 2, 2380-2390.

MAVROTAS, G. 2009. Effective implementation of the epsilon-constraint method in multiobjective mathematical programming problems. Applied Mathematics and Computation, 213, 455-465. 
MENDOZA, G. A. \& MARTINS, H. 2006. Multi-criteria decision analysis in natural resource management: a critical review of methods and new modelling paradigms. Forest Ecology and Management, 230, 1-22.

MIETTINEN, K. 2008. Introduction to multiobjective optimization: noninteractive approaches. In: BRANKE, J., DEB, K., MIETTINEN, K. \& SŁOWIŃSKI, R. (eds.) Multiobjective Optimization. Springer Berlin Heidelberg.

MIRABELlA, N., CASTELlANI, V. \& SALA, S. 2014. Current options for the valorization of food manufacturing waste: a review. Journal of Cleaner Production, 65, 28-41.

MIRET, C., CHAZARA, P., MONTASTRUC, L., NEGNY, S. \& DOMENECH, S. 2016. Design of bioethanol green supply chain: comparison between first and second generation biomass concerning economic, environmental and social criteria. Computers \& Chemical Engineering, 85, 16-35.

MIRZAPOUR AL-E-HASHEM, S. M. J., BABOLI, A. \& SAZVAR, Z. 2013. A stochastic aggregate production planning model in a green supply chain: considering flexible lead times, nonlinear purchase and shortage cost functions. European Journal of Operational Research, 230, 26-41.

MORRIS, D. R. 1991. Exergy analysis and cumulative exergy consumption of complex chemical processes: the industrial chlor-alkali processes. Chemical Engineering Science, 46, 459-465.

MOTA, B., GOMES, M. I., CARVALHO, A. \& BARBOSA-PÓVOA, A. 2015a. Supply chain design and planning accounting for the triple bottom line. Computer Aided Chemical Engineering.

MOTA, B., GOMES, M. I., CARVAlHO, A. \& BARBOSA-POVOA, A. P. 2015b. Towards supply chain sustainability: economic, environmental and social design and planning. Journal of Cleaner Production, 105, 14-27.

MOUZON, G., YILDIRIM, M. B. \& TWOMEY, J. 2007. Operational methods for minimization of energy consumption of manufacturing equipment. International Journal of Production Research, 45, 4247-4271.

MUNHOZ, J. R. \& MORABITO, R. 2014. Optimization approaches to support decision making in the production planning of a citrus company: a Brazilian case study. Computers and Electronics in Agriculture, 107, 45-57.

NAGURNEY, A. 2015. Design of sustainable supply chains for sustainable cities. Environment and Planning B-Planning \& Design, 42, 40-57.

NAGURNEY, A., LIU, Z. G. \& WOOLlEY, T. 2007. Sustainable Supply Chain and Transportation Networks. International Journal of Sustainable Transportation, 1, 2951.

OGLETHORPE, D. 2010. Optimising economic, environmental, and social objectives: a goalprogramming approach in the food sector. Environment and Planning A, 42, 12391254.

OH, J. \& JEONG, B. 2014. Profit analysis and supply chain planning model for closed-loop supply chain in fashion industry. Sustainability, 6, 9027-9056. 
ORJI, I. J. \& WEI, S. 2015a. Dynamic modeling of sustainable operation in green manufacturing environment. Journal of Manufacturing Technology Management, 26, 1201-1217.

ORJI, I. J. \& WEI, S. 2015b. An innovative integration of fuzzy-logic and systems dynamics in sustainable supplier selection: a case on manufacturing industry. Computers \& Industrial Engineering, 88, 1-12.

ORTIZ-GUTIERREZ, R. A., GIAROLA, S. \& BEZZO, F. 2013. Optimal design of ethanol supply chains considering carbon trading effects and multiple technologies for sideproduct exploitation. Environmental Technology, 34, 2189-2199.

OZKIR, V. \& BASLIGIL, H. 2013. Multi-objective optimization of closed-loop supply chains in uncertain environment. Journal of Cleaner Production, 41, 114-125.

PAKSOY, T., BEKTAS, T. \& OZCEYLAN, E. 2011. Operational and environmental performance measures in a multi-product closed-loop supply chain. Transportation Research Part E-Logistics and Transportation Review, 47, 532-546.

PAKSOY, T., ÖZCEYLAN, E. \& WEBER, G. W. A multi objective model for optimization of a green supply chain network. 2010. 311-320.

PAKSOY, T., PEHLIVAN, N. Y. \& OZCEYLAN, E. 2012. Fuzzy multi-objective optimization of a green supply chain network with risk management that includes environmental hazards. Human and Ecological Risk Assessment, 18, 1120-1151.

PAPARGYROPOULOU, E., LOZANO, R., STEINBERGER, J. K., WRIGHT, N. \& BIN UJANG, Z. 2014. The food waste hierarchy as a framework for the management of food surplus and food waste. Journal of Cleaner Production, 76, 106-115.

PAUlS-WORM, K. G. J., HENDRIX, E. M. T., ALCOBA, A. G. \& HAIJEMA, R. 2016. Order quantities for perishable inventory control with non-stationary demand and a fill rate constraint. International Journal of Production Economics, 181, 238-246.

PEREZ-FORTES, M., LAINEZ-AGUIRRE, J. M., ARRANZ-PIERA, P., VELO, E. \& PUIGJANER, L. 2012. Design of regional and sustainable bio-based networks for electricity generation using a multi-objective MILP approach. Energy, 44, 79-95.

PHAN, C. W. \& SABARATNAM, V. 2012. Potential uses of spent mushroom substrate and its associated lignocellulosic enzymes. Applied Microbiology and Biotechnology, 96, 863873.

PISHVAEE, M. S., RAZMI, J. \& TORABI, S. A. 2014. An accelerated Benders decomposition algorithm for sustainable supply chain network design under uncertainty: a case study of medical needle and syringe supply chain. Transportation Research Part E-Logistics and Transportation Review, 67, 14-38.

POCHET, Y. \& WOLSEY, L. A. 2006. Production planning by mixed integer programming, New York, Springer.

POHEKAR, S. D. \& RAMACHANDRAN, M. 2004. Application of multi-criteria decision making to sustainable energy planning - A review. Renewable \& Sustainable Energy Reviews, 8, 365-381.

PULLMAN, M. E., MALONI, M. J. \& CARTER, C. R. 2009. Food for thought: social versus environmental sustainability practices and performance outcomes. Journal of Supply Chain Management, 45, 38-54. 
PWC. 2011. Minerals and metals scarcity in manufacturing: the ticking time bomb [Online]. Sustainable Materials Management. Available: www.pwc.com/resourcescarcity.

QUADT, D. \& KUHN, H. 2008. Capacitated lot-sizing with extensions: a review. 4OR-a Quarterly Journal of Operations Research, 6, 61-83.

QUARIGUASI FROTA NETO, J., BLOEMHOF-RUWAARD, J. M., VAN NUNEN, J. A. E. E. \& VAN HECK, E. 2008. Designing and evaluating sustainable logistics networks. International Journal of Production Economics, 111, 195-208.

QUARIGUASI FROTA NETO, J., WALTHER, G., BLOEMHOF, J., VAN NUNEN, J. A. E. E. \& SPENGLER, T. 2009. A methodology for assessing eco-efficiency in logistics networks. European Journal of Operational Research, 193, 670-682.

QUARIGUASI FROTA NETO, J., WALTHER, G., BLOEMHOF, J., VAN NUNEN, J. A. E. E. \& SPENGLER, T. 2010. From closed-loop to sustainable supply chains: the WEEE case. International Journal of Production Research, 48, 4463-4481.

RADUlESCU, M., RADUlESCU, C. Z. \& FILIP, F. G. 2008. Sustainable production planning models. Proceedings of the Romanian Academy Series a-Mathematics Physics Technical Sciences Information Science, 9, 149-156.

RADULESCU, M., RADULESCU, S. \& RADULESCU, C. Z. 2009. Sustainable production technologies which take into account environmental constraints. European Journal of Operational Research, 193, 730-740.

RAMOS, T. R. P., GOMES, M. I. \& BARBOSA-POVOA, A. P. 2014. Planning a sustainable reverse logistics system: balancing costs with environmental and social concerns. Omega-International Journal of Management Science, 48, 60-74.

RAMUDHIN, A., CHAABANE, A. \& PAQUET, M. 2010. Carbon market sensitive sustainable supply chain network design. International Journal of Management Science and Engineering Management, 5, 30-38.

RAVI, V., SHANKAR, R. \& TIWARI, M. K. 2005. Analyzing alternatives in reverse logistics for end-of-life computers: ANP and balanced scorecard approach. Computers \& Industrial Engineering, 48, 327-356.

RAVI, V., SHANKAR, R. \& TIWARI, M. K. 2008. Selection of a reverse logistics project for end-of-life computers: ANP and goal programing approach. International Journal of Production Research, 46, 4849-4870.

REN, J. Z., MANZARDO, A., TONIOLO, S. \& SCIPIONI, A. 2013. Sustainability of hydrogen supply chain. Part II: Prioritizing and classifying the sustainability of hydrogen supply chains based on the combination of extension theory and AHP. International Journal of Hydrogen Energy, 38, 13845-13855.

RIJPKEMA, W. 2014. Effective use of product quality information in food supply chain logistics. Wageningen University.

ROSTAMZADEH, R., GOVINDAN, K., ESMAEILI, A. \& SABAGHI, M. 2015. Application of fuzzy VIKOR for evaluation of green supply chain management practices. Ecological Indicators, 49, 188-203.

SADRNIA, A., ISMAIL, N., ZULKIFLI, N., ARIFFIN, M. K. A., NEZAMABADI-POUR, H. \& MIRABI, H. 2013. A multiobjective optimization model in automotive supply chain networks. Mathematical Problems in Engineering. 
SAHAY, N. \& IERAPETRITOU, M. 2013. Supply chain management using an optimization driven simulation approach. AIChE Journal, 59, 4612-4626.

SANG, X. Z. \& LIU, X. W. 2016. An interval type-2 fuzzy sets-based TODIM method and its application to green supplier selection. Journal of the Operational Research Society, $67,722-734$.

SANTIBANEZ-AGUILAR, J. E., GONZALEZ-CAMPOS, J. B., PONCE-ORTEGA, J. M., SERNA-GONZALEZ, M. \& EL-HALWAGI, M. M. 2014. Optimal planning and site selection for distributed multiproduct biorefineries involving economic, environmental and social objectives. Journal of Cleaner Production, 65, 270-294.

SANTIBANEZ-AGUILAR, J. E., MARTINEZ-GOMEZ, J., PONCE-ORTEGA, J. M., NAPOLES-RIVERA, F., SERNA-GONZALEZ, M., GONZALEZ-CAMPOS, J. B. \& EL-HALWAGI, M. M. 2015. Optimal planning for the reuse of municipal solid waste considering economic, environmental, and safety objectives. AIChE Journal, 61, 18811899.

SANTIBANEZ-AGUILAR, J. E., PONCE-ORTEGA, J. M., BETZABE GONZALEZCAMPOS, J., SERNA-GONZALEZ, M. \& EL-HALWAGI, M. M. 2013a. Optimal planning for the sustainable utilization of municipal solid waste. Waste Management, $33,2607-22$.

SANTIBANEZ-AGUILAR, J. E., PONCE-ORTEGA, J. M., GONZALEZ-CAMPOS, J. B., SERNA-GONZALEZ, M. \& EL-HAWAGI, M. M. 2013b. Synthesis of distributed biorefining networks for the value-added processing of water hyacinth. Acs Sustainable Chemistry \& Engineering, 1, 284-305.

SAZVAR, Z., AL-E-HASHEM, S. M. J. M., BABOLI, A. \& JOKAR, M. R. A. 2014. A biobjective stochastic programming model for a centralized green supply chain with deteriorating products. International Journal of Production Economics, 150, 140-154.

SCHAEFER, B. \& KONUR, D. 2015. Economic and environmental considerations in a continuous review inventory control system with integrated transportation decisions. Transportation Research Part E-Logistics and Transportation Review, 80, 142-165.

SCOTT, J. A., HO, W. \& DEY, P. K. 2012. A review of multi-criteria decision-making methods for bioenergy systems. Energy, 42, 146-156.

SCOTT, J. A., HO, W. \& DEY, P. K. 2013. Strategic sourcing in the UK bioenergy industry. International Journal of Production Economics, 146, 478-490.

SENTHIL, S., SRIRANGACHARYULU, B. \& RAMESH, A. 2014. A robust hybrid multicriteria decision making methodology for contractor evaluation and selection in thirdparty reverse logistics. Expert Systems with Applications, 41, 50-58.

SEURING, S. 2013. A review of modeling approaches for sustainable supply chain management. Decision Support Systems, 54, 1513-1520.

SEURING, S. \& MULLER, M. 2008. From a literature review to a conceptual framework for sustainable supply chain management. Journal of Cleaner Production, 16, 1699-1710.

SHAW, K., SHANKAR, R., YADAV, S. S. \& THAKUR, L. S. 2012. Supplier selection using fuzzy AHP and fuzzy multi-objective linear programming for developing low carbon supply chain. Expert Systems with Applications, 39, 8182-8192. 
SHAW, K., SHANKAR, R., YADAV, S. S. \& THAKUR, L. S. 2013. Modeling a low-carbon garment supply chain. Production Planning \& Control, 24, 851-865.

SHEN, L. X., OLFAT, L., GOVINDAN, K., KHODAVERDI, R. \& DIABAT, A. 2013. A fuzzy multi criteria approach for evaluating green supplier's performance in green supply chain with linguistic preferences. Resources Conservation and Recycling, 74, 170-179.

SHIMIZU, Y., SAKAGUCHI, T. \& SHIMADA, H. 2015. Multi-objective optimization for creating a low-carbon logistics system through community-based action. Journal of Advanced Mechanical Design Systems and Manufacturing, 9.

SHUKLA, M. \& JHARKHARIA, S. 2013. Agri-fresh produce supply chain management: a state-of-the-art literature review. International Journal of Operations \& Production Management, 33, 114-158.

SINGH, S., OLUGU, E. U., MUSA, S. N., MAHAT, A. B. \& WONG, K. Y. 2016. Strategy selection for sustainable manufacturing with integrated AHP-VIKOR method under interval-valued fuzzy environment. International Journal of Advanced Manufacturing Technology, 84, 547-563.

SOYSAL, M. 2015. Decision support modeling for sustainable food logistics management. Wageningen University.

SOYSAL, M., BLOEMHOF-RUWAARD, J. M., HAIJEMA, R. \& VAN DER VORST, J. G. A. J. 2015. Modeling an Inventory Routing Problem for perishable products with environmental considerations and demand uncertainty. International Journal of Production Economics, 164, 118-133.

SOYSAL, M., BLOEMHOF-RUWAARD, J. M., MEUWISSEN, M. P. M. \& VORST, J. G. A. J. V. D. 2012. A review on quantitative models for sustainable food logistics management. International Journal on Food System Dynamics, 3, 136-155.

SOYSAL, M., BLOEMHOF-RUWAARD, J. M. \& VAN DER VORST, J. G. A. J. 2014. Modelling food logistics networks with emission considerations: the case of an international beef supply chain. International Journal of Production Economics, 152, 57-70.

SOYSTER, A. L. 1973. Technical note-convex programming with set-inclusive constraints and applications to inexact linear programming. Operations Research, 21, 1154-1157.

SRIVASTAVA, S. K. 2007. Green supply-chain management: a state-of-the-art literature review. International Journal of Management Reviews, 9, 53-80.

STAS, D., LENORT, R., WICHER, P. \& HOLMAN, D. 2015. Green transport balanced scorecard model with analytic network process support. Sustainability, 7, 1524315261 .

STINDT, D. \& SAHAMIE, R. 2014. Review of research on closed loop supply chain management in the process industry. Flexible Services and Manufacturing Journal, 26, 268-293.

TANG, C. S. \& ZHOU, S. 2012. Research advances in environmentally and socially sustainable operations. European Journal of Operational Research, 223, 585-594.

TANG, J. H., JI, S. F. \& JIANG, L. W. 2016. The design of a sustainable location-routinginventory model considering consumer environmental behavior. Sustainability, 8. 
TANG, X. F., ZHANG, J. \& XU, P. 2013. A multi-objective optimization model for sustainable logistics facility location. Transportation Research Part D-Transport and Environment, 22, 45-48.

TOGNETTI, A., GROSSE-RUYKEN, P. T. \& WAGNER, S. M. 2015. Green supply chain network optimization and the trade-off between environmental and economic objectives. International Journal of Production Economics, 170, 385-392.

TSENG, M. L., LIN, Y. H., TAN, K., CHEN, R. H. \& CHEN, Y. H. 2014. Using TODIM to evaluate green supply chain practices under uncertainty. Applied Mathematical Modelling, 38, 2983-2995.

TSP. 2010. The Shift Project Data Portal [Online]. http://www.tsp-data-portal.org/Breakdownof-GHG-Emissions-by-Sector. (retrieved 30.04.2015)].

TSUI, C. W. \& WEN, U. P. 2014. A hybrid multiple criteria group decision-making approach for green supplier selection in the TFT-LCD industry. Mathematical Problems in Engineering.

TUZKAYA, G. 2013. An intuitionistic fuzzy Choquet integral operator based methodology for environmental criteria integrated supplier evaluation process. International Journal of Environmental Science and Technology, 10, 423-432.

TUZKAYA, G., OZGEN, A., OZGEN, D. \& TUZKAYA, U. R. 2009. Environmental performance evaluation of suppliers: a hybrid fuzzy multi-criteria decision approach. International Journal of Environmental Science and Technology, 6, 477-490.

TZENG, G. H. \& HUANG, J. J. 2011. Multiple Attribute Decision Making: methods and applications, Taylor \& Francis.

VALIDI, S., BHATTACHARYA, A. \& BYRNE, P. J. 2014a. A case analysis of a sustainable food supply chain distribution system - a multi-objective approach. International Journal of Production Economics, 152, 71-87.

VALIDI, S., BHATTACHARYA, A. \& BYRNE, P. J. 2014b. Integrated low-carbon distribution system for the demand side of a product distribution supply chain: a DoEguided MOPSO optimiser-based solution approach. International Journal of Production Research, 52, 3074-3096.

VALIDI, S., BHATTACHARYA, A. \& BYRNE, P. J. 2015. A solution method for a two-layer sustainable supply chain distribution model. Computers \& Operations Research, 54, 204-217.

VAN DER LAAN, E. 1997. The effects of remanufacturing on inventory control, RePub (University Library).

VAN DER VORST, J. G. A. J. 2000. Effective food supply chains : generating, modelling and evaluating supply chain scenarios. Proefschrift Wageningen, s.n.].

VAN DER VORST, J. G. A. J., BEULENS, A. J. M. \& VAN BEEK, P. 2005. 10. Innovations in logistics and ICT in food supply chain networks. In: W.M.F. JONGEN \& MEULENBERG, M. T. G. (eds.) Innovation in agri-food systems: product quality and consumer acceptance. Wageningen Academic Publishers.

VAN DER VORST, J. G. A. J., TROMP, S. O. \& VAN DER ZEE, D. J. 2009. Simulation modelling for food supply chain redesign; Integrated decision making on product 
quality, sustainability and logistics. International Journal of Production Research, 47, 6611-6631.

VAN MEENSEL, J., LAUWERS, L., VAN HUYLENBROECK, G. \& VAN PASSEL, S. 2010. Comparing frontier methods for economic-environmental trade-off analysis. European Journal of Operational Research, 207, 1027-1040.

WALL, G. 2010. On exergy and sustainable development in environmental engineering. The Open Environmental Engineering Journal, 3, 21-32.

WALlENiUS, J., DYER, J. S., FISHBURN, P. C., STEUER, R. E., ZIONTS, S. \& DEB, K. 2008. Multiple criteria decision making, multiattribute utility theory: recent accomplishments and what lies ahead. Management Science, 54, 1336-1349.

WAN, S. P. \& DONG, J. Y. 2015. Power geometric operators of trapezoidal intuitionistic fuzzy numbers and application to multi-attribute group decision making. Applied Soft Computing, 29, 153-168.

WAN, S. P. \& LI, D. F. 2015. Fuzzy mathematical programming approach to heterogeneous multiattribute decision-making with interval-valued intuitionistic fuzzy truth degrees. Information Sciences, 325, 484-503.

WANG, E. J., LIN, C. Y. \& SU, T. S. 2016. Electricity monitoring system with fuzzy multiobjective linear programming integrated in carbon footprint labeling system for manufacturing decision making. Journal of Cleaner Production, 112, 3935-3951.

WANG, F., LAI, X. F. \& SHI, N. 2011. A multi-objective optimization for green supply chain network design. Decision Support Systems, 51, 262-269.

WANG, X., DANG, Y. G. \& HOU, D. Q. 2014. Multiattribute grey target decision method based on soft set theory. Mathematical Problems in Engineering.

WU, C. \& BARNES, D. 2016. An integrated model for green partner selection and supply chain construction. Journal of Cleaner Production, 112, 2114-2132.

WU, C. C. \& CHANG, N. B. 2004. Corporate optimal production planning with varying environmental costs: a grey compromise programming approach. European Journal of Operational Research, 155, 68-95.

YAN, B., DI SOMMA, M., BIANCO, N., LUH, P. B., GRADITI, G., MONGIBELLO, L. \& NASO, V. 2016. Exergy-based operation optimization of a distributed energy system through the energy-supply chain. Applied Thermal Engineering, 101, 741-751.

YANG, B., HU, Z. H., WEI, C., LI, S. Q., ZHAO, L. \& JIA, S. 2015. Routing with timewindows for multiple environmental vehicle types. Computers \& Industrial Engineering, 89, 150-161.

YEH, W. C. \& CHUANG, M. C. 2011. Using multi-objective genetic algorithm for partner selection in green supply chain problems. Expert Systems with Applications, 38, 42444253.

YILDIRIM, M. B. \& MOUZON, G. 2012. Single-machine sustainable production planning to minimize total energy consumption and total completion time using a multiple objective genetic algorithm. Ieee Transactions on Engineering Management, 59, 585597. 
YOU, F. Q., TAO, L., GRAZIANO, D. J. \& SNYDER, S. W. 2012. Optimal design of sustainable cellulosic biofuel supply chains: multiobjective optimization coupled with life cycle assessment and input-output analysis. AIChE Journal, 58, 1157-1180.

YU, H., SOLVANG, W. D., YUAN, S. \& YANG, Y. 2015. A decision aided system for sustainable waste management. Intelligent Decision Technologies-Netherlands, 9, 2940 .

YU, Q. \& HOU, F. J. 2016. An approach for green supplier selection in the automobile manufacturing industry. Kybernetes, 45, 571-588.

YUE, D., PANDYA, S. \& YOU, F. 2016. Integrating hybrid life cycle assessment with multiobjective optimization: a modeling framework. Environmental Science \& Technology, 50, 1501-9.

YUE, D. J., GONG, J. \& YOU, F. Q. 2015. Synergies between geological sequestration and microalgae biofixation for greenhouse gas abatement: life cycle design of carbon capture, utilization, and storage supply chains. Acs Sustainable Chemistry \& Engineering, 3, 841-861.

YUE, D. J., KIM, M. A. \& YOU, F. Q. 2013. Design of sustainable product systems and supply chains with life cycle optimization based on functional unit: general modeling framework, mixed-integer nonlinear programming algorithms and case study on hydrocarbon biofuels. Acs Sustainable Chemistry \& Engineering, 1, 1003-1014.

YUE, D. J., SLIVINSKY, M., SUMPTER, J. \& YOU, F. Q. 2014. Sustainable design and operation of cellulosic bioelectricity supply chain networks with life cycle economic, environmental, and social optimization. Industrial \& Engineering Chemistry Research, $53,4008-4029$.

ZANONI, S. \& ZAVANELLA, L. 2012. Chilled or frozen? Decision strategies for sustainable food supply chains. International Journal of Production Economics, 140, 731-736.

ZAVADSKAS, E. K., TURSKIS, Z. \& KILDIENE, S. 2014. State of art surveys of overviews on MCDM/MADM methods. Technological and Economic Development of Economy, $20,165-179$.

ZEYDAN, M., COLPAN, C. \& COBANOGLU, C. 2011. A combined methodology for supplier selection and performance evaluation. Expert Systems with Applications, 38, 2741-2751.

ZHANG, Q., SHAH, N., WASSICK, J., HELLING, R. \& VAN EGERSCHOT, P. 2014. Sustainable supply chain optimisation: an industrial case study. Computers \& Industrial Engineering, 74, 68-83.

ZHANG, X. L. \& XU, Z. S. 2015. Hesitant fuzzy QUALIFLEX approach with a signed distance-based comparison method for multiple criteria decision analysis. Expert Systems with Applications, 42, 873-884.

ZHAO, H. R. \& GUO, S. 2014. Selecting green supplier of thermal power equipment by using a hybrid MCDM method for sustainability. Sustainability, 6, 217-235.

ZHONG, J., YU, T. E., LARSON, J. A., ENGLISH, B. C., FU, J. S. \& CALCAGNO, J. 2016. Analysis of environmental and economic tradeoffs in switchgrass supply chains for biofuel production. Energy, 107, 791-803. 
ZHOU, F. L., LIN, Y., WANG, X., ZHOU, L. \& HE, Y. D. 2016. ELV recycling service provider selection using the hybrid MCDM method: a case application in china. Sustainability, 8.

ZHOU, Z. Y., CHENG, S. W. \& HUA, B. 2000. Supply chain optimization of continuous process industries with sustainability considerations. Computers \& Chemical Engineering, 24, 1151-1158.

ZHU, Q. H., LOWE, E. A., WEI, Y. A. \& BARNES, D. 2007. Industrial symbiosis in China - a case study of the Guitang Group. Journal of Industrial Ecology, 11, 31-42.

ZIOLKOWSKA, J. R. 2014. Optimizing biofuels production in an uncertain decision environment: conventional vs. advanced technologies. Applied Energy, 114, 366-376.

ZISOPOUlOS, F. K., MOEJES, S. N., ROSSIER-MIRANDA, F. J., VAN DER GOOT, A. J. \& BOOM, R. M. 2015. Exergetic comparison of food waste valorization in industrial bread production. Energy, 82, 640-649.

ZISOPOULOS, F. K., RAMIREZ, H. A. B., VAN DER GOOT, A. J. \& BOOM, R. M. 2016. A resource efficiency assessment of the industrial mushroom production chain: the influence of data variability. Journal of Cleaner Production, 126, 394-408.

ZISOPOULOS, F. K., ROSSIER-MIRANDA, F. J., VAN DER GOOT, A. J. \& BOOM, R. M. 2017. The use of exergetic indicators in the food industry - A review. Critical Reviews in Food Science and Nutrition, 57, 197-211. 


\section{Acknowledgements}

The PhD journey seems to end here. It will be interesting to discover something new to worry about, knowing that the tiresome thoughts, which made me spend evenings in my office in the Leeuwenborch, will no longer be there. These tiresome thoughts were related to the desire of accomplishing the ultimate goal, which I came up with just before the summer of 2012 when I started my doctoral studies. The ultimate goal being, of course, getting these two letters in front of my surname. No matter what life will bring, it should be mentioned that the work presented on the previous pages, which you surely just have read, and the completion of this book would not be possible without the support of a number of people, and I would like to spend some words to thank them.

First of all, I would like to express my gratitude to my supervisors. Thanks to the guidance of Jack van der Vorst I felt I am always on track. He always provided valuable feedback, and while not diving into each detail and each specificity of the developed models, his remarks often made me look on scientific matters from a different perspective. He made me realize that doing research is not only about numbers and solving mathematical puzzles, but especially about the bigger picture and the implications of solving these puzzles. Thanks to Jacqueline Bloemhof for her positive attitude throughout my $\mathrm{PhD}$, for her insightful feedback, for sparking my interest in sustainable and closed-loop supply chains, and for always being able to find the appropriate outlets for our work. Big thanks to Frits Claassen, who made it possible for me to start my PhD studies. Thanks to him I not only gained the invaluable teaching experience, but also got to know about many aspects of the Dutch way of communicating with people. Thanks Frits for all your support in all moments in this $\mathrm{PhD}$ journey. Without any doubt, completion of this work would not be possible without the support of Argyris Kanellopoulos. He was the person with whom I could think along while developing the mathematical models. It always felt safe knowing that there is a person for a daily discussion on the specificities of the models, and the weird results often obtained. No matter how worried I was on some occasions, thanks to his infinite enthusiasm and positive point of view I managed to overcome numerous obstacles. Thank you loads!

Second of all, thanks to the people involved in the TIFN Project. Thanks to the team leader Friso van Assema, who turned out to be not a typical team leader, but a friendly colleague, who always had a solution ready to any issue that popped-up in the process. He always made sure that everything goes as smooth as possible in the communication with the industrial partners and with all the people involved in the project. Big thanks to Filippos Zisopoulos for being always optimistic, no matter how challenging some moments were. Thanks for showing me how to be cool no matter what the circumstances are. For being always curious about my work and at the same time willing to share personal insights and perceptions. Thanks to all our industrial partners, especially to Caroline van der Horst, Peter Weegels, and Marcel Peeters for the great collaboration, and for the numerous meetings in which you introduced us to the mushroom and bread supply chains, and shared the insiders' information and experiences from industrial practices. Thanks to other people involved in the project, Jan Broeze, Costas 
Nikiforidis, Marta Rodriguez Illera, Nicolas Hardt, for making the project happen and successfully reach the end.

Thanks to all colleagues and staff members working at Operations Research and Logistics chairgroup and Information Technology chairgroup: Ilona, Jeannette, Natasja, Behzad, Dmytro, Eligius, Joke, Karin, Rene, Ayalew, Bedir, Cor, Ioannis, Jacques, Giulia, Gerard, Gert Jan, Huub, Maarten, Mark, Sjoukje. Thanks for all the outings, Veluweloops, and sharing all the happy moments like publishing an article or celebrating one's birthday during the few coffee breaks I attended. Thanks for the support you gave me when I injured my knee. Special thanks to all the $\mathrm{PhD}$ colleagues that I had the pleasure to meet: Agata, Ante, Bing, Cagri, Eline, Femke, Floor, Heleen, Ismail, Jan-Willem, Jochem, Lesley, Marjolein, Marlies, Mehmet, Sonja, Viet, Wenjuan, Willem, Xuezhen, Yun. Thanks guys for all the talks, and for the well-intended support, which was not always distracting from the right direction. I really hope I did not miss many people; make sure you thank yourself on my behalf if I forgot to mention your name.

Thanks to the people that made me feel comfortable and busy outside the office hours. Thanks to all players of GVC, it was a pleasure to be a part of the football team. Thanks to all my friends both from my Polish circle: Alicja, Agata, Ilona, Marcin, Max, Michal, Natalia, and Rui (even though not all of you are Polish) for all those weekend nights; and friends from the nonPolish circle: Aogán, Maartje, Marcel, Nyamwaya, Stuti, and Tanya for all the hang-outs. The support you guys gave was invaluable! Great thanks to Marit for creating the lovely cover for this book. Thanks for being patient and being able to stand me throughout this last year of my $\mathrm{PhD}$. It was a crazy year, and I appreciate the support you gave me. It would not be possible without you.

Last, but not least, thanks to my family. You were always my inspiration and the driving force to accomplish something in life. I dedicate this to you Mom, Dad, Jerzy, and Natalia. There are no words that can express my gratitude. Thanks for always being there for me. By the way, sorry sis and sorry bro for not letting you guys finish your dissertations before me. My bad. Better luck next time.

That is the end of this journey and I'm looking forward to the next one. While looking back on these four years I think: it wasn't too bad after all. 


\section{Completed Training and Supervision Plan}

Aleksander Banasik

Wageningen School of Social Sciences (WASS)

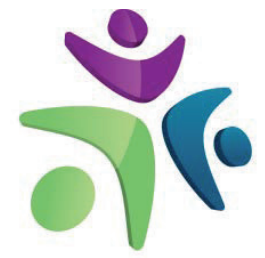

Wageningen School of Social Sciences

\begin{tabular}{|c|c|c|c|}
\hline Name of the learning activity & Department/Institute & Year & ECTS* \\
\hline \multicolumn{4}{|l|}{ A) Project related competences } \\
\hline 'MCDM in food production' & TIFN workshop & 2012 & 1 \\
\hline Convex Analysis for Optimization & LNMB & 2012 & 1 \\
\hline Writing $\mathrm{PhD}$ research proposal & & $2012 / 2013$ & 4 \\
\hline Robust Optimization & LNMB & 2013 & 4 \\
\hline $\begin{array}{l}\text { Sustainability analysis in Food and } \\
\text { Biobased production }\end{array}$ & VLAG and FPE & 2013 & 1.4 \\
\hline Integer Programming Methods & LNMB & 2014 & 4 \\
\hline Inventory Management in Supply Chains & LNMB & 2014 & 4 \\
\hline \multicolumn{4}{|l|}{ B) General research related competences } \\
\hline Introduction course & WASS & 2012 & 1 \\
\hline $\begin{array}{l}\text { Techniques for Writing and Presenting a } \\
\text { Scientific Paper }\end{array}$ & WGS & 2013 & 1.2 \\
\hline Scientific Writing & WGS & 2013 & 1.8 \\
\hline \multicolumn{4}{|c|}{ C) Career related competences/personal development } \\
\hline $\begin{array}{l}\text { Teaching assistant for courses: } \\
\text { - Decision Science } 1 \\
\text { - Food Production Chains }\end{array}$ & $\begin{array}{l}\text { ORL } \\
\text { ORL }\end{array}$ & $\begin{array}{l}2012 \\
2012,2013\end{array}$ & 2 \\
\hline Supervision of MSc students & ORL & $\begin{array}{l}2012 \\
2013\end{array}$ & 2 \\
\hline Zaragoza Summer Academy & Zaragoza Logistics Center & 2014 & 3 \\
\hline $\begin{array}{l}\text { 'Multi-criteria decision making approach } \\
\text { for resource efficient bread supply } \\
\text { chains' }\end{array}$ & $\begin{array}{l}22^{\text {nd }} \text { International } \\
\text { Conference on Multiple } \\
\text { Criteria Decision Making, } \\
\text { University of Malaga }\end{array}$ & 2013 & 1 \\
\hline $\begin{array}{l}\text { 'Eco-efficient agri-food supply chains: } \\
\text { dealing with uncertain model parameters' }\end{array}$ & $\begin{array}{l}28^{\text {th }} \text { European Conference } \\
\text { on Operational Research, } \\
\text { Poznan University of } \\
\text { Technology }\end{array}$ & 2016 & 1 \\
\hline
\end{tabular}

Total

* One credit according to ECTS is on average equivalent to 28 hours of study load 
The studies presented in this thesis were performed within the framework of TiFN Cover photos by graphicsdunia4you/Shutterstock.com, Flas100/Shutterstock.com, Dragana Gerasimoski/Shutterstock.com

Printed by Digiforce / Profschriftmaken.nl, Vianen 
